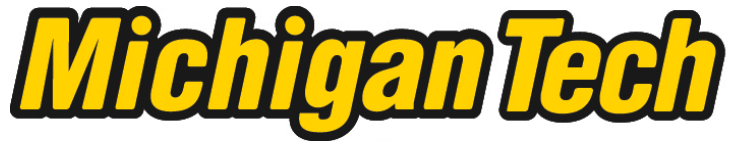 \\ Michigan Technological University Create the Future Digital Commons @ Michigan Tech
}

\section{Invasion patterns of emerald ash borer and European earthworms in forested ecosystems}

Lindsey M. Shartell

Michigan Technological University

Follow this and additional works at: https://digitalcommons.mtu.edu/etds

Part of the Forest Sciences Commons

Copyright 2012 Lindsey M. Shartell

\section{Recommended Citation}

Shartell, Lindsey M., "Invasion patterns of emerald ash borer and European earthworms in forested ecosystems", Dissertation, Michigan Technological University, 2012.

https://doi.org/10.37099/mtu.dc.etds/130

Follow this and additional works at: https://digitalcommons.mtu.edu/etds

8 Part of the Forest Sciences Commons 


\title{
INVASION PATTERNS OF EMERALD ASH BORER AND EUROPEAN EARTHWORMS IN FORESTED ECOSYSTEMS
}

\author{
By \\ Lindsey Marie Shartell
}

\begin{abstract}
A DISSERTATION
Submitted in partial fulfillment of the requirements for the degree of DOCTOR OF PHILOSOPHY
\end{abstract}

Forest Science

MICHIGAN TECHNOLOGICAL UNIVERSITY

2012

(C) 2012 Lindsey Marie Shartell 
This dissertation, "Invasion Patterns of Emerald Ash Borer and European Earthworms in Forested Ecosystems," is hereby approved in partial fulfillment of the requirements for the Degree of DOCTOR OF PHILOSOPHY IN FOREST SCIENCE.

School of Forest Resources and Environmental Science

Signatures:

Dissertation Advisor

Dr. Andrew J. Storer

Dean

Dr. Margret R. Gale

Date 


\section{Table of Contents}

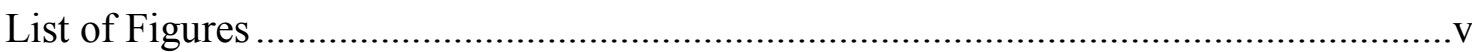

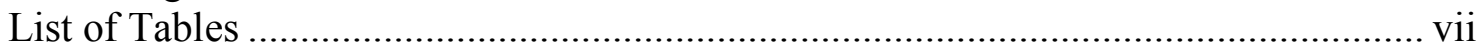

Acknowledgements ....................................................................................................

Dissertation Abstract .............................................................................................. xi

1. Introduction

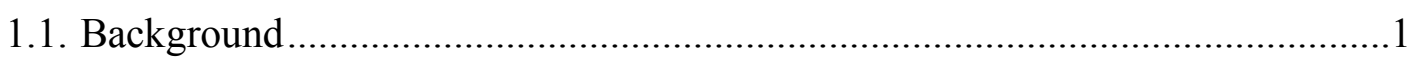

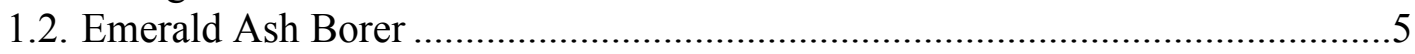

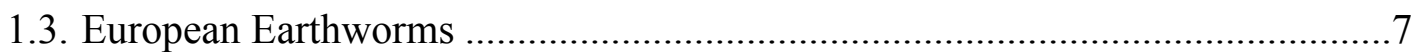

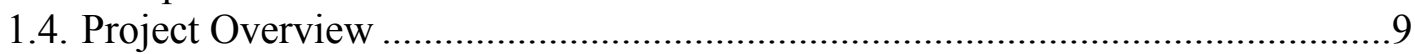

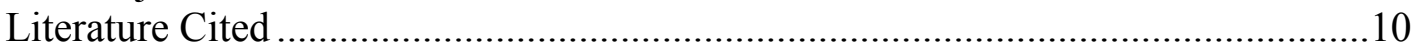

2. Detection of Northern Michigan Emerald Ash Borer Satellite Invasion Sites through Predictive Spatial Modeling

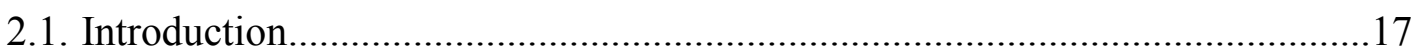

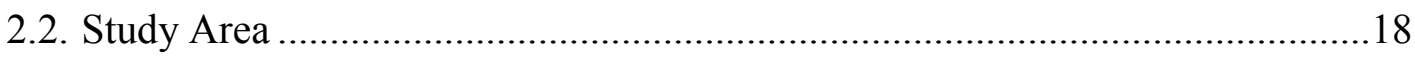

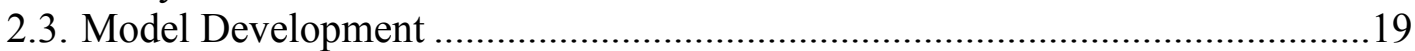

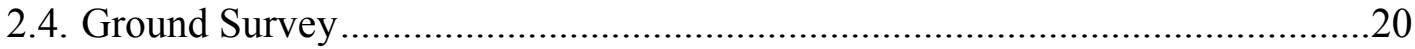

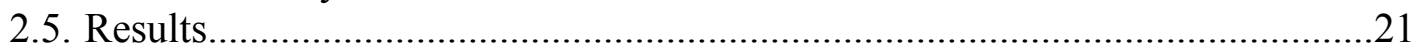

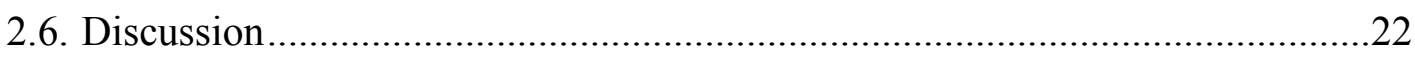

2.7. Conclusions

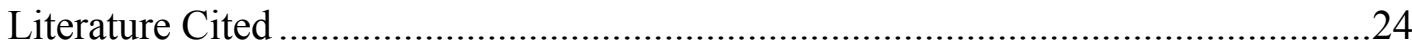

3. Patterns and Predictions of Exotic Earthworm Distribution in the Huron Mountains of the Upper Peninsula, Michigan

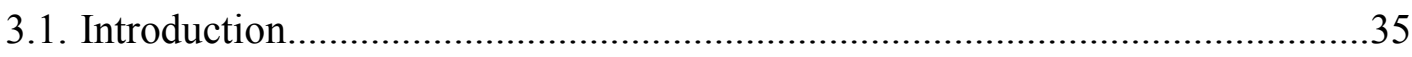

3.2. Study Area

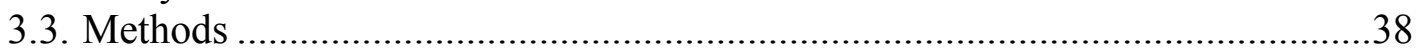

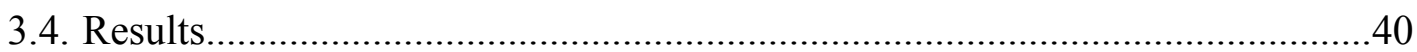

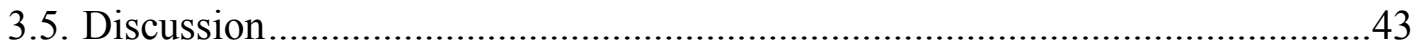

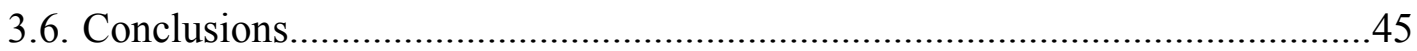

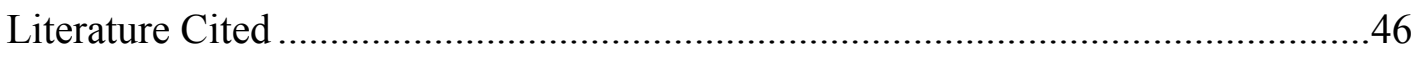




\section{Invasion Patterns of Exotic Earthworms in Forest Ecosystems across the Upper Great Lakes Region}

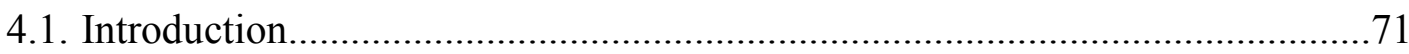

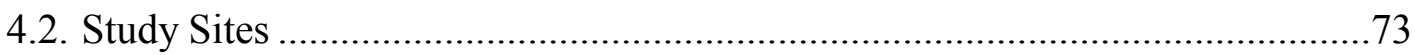

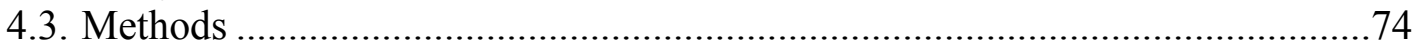

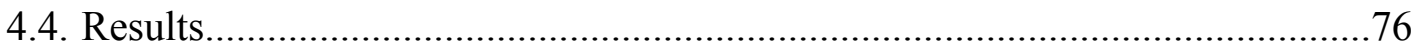

4.4.1. Earthworm Impact ........................................................................ 77

4.4.2. Stand Level Effects.......................................................................... 78

4.4.3. Landscape Level Effects................................................................78

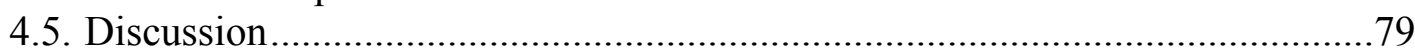

4.6. Conclusions

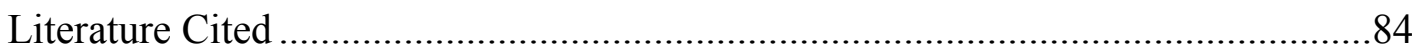

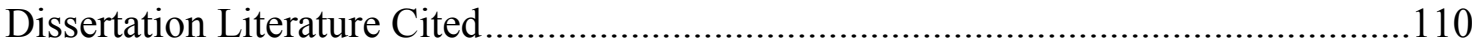

Appendix 


\section{List of Figures}

Figure 2.1 The locations of known emerald ash borer (EAB) satellite invasion sites used in the development and validation of the multicriteria risk model predicting invasion risk for emerald ash borer across northern Michigan

Figure 2.2 Design and layout of the multicriteria risk model predicting invasion risk for emerald ash borer across northern Michigan

Figure 2.3 Risks assigned to the model parameters a) road proximity, b) land cover class, and c) campground proximity used in the multicriteria risk model to predict emerald ash borer invasion risk

Figure 2.4 Predicted risk of early-stage emerald ash borer invasion across the Upper Peninsula and northern portion of the Lower Peninsula of Michigan

Figure 2.5 Emerald ash borer ground survey locations, indicating the presence of ash.....

Figure 3.1 Locator map for the area of study, the Huron Mountains, located in Marquette County in the Upper Peninsula of Michigan.

Figure 3.2 Design and layout of the preliminary GIS model developed to predict risk of invasion by exotic earthworms within the Huron Mountains, Upper Peninsula, Michigan

Figure 3.3 Preliminary predicted risk of invasion by earthworms across the study area in the Huron Mountains, Upper Peninsula, Michigan.

Figure 3.4 The distribution of earthworm signs and middens at sample points across the Huron Mountains

Figure 3.5 The relationship between forest floor condition and earthworm midden abundance

Figure 3.6 Interpolated soil $\mathrm{pH}(\mathrm{CaCl} 2)$ across the Huron Mountains created using ordinary kriging (ArcGIS 10 Spatial Analyst, ESRI 2011) of the 235 field sample points.

Figure 3.7 Design and layout of the final (current) GIS model developed to predict risk of invasion by exotic earthworms within the Huron Mountains, Upper Peninsula, Michigan. 
Figure 3.8 Current predicted risk of invasion of Lumbricus terrestris across the study area in the Huron Mountains, Upper Peninsula, Michigan ...........56

Figure 3.9 Future predicted distribution of Lumbricus terrestris across the study area in the Huron Mountains, Upper Peninsula, Michigan....................57

Figure 4.1 National Wildlife Refuges included in the study, located within the Upper Great Lakes region ....................................................................8 88

Figure 4.2 Forest rapid ecological assessment (REA) plot and subplot design .......89

Figure 4.3 Mean (+1SE) earthworm biomass at six National Wildlife Refuges in the Great Lakes region ................................................................90

Figure 4.4 Variation in earthworm biomass $\left(\mathrm{AFDg} / \mathrm{m}^{2}\right.$ ) by earthworm functional group at six National Wildlife Refuges in the Great Lakes region.........91

Figure 4.5 Canonical correspondence analysis (CCA) biplot relating earthworm community composition with environmental variables........................92

Figure 4.6 Correlation between refuge mean patch area of anthropogenic cover (ha, NLCD 2006) and mean earthworm biomass (AFDg/m²) ..............93 


\section{List of Tables}

Table 2.1 Description of parameters used in the multicriteria risk model developed to predict satellite invasion sites of emerald ash borer across Northern Michigan 32

Table 2.2 Risk values assigned to National Land Cover Data classes...................33

Table 2.3 Comparison of the original and two alternative multicriteria risk models for predicting risk of emerald ash borer invasion..... 34

Table 3.1 Risk values assigned to IFMAP (MI DNR 2001) land cover types within the Huron Mountains for the preliminary and final (both current and future) predictive GIS models.

Table 3.2 Earthworm preference for leaf litter from tree species encountered during field sampling within the Huron Mountains.

Table 3.3 Description of forest floor condition ratings from 1-lowest quality to 5-highest quality

Table 3.4 Description of environmental variables selected to test associations with exotic earthworm presence and abundance

Table 3.5 Correlation matrix showing Pearson's correlation coefficients for environmental variables

Table 3.6 Results (mean \pm standard deviation and significance) of analyses testing differences between plots with earthworm signs $(\mathrm{N}=135)$ and plots without $(\mathrm{N}=100)$

Table 3.7 Summary statistics (coefficients, significance, and odds ratios) for the logistic regression model analyzing presence of earthworm signs

Table 3.8 Results (mean \pm standard deviation and significance) of analyses testing differences in environmental variables between plots with middens present $(\mathrm{N}=47)$ and plots without middens $(\mathrm{N}=188)$

Table 3.9 Summary statistics (coefficients, significance, and odds ratios) for the logistic regression model analyzing presence of middens.

Table 3.10 Results of linear regression analyses testing relationships between environmental variables and midden abundance 
Table 3.11 Results (Moran's Index, significance and pattern) of tests for spatial autocorrelation in significant environmental variables. .68

Table 3.12 Results (sample size, mean \pm standard deviation and significance) of analyses of forest floor condition in relation to the presence and absence of earthworm signs and middens....

Table 3.13 Average midden abundance (mean \pm standard deviation) at each forest floor rating and analysis of variance table comparing ratings ......70

Table 4.1 Description of environmental variables assessed in association with earthworm abundance and community composition data.

Table 4.2 National Wildlife Refuges of study and their associated state and ecoregion subsection(s) (Cleland et al. 1997)....

Table 4.3 Landscape metrics selected to represent patterns of composition and fragmentation within refuges and associated ecoregions....

Table 4.4 Mean earthworm biomass (AFDg/m2 $\pm \mathrm{SE}$ ), refuge earthworm taxa richness, mean earthworm Shannon's diversity $( \pm \mathrm{SE})$, and mean earthworm Shannon's evenness $( \pm \mathrm{SE})$....

Table 4.5 Refuge mean earthworm biomass (AFDg $/ \mathrm{m}^{2} \pm 1 \mathrm{SE}$ ) by taxonomic and functional groups

Table 4.6 Linear regression results by functional group for forest floor condition, litter depth, herbaceous understory cover, woody understory cover, and invasive exotic plant presence

Table 4.7 Correlation matrix showing Pearson's correlation coefficients for environmental variables....

Table 4.8 Linear regression results comparing mean stand (transect) earthworm biomass to environmental variables

Table 4.9 Summary of multivariate regression results for the best model predicting earthworm biomass from environmental variables.

Table 4.10 Summary statistics for the canonical correspondence analysis (CCA) of earthworm community composition as related to environmental variables 
Table 4.11 Linear regression results comparing refuge mean earthworm biomass to landscape metrics calculated using all National Land Cover Dataset cover types

Table 4.12 Linear regression results comparing refuge mean earthworm biomass to landscape metrics calculated for anthropogenic land cover types....105

Table 4.13 Linear regression results comparing refuge mean earthworm biomass by functional group to landscape metrics calculated using all land cover types 106

Table 4.14 Linear regression results comparing refuge mean earthworm biomass to landscape metrics calculated for anthropogenic land cover types ....107

Table 4.15 Linear regression results comparing refuge earthworm community diversity to landscape metrics calculated for all land cover types........108

Table 4.16 Linear regression results comparing refuge earthworm community diversity to landscape metrics calculated for anthropogenic land cover types

Table A.1 Landscape metrics based on the 2006 National Land Cover Dataset at the refuge and ecoregion levels (Chapter 4)

Table A.2 Landscape metrics for anthropogenic cover types at the refuge and ecoregion levels (Chapter 4)

Table B.1 Descriptive statistics (number of plots, mean, standard deviation, minimum, and maximum) by transect for environmental variables used in the assessment of earthworm patterns in National Wildlife Refuges (Chapter 4) 


\section{Acknowledgements}

Completion of this dissertation would not have been possible without the continuous support and encouragement of many individuals. I am first of all thankful for the guidance, reassurance, and financial backing from my advisor, Dr. Andrew Storer. I am also grateful for the time, advice, feedback, and encouragement provided by my graduate committee members, Dr. Erik Lilleskov, Dr. Ann Maclean, and Dr. Nancy Auer. Special thanks are due to Dr. Greg Corace, Seney National Wildlife Refuge for assisting with grant writing, funding, project coordination, and manuscript review for the National Wildlife Refuge project. I would also like to thank Dr. Dan Kashian for a thorough review of the refuge earthworm chapter.

Many individuals assisted with the field and lab work associated with the projects presented here, and this work would not have been possible without them. Included are Amy Berns, James Klapperich, Jimmy Maltese, Jonathan Fournier, Mike Hyslop, Karl Romanowicz, Lynette Potvin, Holly Petrillo, Alina Neel, Dakota Hunter, Joe May, Max Henschell, Adam Komar, John Otterbein, and National Wildlife Refuge staff and volunteers.

Funding for these projects came from a variety of sources including the USDA Forest Service Northern Research Station, U.S. Fish and Wildlife Service Midwest Region, Seney National Wildlife Refuge, and Michigan Technological University. Tuition and stipend during my final semester was sponsored by the Neil V. Hakala Endowed Fellowship.

Last but not least, I would like to thank my family and friends, especially my mom, for always being encouraging and supportive, and my favorite guy for always reminding me to have passion and purpose! 


\section{Dissertation Abstract}

Invasive and exotic species present a serious threat to the health and sustainability of natural ecosystems. These species often benefit from anthropogenic activities that aid their introduction and dispersal. This dissertation focuses on invasion dynamics of the emerald ash borer, native to Asia, and European earthworms. These species have shown detrimental impacts in invaded forest ecosystems across the Great Lakes region, and continue to spread via human-assisted long distance dispersal and by natural modes of dispersal into interior forests from areas of introduction. Successful forest management requires that the impact and effect of invasive species be considered and incorporated into management plans. Understanding patterns and constraints of introduction, establishment, and spread will aid in this effort.

To assist in efforts to locate introduction points of emerald ash borer, a multicriteria risk model was developed to predict the highest risk areas. Important parameters in the model were road proximity, land cover type, and campground proximity. The model correctly predicted $85 \%$ of known emerald ash borer invasion sites to be at high risk. The model's predictions across northern Michigan can be used to focus and guide future monitoring efforts. Similar modeling efforts were applied to the prediction of European earthworm invasion in northern Michigan forests. Field sampling provided a means to improve upon modeling efforts for earthworms to create current and future predictions of earthworm invasion. Those sites with high soil $\mathrm{pH}$ and high basal area of earthworm preferred overstory species (such as basswood and maples) had the highest likelihood of European earthworm invasion. Expanding beyond Michigan into the Upper Great Lakes region, earthworm populations were sampled across six National Wildlife Refuges to identify potential correlates and deduce specific drivers and constraints of earthworm invasion. Earthworm communities across all refuges were influenced by patterns of anthropogenic activity both within refuges and in surrounding ecoregions of study. Forest composition, soil $\mathrm{pH}$, soil organic matter, anthropogenic cover, and agriculture proximity also proved to be important drivers of earthworm abundance and community composition.

While there are few management options to remove either emerald ash borer or European earthworms from forests after they have become well established, prevention and early detection are important and can be beneficial. An improved understanding the factors controlling the distribution and invasion patterns of exotic species across the landscape will aid efforts to determine their consequences and generate appropriate forest management solutions to sustain ecosystem health in the presence of these invaders. 


\section{Chapter 1. Introduction}

\subsection{Background}

The field of invasion ecology involves the study of introduced species, particularly those associated with humans, and their interactions and impacts. These species (also referred to as exotic, nonnative, nonindigenous, or alien species) are of serious concern in many ecosystems worldwide, particularly because of their ability to alter natural patterns and processes. Interest in invasion ecology is thought to have begun with the book The Ecology of Invasions by Animals and Plants published by Charles Elton in 1958. It was not until the 1980s, however, that invasion ecology was considered a distinct field of study (Richardson and Pyšek 2008). Elton's book has since become the most cited work in the field of invasion ecology. In addition to the topics Elton focused on (e.g. dispersal and spread, effects on biodiversity, association with disturbance), more technical approaches have also become important in invasion ecology, such as risk prediction and spatial distribution modeling (Richardson and Pyšek 2008). The use of ecological niche modeling combined with knowledge of the processes and patterns of invasion provides a method for predicting the spatial distribution of invasive species (Peterson 2003).

The ecological niche is a fundamental theory that can be applied to all fields of ecology. In invasion ecology, ecological niche theory plays a central role in explaining the ability of invasive species to establish and survive in new sites. The term ecologic niche was first introduced by Grinnell (1924) to describe the distributional unit in which a single species occurs. Around this same time, the term niche was used by Elton (1927) to include the species' role in, and impact on, the environment. Today's understanding of niche has evolved to include both perspectives. In their review of ecological niche theory, Chase and Leibold (2003) define the ecological niche as, "the joint description of the environmental conditions that allow a species to satisfy its minimum requirements so that birth rate of a local population is equal to or greater than its death rate along with the set of per capita effects of that species on these environmental conditions." The ecological niche can be represented as either the fundamental niche or the realized niche (Hutchinson 1957). The species potential distribution represents the fundamental niche and is made up of all environments suitable for a species, while the realized niche incorporates limitations to distribution imposed by competition with other species (Hutchinson 1957). In the case of exotic species, the fundamental niche may also be limited by time since introduction, as a species may not have reached its full distribution yet but may still be expanding. In predicting invasion by exotic species, fundamental niche modeling provides one component of a complex process. The fundamental niche represents the spatial extent in which a species will potentially be able to establish populations based on environmental constraints, however how colonization, dispersal, and biotic interactions will contribute to the actual distribution is important in determining the realized niche, making it more difficult to predict (Peterson 2003). 
In the United States, invasive exotic species are thought to be one of the greatest priorities and challenges for ecosystem conservation and restoration (Coblentz 1990; Allendorf and Lundquist 2003). Executive Order 13112 provided a formal definition for the term invasive species, "an alien species whose introduction does or is likely to cause economic or environmental harm or harm to human health" (Clinton 1999). Invasive species cause harm by disrupting native communities and the ecosystem services that they provide. Environmental impacts can include native species decline or extinction, ecosystem homogenization, loss of diversity, altered ecosystem processes, loss of genetic integrity, and aesthetic decline. Economically invasive species can have direct and indirect impacts, such as loss of resources and revenue, cost of control, restricted trade and goods movement, and loss of potential value and future gain. It is estimated that impact and control of invasive species in the United States alone costs $\$ 120$ billion annually (Pimental et al. 2005). Invasive species also pose a threat to human health through spread of disease agents (e.g., West Nile virus), loss of native medicinal species, and use of pesticides and herbicides for control (Pimental et al. 2005).

Invasive species pose a serious threat for the sustainability of forested ecosystems (Chornesky et al. 2005). Forests are an important source of biodiversity, habitat, carbon storage, wood and other products, and recreational land, and they also play a role in providing clean air and water. The greatest concern in forested ecosystems is the potential for invasive species to negatively affect community composition, structure, function, productivity, and carbon sequestration, which will in turn affect the beneficial products and services that forests provide (Moser et al. 2009). This includes ecological threats to biodiversity, wildlife habitat, endangered and threatened species, natural disturbance patterns (Moser et al. 2009), and economic threats from management costs and loss of forest products, services, and other intrinsic values (Holmes et al. 2009). For example, the invasion of eastern forests by woody vines, shrubs and trees has altered composition, structure, and function by reducing regeneration of desired species, impacting overstory trees through strangulation and overtopping, and decreasing biodiversity creating a more simplified community (Webster et al. 2006).

The invasion process can be broken down into three main stages: introduction, establishment, and spread. For use in this manuscript, each stage will be defined as follows (adapted from Williamson 1996; Kolar and Lodge 2001; Sakai et al. 2001), however variations in definition exist. Introduction is defined as the transport and arrival of a species in an area where it is not native. The introduction of exotic species can be natural, however current rates and distances of transport are clearly linked to human activity, whether accidental or intentional (Lodge and Shrader-Frechette 2003). Establishment follows introduction and is defined as the development of a free-living, reproducing population of a species. Although many exotic species are introduced, not all can survive and even fewer become invasive. Spread is defined as an increase in number of individuals or area occupied of an established population. Spread involves both short and long distance dispersal. Humans again play an important role in facilitating invasive species by aiding long distance spread within the invaded region. 
The factors and influences that control the success of invasive species can be dynamic, varying by phase, or static, consistent across all phases.

Management approaches for exotic species have been developed and applied at all stages of invasion. Prevention or exclusion aims to stop the introduction of exotic species by regulating pathways and vectors of dispersal. While prevention is the ideal answer for reducing the future impact of exotic species, even the best possible application may not be completely successful. Rates of exotic species transport continue to increase, and it is likely that as globalization of trade occurs, the diversity and magnitude of introductions will be amplified (Hulme 2009). Early detection and rapid response (EDRR) management is considered the next best option (NISC 2008). EDRR focuses on preventing the establishment and further spread of exotic species. Though it can be intensive and costly, the long-term economic and ecological benefits outweigh initial investments (Pimental et al. 2005). EDRR management relies on close monitoring and immediate action to locate and control newly introduced or established populations before they are able to become abundant and cause detrimental effects. A National EDRR program exists for detecting and identifying invasive plant species in the United States. Similar methods are also used in detecting exotic insects and other invasive animals (Rabaglia et al. 2008). This approach has been valuable in reacting to identified populations of the Asian longhorned beetle (Anoplophora glabripennis), which has the potential to be a serious pest of hardwood trees but is not yet widely distributed. The rapid response of federal agencies to regulate and control known Asian longhorned beetle infestations has been successful in eradicating small populations and containing larger populations (Haack et al. 2010). For well-established and spreading invasive species, efforts of control to reduce extent and impact utilize physical, chemical, and biological methods.

Research and support for prevention and early detection management increased rapidly following the recognition of the substantial impact and cost associated with invasive species (Kolar and Lodge 2001). The National Invasive Species Council (NISC) encourages the use of prevention and EDRR as best management practices for defense against invasive species (NISC 2008). Predicting patterns of invasion by exotic species aids prevention and early detection management. Ability to make such predictions is dependent on an understanding of the patterns and factors influencing invasive species introduction, dispersal, distribution, and population dynamics. With this information, methods for prevention and early detection can be focused towards high risk taxa and species, common transport pathways and vectors, and ecosystems with high invasibility. Future research should also incorporate anticipated changes in climate, which are expected to alter pathways of introduction, change the potential distributions of invasive species, and cause disturbance to native ecosystems offering opportunities for invasion (Hellmann et al. 2008).

By exploring the patterns and factors influencing the stages of invasion, improvements can be made to prevention and early detection efforts. Conditions that facilitate the introduction and dispersal of exotic species are dynamic factors that regulate 
the initial distribution and subsequent pattern of spread. The vector and pathway of transport are important considerations for predicting both exotic species introductions and the spread of established invasive species into new sites (Lockwood et al. 2007). Few "accidental" vectors for the introduction of invasive species, with the exception of ballast water, have been formally researched to identify risk or formulate solutions (Lockwood et al. 2007). Much research, however, has been devoted to predicting other aspects of invasion, such as which exotic species have the potential to be invasive. Predictive modeling has been used to assess the probability that a species will become invasive based on life history traits (Kolar and Lodge 2001). These predictions are usually directed at specific taxa in a specific region, for example exotic plants invading the United States (Sutherland 2004). Traits associated with invasive potential are typically also those that facilitate rapid reproduction and dispersal that will aid in future spread. Knowledge of these traits, and the species that possess them, provides valuable information for prevention and early detection management.

Predicting ecosystem or site invasibility, the tendency to be invaded by exotic species, is also used to guide prevention and early detection. The most common factors used in estimating site invasibility are diversity, biotic interactions, disturbance, and propagule pressure. Invasibility is often linked to diversity, although the exact relationship is highly debated. High diversity sites may be less invasible because of their perceived high biotic resistance, efficient use of all available resources and niches, and competitive ability (Elton 1958), however they may offer more resources and opportunities for exotic species to find a suitable niche (Shea and Chesson 2002). Biotic interactions between native and other invasive species can act to facilitate or resist invasion. For example, the invasive herb garlic mustard (Alliaria petiolata) is facilitated by the presence of white-tailed deer (Odocoileus virginianus), which selectively feed on native herbs, avoiding garlic mustard (Knight et al. 2009). Therefore, native plant communities at sites with high deer herbivory may lack the competitive ability necessary to resist invasion by garlic mustard. Other more extreme models of "invasional meltdown" propose that invasive species facilitate or co-facilitate each other, increasing their survival, abundance, and ultimately impact on the ecosystem (Simberloff and Von Holle 1999). Invasibility is also greatly influenced by disturbance. Although disturbance is an essential and natural component in many ecosystems, it can promote species invasions, especially in sites where propagule pressure is high (Hobbs and Huenneke 1992). Disturbance is generally expected to increase the likelihood of invasion by disrupting the native community and freeing up available resources, especially when alterations are made to the natural disturbance regime, including human-induced disturbances (Hobbs and Huenneke 1992). Some types of human disturbance can also be associated with increased propagule pressure. One example is the construction and use of roads, which facilitates long-distance spread through movement of propagules on and in construction materials, equipment, and vehicles (Hulme 2009).

For introduced species static environmental and ecological constraints, such as those used in ecological niche modeling (e.g. ecosystem type, host availability, soil properties, light, climate, and elevation), affect the suitability of a site for species 
establishment. Ecological niche modeling, also referred to as habitat suitability modeling, is often used to predict the spatial distribution and expected spread of invasive species (Peterson and Vieglais 2001). Many differing statistical and conceptual methods for model development exist, though models are commonly developed using a geographic information system (GIS) to provide spatial representation useful in research and management (Guisan and Zimmermann 2000). Habitat suitability modeling can also be applied to exotic species that have not yet been introduced or established to estimate a potential distribution based on data from the native range (Peterson and Vieglais 2001). Unfortunately, many invasive species are generalists that can tolerate a wide variety of conditions or have the ability to readily adapt and evolve to the conditions encountered (Whitney and Gabler 2008). Thus their potential distribution may cover a large portion of the United States, providing little information to guide prevention and detection efforts. By combining habitat suitability models with other factors related to invasion, more detailed risk prediction is possible. In the case of newly introduced species, where species occurrence data is limited, expert knowledge can be used in addition to traditional statistical methods to predict potential risk of invasion (Store and Kangas 2001). For example, multicriteria risk modeling was used to estimate the risk of invasion of garlic mustard based on habitat suitability (land cover, soil moisture, and soil $\mathrm{pH}$ ) and human influence (transportation routes, campgrounds, and other disturbance features) to aid early detection in uninvaded sites (Shartell et al. 2011).

Among the needs for research in invasion ecology, Richardson and Pyšek (2008) list the improvement and application of distribution models. Using an approach that combines ecological niche modeling with processes and patterns of invasion is a promising method (Peterson 2003). Verification and application of distribution models using real data sets is greatly needed to advance their incorporation into management against invasive species. The research included in this dissertation aims to explore, create and apply predictive models and deduce specific drivers of invasion patterns at a landscape scale for emerald ash borer (Agrilus planipennis Fairmaire [Coleoptera: Buprestidae]) and European earthworms (family Lumbricidae [Annelida: Oligochaeta]) in the Great Lakes region.

\subsection{Emerald Ash Borer}

The emerald ash borer (EAB) is an exotic wood boring beetle native to Asia that attacks ash trees from the genus Fraxinus. In its native range, EAB is only a minor pest of Asian ash species, which have shown increased resistance (Rebek et al. 2008). In all North American ash species, however, the insect causes significant damage leading to death of the tree within one to four years (Poland 2007). This occurs due to the feeding behavior of the larvae on the tree phloem and cambium, which in heavily infested trees disrupts the translocation of water and nutrients, girdling the tree. Adult insects feed on ash leaves, but do not contribute significantly to tree decline or death. EAB was an accidental introduction, most likely associated with the transport of larva in wood packing crates (Cappaert et al. 2005). It was first discovered in southeast Michigan in 
2002, but it is likely that the beetle had been established in the area for at least ten years prior to identification (Poland and McCullough 2006). At the time of identification, it was estimated that five to seven million ash trees were already dead or dying due to the insect (Cappaert et al. 2005), and 7,553 million ash trees in the United States were at risk, an estimated value of $\$ 282$ billion (Federal Register 2003). Ecologists agree that emerald ash borer has the potential to spread throughout the full range of ash causing large scale loss and ultimately changing forest and ecosystem composition and dynamics at varying levels of severity (MacFarlane and Meyer 2005; Kovacs et al. 2010).

The life cycle of the emerald ash borer lasts one to two years (Cappaert et al. 2005). The larvae are legless, white or cream colored, and 26 to $32 \mathrm{~mm}$ long at maturity (McCullough and Katovich 2004). The adults are 7.5 to $13.5 \mathrm{~mm}$ long, slender and a metallic coppery-green color, hence its common name (McCullough and Katovich 2004). Emerging adults produce characteristic D-shaped exit holes used to confirm presence. Other signs of EAB include serpentine galleries under the bark and woodpecker activity. Symptoms of EAB are canopy dieback, epicormic sprouts, splits in the bark, and ultimately death of the tree. EAB colonizes the upper canopy of trees first, making it difficult to detect until the tree is heavily infested (Poland and McCullough 2006). Natural dispersal of EAB is estimated to be less than $1 \mathrm{~km}$ per year in low density sites (Cappaert et al. 2005) and is limited by flight ability and ash connectivity, however, laboratory studies suggest that mated females could potentially fly distances as far as 20 $\mathrm{km}$ (Taylor et al. 2007). Spread of EAB has been aided greatly by human activity. Invasion is positively correlated with human population centers (Muirhead et al. 2006) and roads (Prasad et al. 2010). The long distance spread of EAB within North America has been aided by the movement of infested firewood, nursery stock, and other wood products such as logs, lumber, and wood chips.

Prevention of further spread of EAB focuses on the use of quarantine and regulation, particularly the restriction of movement of firewood and other wood products from invaded sites. In addition, an extensive public outreach and education effort was initiated in Michigan and surrounding states (Poland and McCullough 2006). Early detection and rapid response has also been an important component of management. Detection surveys are used to assess current populations of EAB and identify new invasions. Research is ongoing to expand knowledge of EAB biology, its relationship with the host, trapping and detection methods, biological control organisms such as parasitic wasps, and many other subjects. Control and containment methods for EAB include removal of infested trees, creation of sink trees, ash reduction, and insecticide treatment using the Slow Ash Mortality (SLAM) approach (Poland and McCullough 2010). Many commercial insecticide products have been developed for application on individual or small groups of ash trees, to both prevent and treat infestation (Poland and McCullough 2006). Biological control for EAB is also being developed. Three parasitoid wasps from China, Oobius agrili, Spathius agrili, and Tetrastichus planipennisi, have been identified and approved for release (Bauer et al. 2010). The USDA Forest Service, Animal and Plant Health Inspection Service (APHIS), and other organizations monitor the current status of EAB and regularly provide updated 
distribution maps online (see http://emeraldashborer.info). Currently EAB is present in 15 states and two Canadian provinces (EAB Info 2011).

Patterns of EAB invasion are dependent on the distribution of ash. Ash is present in many forest ecosystems, sometimes as a dominant, but most often as a co-dominant or minor component (MacFarlane and Meyer 2005; Kashian and Witter 2011). Ash seedling and sapling regeneration provides potential for ash to become reestablished in forests, although whether ash will return as an overstory component is dependent on EAB population dynamics and management success (Kashian and Witter 2011). Tree species expected to replace ash in the overstory include maple (Acer spp.), elm (Ulmus spp.), basswood (Tilia americana), and beech (Fagus grandifolia), but changes will be site specific. Extensive ash removal and mortality could also lead to secondary invasion by exotic plants into gaps and disturbed areas (Hausman et al. 2010). Other ecological changes expected to occur are increased coarse woody debris due as ash trees decline and die, effects on existing invertebrate communities (Herms et al. 2009), and altered hydrology in lowland forests (Kashian and Witter 2011). The full extent of ecosystem consequences has yet to be explored.

\subsection{European Earthworms}

Increasing attention is being directed to the invasion of forests by exotic European earthworms. Much of the northern Great Lakes region lacks native earthworm populations due to glaciation during the Pleistocene (Gates 1982). Thus the forests in this region have developed and evolved without the influence of earthworms. Though native species exist further south, their recolonization northward is slow, and likely hindered by the presence of exotic species (Kalisz and Wood 1995). Today the Great Lakes is inhabited most commonly by European earthworms, first introduced by early settlers and likely transported and reintroduced many times since (Hale et al. 2005). These species are considered peregrine for their tendency and ability to be transported long distances by humans (Lee 1985). Further spread is facilitated by release of fishing bait (Hale et al. 2005) and transport in soils, horticultural material, and on vehicles (Bohlen et al. 2004c). No methods of control for earthworms exist thus far; therefore, prevention of introduction into uninvaded sites is the best defense. An improved understanding of invasion patterns and impacts will be beneficial to planning and implementation of conservation and management efforts in invaded sites. Furthermore, public education and policies to regulate importation and transport of earthworms are lacking, and a better understanding of earthworm invasion and its effects will benefit the creation and implementation of proper education and policies (Callaham et al. 2006).

It is only within the last two decades that exotic earthworms have been acknowledged as detrimental invasive species. Early research, primarily from agricultural systems, had found earthworms to be beneficial, particularly to soil and plant productivity (Hendrix and Bohlen 2002; Scheu 2003). Initial concern over the introduction of earthworms focused on their ability to act as vectors of plant and animal 
pathogens (Hendrix and Bohlen 2002), rather than their potential effects as invaders in natural ecosystems that previously lacked earthworms. While many of the effects of earthworms can still be seen as beneficial in some systems, their impact on forested ecosystems, especially those that have lacked native earthworms, is generally agreed to be undesirable (Bohlen et al. 2004c). Exotic earthworms are recognized to have significant physical, chemical, and biological impacts in forests that can facilitate ecosystem level changes (Bohlen et al. 2004c).

The direct effects of exotic earthworms on soils and belowground processes are complex and at times conflicting, yet it is clear that earthworms, whether beneficial or detrimental, have the ability to cause considerable change. It is agreed that earthworms reduce the thickness of forest floor litter layer and decrease organic matter content (Alban and Berry 1994; Burtelow et al. 1998; Bohlen et al. 2004b). The remaining soil horizons typically have an organic layer consisting of only the Oi horizon, increased thickness and decreased variability in the A horizon, and, if previously present, an E horizon that has been mixed into the A horizon (Alban and Berry 1994). Changes in soil microorganism biomass and community composition occur due to the changes in the litter layer and organic horizon (Bohlen et al. 2001). Earthworms tend to decrease fungal populations by the disruption of fungal hyphae, increasing the ratio of bacteria to fungi (Scheu and Parkinson 1994; McLean et al. 2006). Earthworms have also been found to modify mycorrhizal colonization, decreasing hyphal colonization and hyphal coils while increasing vesicles, which are known to be associated with plant stress (Lawrence at al. 2003). Earthworm presence has also been linked to decreased total carbon, nitrogen, and carbon to nitrogen ratios in soils (Bohlen et al. 2004b). There have been conflicting studies, however, that show increases in soil carbon with earthworm presence (Burtelow et al. 1998). Conflicting results may be due to the differing effects of earthworm functional groups (described by Bouché 1977) on the forest floor and mineral soil. Epigeic species (e.g. Dendrobaena octaedra, Dendrodrilus rubidus) live and feed in the litter layer, having an overall low impact (Frelich et al. 2006). Endogeic species (e.g. Aporrectodea spp., Octolasion spp.) live and feed in the mineral soil and thus their impact is limited to the mineral soil horizon. Epi-endogeic species (e.g. Lumbricus rubellus) live and feed in both the litter and mineral soil, and tend to have a rapid and large impact (Frelich et al. 2006). Anecic species (e.g. Lumbricus terrestris) feed on surface litter, creating deep burrows that slowly increase mixing of organic matter from the litter layer into the mineral soil resulting in a large impact over time (Frelich et al. 2006). These groups are thought to invade in waves, from epigeic to anecic, due to their differing feeding and colonization habits (Hale et al. 2005).

For their ability to modify ecosystems and the resources they provide earthworms are considered to be ecosystem engineers (Jones et al. 1994). As ecosystem engineers, earthworms are expected to have indirect ecosystem level consequences associated with their invasion. Invasive earthworm presence has been linked to decreased plant species richness and changes in plant community composition (Holdsworth et al. 2007a). Earthworms also have the potential to indirectly impact wildlife communities (MiggeKleian et al. 2006). Hale (2008) predicted that earthworms will cause declines in native 
arthropods, salamanders, ground-nesting birds, and small mammal populations in forests. Accordingly, recent research has shown that removal of leaf litter by earthworms caused a decrease in salamander abundance due to decreased habitat quality and prey abundance (Maerz et al. 2009), as well as a decrease in ground nesting songbirds likely due to reduced nest concealment (Loss and Blair 2011). European earthworms have also been suggested to play a role in cases of invasional meltdown, leading to increased success and impact of a suite of exotic species, and theoretically resulting in a "meltdown" of the native community (Simberloff 2006). This scenario has been suggested in the central United States, where European buckthorn (Rhamnus cathartica), facilitated by European earthworms, is thought to interact with as many as nine associated exotic species including a pathogen, various insects, a bird, and two introduced crop plants (Heimpel et al. 2010). In forests, earthworms are expected to act in combination with other drivers (e.g. increased deer densities, invasive plant species, and climate change) to accelerate ecosystem change (Frelich et al. 2006).

\subsection{Project Overview}

The research described in this dissertation consists of three separate but related projects. The first focuses specifically on emerald ash borer, and the remaining two on European earthworms. All projects were based in forested ecosystems of the Upper Great Lakes region and explore patterns of introduction, establishment, and spread in order to improve understanding and potential management.

The first project, described in Chapter 2, seeks to improve the detection of emerald ash borer in northern Michigan through spatial predictive modeling. This research uses an applied approach to test the feasibility of creating and applying a predictive multicriteria risk model for use in the detection of satellite invasion sites of EAB. In doing so, the work focuses on the introduction and spread phases of the invasion process. Early detection of satellite invasion sites is one of the best defenses against the further spread of this insect, and the predictive risk model developed from this research aims to guide detection surveys and improve the success of efforts to slow the spread, such as the SLAM program (Poland and McCullough 2010). This research incorporates the use of a geographic information system (GIS) and spatial data layers into prediction and detection efforts. The use of GIS has become a common and valuable tool for both research and management in ecology and related fields.

The second project, described in Chapter 3, explores factors influencing exotic earthworm populations within the Huron Mountains located in Marquette County, Michigan. In this project earthworm activity was assessed in order to uncover factors influencing distribution and abundance of earthworms and develop predictive models to describe invasion potential. Earthworm populations were described by identifying earthworm signs within the forest floor and counting middens created by the deep burrowing $L$. terrestris. Site and spatial characteristics of the plot locations were related to earthworm presence and midden abundance to address the hypothesis that earthworm 
signs and middens will be positively influenced by forest characteristics favoring earthworm dispersal and survival. Specifically, it was hypothesized that earthworm signs and middens would be present in those sites in closest proximity to human activity (such as roads and waterways used for fishing), with high basal area of earthworm preferred overstory tree species, and in warm, mesic, slightly acidic to calcareous soils on flat sites at low elevation. As in the previous project, a GIS modeling component was included. A predictive risk model was developed using significant factors to predict the potential distribution of earthworms before sampling and improved using the results of the field data analysis. Understanding the factors controlling earthworm distribution and abundance across the landscape, as well as the future potential for invasion, will aid efforts to determine consequences and generate potential forest management options to prevent further spread and mitigate negative impacts.

The final project, described in Chapter 4, expands on the previous exotic earthworm work, involving a more in-depth analysis of patterns and employing a larger, landscape level approach. The project is also enhanced by including direct sampling of earthworms and identification and separation of specific earthworm taxa into functional groups. The research samples earthworm populations across six National Wildlife Refuges in the Great Lakes states of Minnesota, Wisconsin, Michigan, and Ohio, with the goal of identifying potential correlates and deducing specific drivers and constraints of earthworm invasion. To do so, the following three hypotheses are addressed: earthworm impact will be most pronounced in sites with high earthworm biomass and presence of epi-endogeic and anecic species, stand level environmental variables related to earthworm habitat suitability and dispersal opportunity will be correlated with earthworm biomass and community composition, and landscape level patterns dominated by anthropogenic cover types will promote increased earthworm biomass and diversity.

\section{Literature Cited}

Alban DH, Berry EC. 1994. Effects of earthworm invasion on morphology, carbon, and nitrogen of a forest soil. Applied Soil Ecology. 1:243-249.

Allendorf FW, Lundquist LL. 2003. Introduction: population biology, evolution, and control of invasive species. Conservation Biology. 17:24-30.

Bauer L, Gould J, Duan J, Ulyshen M. 2010. Emerald ash borer biological control. In: McManus KA, Gottschalk KW, editors. Proceedings of the 21st U.S. Department of Agriculture interagency research forum on invasive species 2010. USDA Forest Service, Northern Research Station, Gen. Tech. Rep. NRS-P-75. 70-73 p.

Bohlen PJ, Groffman PM, Driscoll CT, Fahey TJ, Siccama TG. 2001. Plant-soilmicrobial interactions in a northern hardwood forest. Ecology. 82:965-978. 
Bohlen PJ, Pelletier DM, Groffman PM, Fahey TJ, Fisk MC. 2004b. Influence of earthworm invasion on redistribution and retention of soil carbon and nitrogen in northern temperate forests. Ecosystems. 7:13-27.

Bohlen PJ, Scheu S, Hale CM, McLean MA, Migge S, Groffman PM, Parkinson D. $2004 \mathrm{c}$. Non-native invasive earthworms as agents of change in northern temperate forests. Frontiers in Ecology and the Environment. 2:427-435.

Bouché MB 1977. Strategies lombricienes. Soil organisms as components of ecosystems. In: Lohm U, Persson T, editors. Ecological Bulletins, Stockholm. p. 122-132.

Burtelow AE, Bohlen PJ, Groffman PM. 1998. Influence of exotic earthworm invasion on soil organic matter, microbial biomass and denitrification potential in forest soils of the northeastern United States. Applied Soil Ecology. 9:197-202

Callaham MA, Gonzalez G, Hale CM, Heneghan L, Lachnicht SL, Zou X. 2006. Policy and management responses to earthworm invasions in North America. Biological Invasions. 8:1317-1329.

Cappaert D, McCullough DG, Poland TM, Siegert NW. 2005. Emerald ash borer in North America: a research and regulatory challenge. American Entomologist. 51:152165.

Chase JM, Leibold MA. 2003. Ecological niches: linking classical and contemporary approaches. Chicago, IL: The University of Chicago Press.

Chornesky EA, Bartuska AM, Aplet GH, Britton KO, Cummings-Carlson J, Davis FW, Eskow J, Gordon DR, Gottschalk KW, Haack RA, Hansen AJ, Mack RN, Rahel FJ, Shannon MA, Wainger LA, Bently Wigley T. 2005. Science priorities for reducing the threat of invasive species to sustainable forestry. BioScience. 55:335-348.

Clinton WJ. 1999. Executive Order No. 13112: Invasive Species. Federal Register 64. (http://www.invasivespeciesinfo.gov/laws/execorder.shtml)

Coblentz BE. 1990. Exotic organisms: a dilemma for conservation biology. Conservation Biology. 4:261-265.

Emerald Ash Borer (EAB) Info. 2011. http://emeraldashborer.info. Accessed 1 April 2011.

Elton CS. 1927. Animal ecology. London, UK: Sidgewick and Jackson. 204 p.

Elton CS. 1958. The ecology of invasions by animals and plants. London, UK: Methuen. 
Federal Register. 2003. Emerald ash borer, quarantine and regulations. 7 CFR Part 301. 68:59082-59091.

Frelich LE, Hale CM, Scheu S, Holdsworth AR, Heneghan L, Bohlen PJ, Reich PB. 2006. Earthworm invasion into previously earthworm-free temperate and boreal forests. Biological Invasions. 8:1235-1245.

Gates GE. 1982. Farwell to North American megadriles. Megadrilogica. 4:12-77.

Grinnell J. 1924. Geography and evolution. Ecology. 5:225-229.

Guisan A, Zimmermann NE. 2000. Predictive habitat distribution models in ecology. Ecological Modeling. 135:147-186.

Haack RA, Herard F, Sun J, Turgeon JJ. 2010. Managing invasive populations of Asian longhorned beetle and citrus longhorned beetle: a worldwide perspective. Annual Review of Entomology. 55:521-546.

Hale CM. 2008. Evidence for human-mediated dispersal of exotic earthworms: support for exploring strategies to limit further spread. Molecular Ecology. 17:1165-1169.

Hale CM, Frelich LE, Reich PB. 2005. Exotic European earthworm invasion dynamics in northern hardwood forests of Minnesota, USA. Ecological Applications. 15:848-860.

Hausman CE, Jaeger JF, Rocha OJ. 2010. Impacts of the emerald ash borer (EAB) eradication and tree mortality: potential for a secondary spread of invasive plant species. Biological Invasions. 12:2013-2023.

Heimpel GE, Frelich LE, Landis DA, Hopper KR, Hoelmer KA, Sezen Z, Asplen MK, Wu K. 2010. European buckthorn and Asian soybean aphid as components of an extensive invasional meltdown in North America. Biological Invasions. 12:29132931.

Hellmann JJ, Byers JE, Bierwagen BG, Dukes JS. 2008. Five potential consequences of climate change on invasive species. Conservation Biology. 22:534-543.

Hendrix PF, Bohlen PJ. 2002. Exotic earthworm invasions in North America: ecological and policy implications. BioScience. 52:801-811.

Herms DA, Gandhi KJK, Smith A, Cardina J, Knight KS, Herms CP, Long RP, McCullough DG. 2009. Ecological impacts of emerald ash borer in forests of southeast Michigan. In: McManus KA, Gottschalk KW, editors. Proceedings of the 20th U.S. Department of Agriculture interagency research forum on invasive species 2009. USDA Forest Service, Northern Research Station, Gen. Tech. Rep. NRS-P-51. 36-37 p. 
Hobbs RJ, Huenneke LF. 1992. Disturbance, diversity, and invasion: implications for conservation. Conservation Biology. 6:324-337.

Holdsworth AR, Frelich LE, Reich PB. 2007a. Effects of earthworm invasion on plant species richness in northern hardwood forests. Conservation Biology. 21:997-1008.

Holmes TP, Aukema JE, Von Holle B, Liebhold A, Sills E. 2009. Economic impacts of invasive species in forests: Past, present, and future. Annals of the New York Academy of Sciences Year in Ecology and Conservation Biology 2009. 1162: 18-38.

Hulme PE. 2009. Trade, transport, and trouble: managing invasive species pathways in an era of globalization. Journal of Applied Ecology. 46:10-18.

Hutchinson RE. 1957. Concluding remarks. Cold Spring Harbor Symposia on Quantitative Biology. 22:415-427.

Jones CG, Lawton JH, Shachak M. 1994. Organisms as ecosystem engineers. Oikos. 689:373-386.

Kalisz PJ, Wood HB. 1995. Native and exotic earthworms in wildland ecosystems. In: Hendrix, PF, editor. Earthworm ecology and biogeography in North America. Boca Raton, FL: Lewis Publishers. p. 117-126.

Kashian DM, Witter JA. 2011. Assessing the potential for ash canopy tree replacement via current regeneration following emerald ash borer-caused mortality on southeastern Michigan landscapes. Forest Ecology and Management. 261:480-488.

Knight TM, Dunn JL, Smith LA, Davis J, Kalisz S. 2009. Deer facilitate invasive plant success in a Pennsylvania forest understory. Natural Areas Journal. 29:110-116.

Kolar CS, Lodge DM. 2001. Progress in invasion biology: predicting invaders. Trends in Ecology and Evolution. 16:199-204.

Kovacs KF, Haight RG, McCullough DG, Mercader RJ, Siegert NW, Liebhold AM. 2010. Cost of potential emerald ash borer damage in U.S. communities, 2009-2019. Ecological Economics. 69:569-578.

Lawrence B, Fisk MC, Fahey TJ, Suarez ER. 2003. Influence of nonnative earthworms in mycorrhizal colonization of sugar maple (Acer saccharum). New Phytologist. 157:145-153.

Lee KE. 1985. Earthworms, their ecology and relationships with soils and land use. New York: Academic Press. 
Lockwood JL, Hoopes MF, Marchetti MP. 2007. Invasion ecology. Malden, MA: Blackwell Sci. 304 p.

Lodge DM, Shrader-Frechette K. 2003. Nonindigenous species: ecological explanation, environmental ethics, and public policy. Conservation Biology. 17:31-37.

Loss SR, Blair RB. 2011. Reduced density and nest survival of ground-nesting songbirds relative to earthworm invasions in northern hardwood forests. Conservation Biology. 25:983-992.

MacFarlane DW, Meyer SP. 2005. Characteristics and distribution of potential ash tree hosts for emerald ash borer. Forest Ecology and Management. 213:15-24.

Maerz JC, Nuzzo VA, Blossey B. 2009. Declines in woodland salamander abundance associated with non-native earthworm and plant invasions. Conservation Biology. 23:975-981.

McLean MA, Migge-Kleian S, Parkinson D. 2006. Earthworm invasions of ecosystems devoid of earthworms: effects on soil microbes. Biological Invasions. 8:1257-1273.

McCullough DG, Katovich SA. 2004. Emerald ash borer. USDA Forest Service, Northeastern Area, State and Private Forestry, Pest Alert NA-PR-02-04.

Migge-Kleian S, McLean MA, Maerz JC, Heneghan L. 2006. The influence of invasive earthworms in indigenous fauna in ecosystems previously uninhabited by earthworms. Biological Invasions. 8:1275-1285.

Moser WK, Branard EL, Billings RF, Crocker SJ, Dix ME, Gray AN, Ice GG, Kim MS, Reid R, Rodman SU, McWilliams WH. 2009. Impacts of nonnative invasive species of US forests and recommendations for policy and management. Journal of Forestry. 107:320-327.

Muirhead JR, Leung B, van Overdijk C, Kelly DW, Nandakumar K, Marchant KR, MacIsaac HJ. 2006. Modelling local and long-distance dispersal of invasive emerald ash borer Agrilus planipennis (Coleoptera) in North America. Diversity and Distributions. 12:71-79.

National Invasive Species Council (NISC). 2008. 2008-2012 National Invasive Species Management Plan. 35 p.

Peterson AT. 2003. Predicting the geography of species' invasions via ecological niche modeling. The Quarterly Review of Biology. 78:419-433. 
Peterson AT, Vieglais DA. 2001. Predicting species invasions using ecological niche modeling: new approaches from bioinformatics attack a pressing problem.

BioScience. 51:363-371.

Pimental D, Zuniga R, Morrison D. 2005. Update on the environmental and economic costs associated with alien-invasive species in the United States. Ecological Economics. 52:273-288.

Poland TM. 2007. Twenty million ash trees later: current status of emerald ash borer in Michigan. Newsletter of the Michigan Entomological Society. 52:10-14.

Poland TM, McCullough DG. 2006. Emerald ash borer: invasion of the urban forest and the threat to North America's ash resource. Journal of Forestry. 104:118-124.

Poland TM, McCullough DG. 2010. SLAM: A multi-agency pilot project to SL.ow A.sh M.ortality caused by emerald ash borer in outlier sites. Newsletter of the Michigan Entomological Society. 55:4-8.

Prasad AM, Iverson LR, Peters MP, Bossenbroek JM, Matthews SN, Sydnor TD, Schwartz MW. 2010. Modeling the invasive emerald ash borer risk of spread using a spatially explicit cellular model. Landscape Ecology. 25:353-369.

Rabaglia R, Duerr D, Acciavatti R, Ragenovich I. 2008. Early detection and rapid response for non-native bark and ambrosia beetles. USDA Forest Service, Forest Health Protection. (http://fs.fed.us/foresthealth/publications/EDRRProjectReport.pdf).

Rebek EJ, Herms DA, Smitley DR. 2008. Interspecific variation in resistance to emerald ash borer (Coleoptera: Buprestidae) among North American and Asian ash (Fraxinus spp.). Environmental Entomology. 37:242-246.

Richardson DM, Pyšek P. 2008. Fifty years of invasion ecology - the legacy of Charles Elton. Diversity and Distributions. 14:161-168.

Sakai AK, Allendorf FW, Holt JS, Lodge DM, Molofsky J, With KA, Baughman S, Cabin RJ, Cohen JE, Ellstrand NC, McCauley DE, O’Neil P, Parker IM, Thompson JN, Weller SG. 2001. The population biology of invasive species. Annual Review of Ecology, Evolution, and Systematics. 32:305-332.

Scheu S. 2003. Effects of earthworms on plant growth: patterns and perspectives. Pedobiologia. 47:846-856.

Scheu S, Parkinson D. 1994. Effects of earthworms on nutrient dynamics, carbon turnover and microorganisms in soils from cold temperate forests of the Canadian Rocky Mountains - laboratory studies. Applied Soil Ecology. 1:113-125. 
Shartell LM, Nagel LM, Storer AJ. 2011. Multi-criteria risk model for garlic mustard (Alliaria petiolata) in Michigan's Upper Peninsula. American Midland Naturalist. 165:116-127.

Shea K, Chesson P. 2002. Community ecology theory as a framework for biological invasions. Trends in Ecology and Evolution. 17:170-176.

Simberloff D. 2006. Invasional meltdown 6 years later: important phenomenon, unfortunate metaphor, or both? Ecology Letters. 9:912-919.

Simberloff D, Von Holle B. 1999. Positive interactions of nonindigenous species: invasional meltdown? Biological Invasions. 1:21-32.

Store R, Kangas J. 2001. Integrating spatial multi-criteria evaluation and expert knowledge for GIS-based habitat suitability modeling. Landscape and Urban Planning. 55:79-93.

Sutherland S. 2004. What makes a weed a weed: life history traits of native and exotic plants in the USA. Population Ecology. 141:24-39.

Taylor RAJ, Poland TM, Bauer LS, Windell KN, Kautz JL. 2007. Emerald ash borer flight estimates revised. In: Mastro V, Reardon R, Parra G, compilers. Proceedings of the emerald ash borer and Asian longhorned beetle research and technology development meeting. USDA Forest Service FHTET-2007-04.

Webster CR, Jenkins MA, Jose S. 2006. Woody invaders and the challenges they pose to forest ecosystems in the eastern United States. Journal of Forestry. 104:366-374.

Whitney KD, Gabler CA. 2008. Rapid evolution in introduced species, 'invasive traits' and recipient communities: challenges for predicting invasive potential. Diversity and Distributions. 14:569-580.

Williamson M. 1996. Biological invasions. London, UK: Chapman \& Hall. 


\section{Chapter 2. Detection of Northern Michigan Emerald Ash Borer Satellite Invasion Sites through Predictive Spatial Modeling}

\subsection{Introduction}

Emerald ash borer (Agrilus planipennis Fairmaire [Coleoptera: Buprestidae], EAB) is an exotic wood boring beetle that has invaded North America, in particular the Midwest. The first encounter of EAB was in 2002 and, since that time, it has become a major pest of ash trees (Fraxinus spp.) throughout the region. It is suspected that EAB was transported from Asia in wood packaging material such as crates (Cappaert et al. 2005). Presently, the initial invasion site and core of the infested area is in southeast Michigan, though it has since spread to 14 surrounding states and two Canadian provinces (EAB Info 2011). Human movement of firewood, nursery stock, and other wood materials has been the driving force of long distance spread (Cappaert et al. 2005).

At the time of identification in Michigan in 2002, EAB had already infested an estimated 5-7 million ash trees, prompting continued monitoring of its spread and the development of trapping and survey techniques (Poland and McCullough 2006). Despite some efforts to locate surviving trees in highly infested areas, future efforts will likely focus on monitoring and management of satellite populations (Mercader et al. 2009). Liebhold and Tobin (2008) recommended that management efforts for established invasive insects include limiting long distance dispersal and suppression of satellite populations formed from long distance dispersal. Where EAB is now found in Michigan and elsewhere in the Midwest, quarantines and restrictions on the movement of firewood have been used to limit the spread of EAB (Cappaert et al. 2005). However, satellite populations continue to be found in the Upper Peninsula (UP) of Michigan and the surrounding states and provinces, some of which have been established for many years prior to discovery.

Unfortunately, the lack of an efficient and effective method for detecting lowdensity populations of EAB has limited the application of suppression efforts for satellite populations. Pheromone-baited traps have not been useful since the insect is not thought to use pheromones, and newly infested trees show few to no symptoms, so are rarely identified by visual surveys (McCullough et al. 2009). Most satellite invasions are not identified until the insect is well established in the area and canopy dieback and tree mortality is evident (Kovacs et al. 2010). Despite the difficulty of their detection, containment of EAB satellite invasion sites could still play a vital role in slowing further spread of EAB. The Slow Ash Mortality (SLAM) approach has been used to contain the spread of EAB by combining a variety of site-specific management options (Poland and McCullough 2010). The methods can consist of cutting EAB infested ash trees, cutting all ash trees surrounding an infestation, creating a sink in the infested area, and monitoring the site with artificial traps that attract EAB using color and chemical attractants (Poland and McCullough 2010). An economic assessment of the cost of treating and replacing ash trees found justification for investing in efforts to slow the 
spread of EAB (Kovacs et al. 2010), but this can only be applied if satellite invasions are located.

A number of efforts have been made to use spatial data to predict areas of potential invasion for EAB (Minnesota Department of Agriculture 2006; Muirhead et al. 2006; Ayersman et al. 2009). The Minnesota Department of Agriculture (2006) developed an introduction risk map for emerald ash borer based on the locations of campgrounds, seasonal homes, urban areas, sawmills, firewood dealers, nurseries, and roads. These predictors were used because it is generally thought the distribution of EAB is highly correlated to human activity. Likewise, Ayersman et al. (2009) created a risk map covering Ohio, Pennsylvania, New Jersey, Delaware, Maryland, and West Virginia for EAB based on the locations of campgrounds, nurseries, and sawmills. These models were created in uninvaded areas and have not yet had the opportunity for peer review, testing or validation. Muirhead et al. (2006) used a different approach, combining factors of anthropogenic spread with diffusion and gravity models that increased the risk depending on distance from invaded sites. This was done for southern Michigan, Indiana, and Ohio, using the core infestation in southeast Michigan as the source for spread (Muirhead et al. 2006). Satellite invasion sites are not likely to influence the locations of other satellite sites so this type of approach may not be appropriate farther from the core infestation. Rather, a predictive model developed based on factors affecting known satellite invasion sites would be useful for the detection of existing and future satellite sites.

The discovery of isolated, well-established populations of emerald ash borer in the UP of Michigan, an area relatively isolated from the initial invasion site, prompted questions regarding the likelihood of other existing populations and whether landscape characteristics could be used to predict the locations of other EAB satellite invasion sites. The objectives of this study were to 1) use known EAB satellite locations to create a multicriteria risk model for EAB in northern Michigan and 2) quantify the efficiency of this predictive model by conducting a ground survey across the UP.

\subsection{Study Area}

The main area of interest was the UP of Michigan. The area selected for modeling included the 15 counties of the UP and the eight northern most counties of the Lower Peninsula (LP). Despite its larger land area, northern Michigan has a significantly smaller human population density than southern Michigan. Consequently, because most colonization of EAB is correlated to human activity, we assumed that EAB presence data from the northern eight counties of the LP represented satellite invasions caused by long distance dispersal events of individual EAB comparable to those in the UP. The invasion sites in the northern LP occur in similar rural landscapes as the UP, as opposed to the core infestation in more urbanized southeast Michigan. 


\subsection{Model Development}

A multicriteria risk model was created within ArcGIS 9.3 using ModelBuilder (ESRI 2008) and later updated for use in ArcGIS 10 (ESRI 2011). Since EAB has not yet reached its full invasion potential in northern Michigan, only presence data is available, and for this reason statistical analysis alone was not appropriate. Store and Kangas (2001) acknowledged that when species occurrence data is limited, as in the case of newly invading species, "expert knowledge" could be used in place of traditional statistical evaluation to create spatial models. Here an effort was made to combine statistical analysis and "expert knowledge" of introduction and occurrence of EAB for development of the model. Parameters selected for inclusion in the model were distance to roads, land cover type, and campground proximity (Table 2.1). Parameters were limited to those with spatial GIS data. The known locations of EAB infestations were obtained from the Animal and Plant Health Inspection Service (APHIS). Those points in northern Michigan were extracted, and a minimum distance of $10 \mathrm{~m}$ between points was used to avoid redundancy in the dataset. A total of 163 known EAB presence points were found within the 23 counties of interest (Figure 2.1). The sample was split randomly into two subsamples $(\mathrm{N}=82$ and $\mathrm{N}=81)$ stratifying by UP and LP so that points from both were represented in each subsample. The first subsample (development subsample) was used to assess the importance of suspected factors affecting EAB introduction and occurrence and develop the risk model. The second subsample (validation subsample) was used to validate the risk model predictions.

The importance of roads in the long distance spread of invasive species has been well documented (Forman and Alexander 1998, Ruiz and Carlton 2003). In the case of $\mathrm{EAB}$, roads provide a means for anthropogenic dispersal through the movement of firewood and other wood products, as well as incidental movement of insects on such things as vehicle windshields and radiators. There is also some evidence that EAB preferentially selects ash that is open-grown or on the edge of forested areas, like those along road corridors and right-of-ways (Francese et al. 2008). Michigan Geographic Framework data, available from the Michigan Geographic Data Library (State of Michigan 2007), was used as the spatial data for roads. All roads in this dataset were included, and the distance from each pixel to a road was determined using the Euclidean distance tool in ArcGIS.

Emerald ash borer distribution is dependent upon the presence of ash trees. Ash is found in a variety of forest ecosystems, from uplands to wetlands, typically as a minor component (MacFarlane and Meyer 2005). Ash is also a popular, widely-planted street tree in urban settings (Poland and McCullough 2006). We assessed a number of land cover datasets for use in the model, including two specific to ash. Unfortunately, due to a patchy distribution, ash is difficult to map, and in more general datasets is a component of a number of land cover classes. National Land Cover Data 2006 (NLCD, USGS 2011) was chosen to describe land cover type for the model. The dataset is available for the entire United States at a $30 \mathrm{~m}$ spatial resolution. 
The movement of firewood has played a major role in the dispersal of EAB (Poland and McCullough 2006). Campgrounds are considered high risk areas due to the amount of firewood brought in and the distance that visitors travel with firewood. A comprehensive GIS data layer for Michigan campgrounds was not available; however point GIS data for campgrounds was created for this project which included Michigan Department of Natural Resources (MDNR) State Forest campgrounds, MDNR State Parks, and U.S. Forest Service National Forest campgrounds. Private campgrounds were not included. Campground points were buffered by $500 \mathrm{~m}$. Proximity to campgrounds was then calculated using the Euclidean distance tool.

The above three parameters were processed and combined using the ArcGIS weighted overlay tool to create a multicriteria risk model (Figure 2.2). Using this tool, a weight (out of 100) was assigned to each parameter. The output was a raster grid with a spatial resolution of $30 \mathrm{~m}$. The weighted overlay assigned each pixel a risk from one to five. Model accuracy during development was assessed by comparing the development subsample of EAB presence points to the predicted results, and was calculated as the percent of data points assigned a high risk prediction value (four or five). The parameter weights were subjectively selected and adjusted to obtain greatest accuracy while also keeping the total area at high risk low. This was done to avoid over-fitting the model.

\subsection{Ground Survey}

Using the predictions from the model, a ground survey was developed to further test the model efficiency. Random points across the UP were visited during 2009, focusing on high risk areas as determined by the predictive model, so that $80 \%$ of points fell in areas assigned a risk of four or five. Any areas of declining ash encountered during travel to the survey points were also assessed as additional points. Point locations were restricted to within $30 \mathrm{~m}$ of roads to maximize the number of points that could be sampled over one field season and give as much geographic breadth to sampling as possible.

Field crews navigated to points using a handheld geographic positioning system (GPS) unit. GPS coordinates were provided and recorded using a standard coordinate system and projection (UTM NAD 83). Those points that fell directly on a road or other non-forested area were relocated to the nearest forested site. Actual GPS coordinates recorded in the field were averaged over one to two minutes per point to reduce spatial error. Basal area by species, for all tree species present, was determined using a 10-factor prism at plot center and at endpoints of transects running one chain $(20.1 \mathrm{~m})$ in each cardinal direction from plot center. Additionally, all ash trees within a 1/10 acre $(0.04$ ha) plot around the central point were counted and assessed. If the number of ash trees within the plot exceeded ten, the plot size was reduced to $1 / 20$ acre $(0.02$ ha) or $1 / 30$ acre $(0.01 \mathrm{ha})$ accordingly. For each ash tree $(\geq 5 \mathrm{~cm}$ diameter breast height, $\mathrm{dbh})$, species, dbh, percent crown dieback, and vigor rating (Millers et al. 1991) were recorded. Any signs and symptoms of EAB including epicormic sprouts, splits in the bark, D-shaped 
exit holes, serpentine galleries, woodpecker damage, and/or presence of larva, pupae or adults were noted.

\subsection{Results}

In the comparison of EAB presence points from the development subsample to the distance to nearest road, we found that $77 \%$ of known EAB presence points were within $100 \mathrm{~m}$ of a road. The remaining points were within $400 \mathrm{~m}$. Thus risks from five (high risk) to one (low risk) were assigned to the following five distance categories: 0$100 \mathrm{~m}, 100-400 \mathrm{~m}, 400-1,000 \mathrm{~m}, 1,000-2,000 \mathrm{~m}$, and $>2,000 \mathrm{~m}$ (Figure 2.3a). In the development subsample, EAB was present in 13 of the 15 NLCD classifications. It was most commonly associated with the following cover types: woody wetlands $(22 \%)$, developed open space (20\%), developed low intensity (15\%), deciduous forest $(10 \%)$, and mixed forest (10\%). Together these five cover types contained $76 \%$ of EAB presence points. These results were consistent with cover types expected to contain ash. Risks were assigned to cover types based on the number of EAB presence points in each class (Table 2.2, Figure 2.3b).

Across northern Michigan, $>1 \%$ of the land was within $500 \mathrm{~m}$ of a known campground, and approximately $5 \%$ of the land was within $2000 \mathrm{~m}$ of a campground. Of the EAB presence points from the development subsample, $16 \%$ were in the $>1 \%$ of northern Michigan that was within $500 \mathrm{~m}$ of a campground, and $45 \%$ of the EAB presence points fell within $2000 \mathrm{~m}$ of a campground. Campground risk was assigned to six distance categories, 0-500 m, 500-2,000 m, 2,000-5,000 m, 5,000-7,500 m, 7,500$10,000 \mathrm{~m}$, and $>10,000 \mathrm{~m}$ (Figure $2.3 \mathrm{c}$ ). Using chi square analysis, the proportion of EAB presence points within each distance category was greater than expected for the 0 $500 \mathrm{~m}$ and 500-2,000 $\mathrm{m}$ classes, indicating that campground proximity was significantly related to $\mathrm{EAB}$ presence $\left(\chi^{2}=326.25, \mathrm{P}<0.001\right)$. Private campgrounds were not represented in the layer due to a lack of spatial data for their locations, yet they may present even greater risk for the introduction of EAB due to a lack of regulation of firewood in these campgrounds as compared to state and federal campgrounds.

The final weights (out of 100) used in the weighted overlay were 40 for distance to roads, 30 for land cover class and 30 for campground proximity. The accuracy was calculated as the percent of EAB presence points accurately predicted to be at high risk (a predicted risk of four or five). Based on our comparison with the model development subsample of EAB presence points, our model had an accuracy of 78\%. Assessment of the model using the validation subsample resulted in an accuracy of $85 \%$. Across the UP and northern LP, $17 \%$ of the area (approximately 9,580 of $56,099 \mathrm{~km}^{2}$ ) was predicted to be at high risk (Figure 2.4). In the UP alone, 15\% of the area (approximately 6,743 of $44,120 \mathrm{~km}^{2}$ ) was at high risk. Two alternative models with varied weights were also assessed (Table 2.3). In the first alternate model greatest weight was assigned to land cover class (40) rather than road proximity. In the second, the weight of campgrounds was reduced (20), and road proximity and land cover class were equal (40 each). 
Assessment of alternative model one resulted in accuracies of $76 \%$ and $81 \%$ for the development and validation subsamples respectively, with $19 \%$ of the area predicted to be at high risk. Alternative model two had the highest accuracies, $85 \%$ and $93 \%$, however predicted $28 \%$ of the area to be at high risk suggesting that the model may be over-predicting risk.

A total of 304 ground survey points across the Upper Peninsula of Michigan were sampled over one field season, however only $22 \%$ of the sites visited had ash present, and thus the potential for EAB presence (Figure 2.5). The majority of survey points $(80 \%)$ had a high risk for EAB (four or five) and the remaining 20\% were at low risk (two or three). Emerald ash borer was not confirmed at any of the sampled sites and no signs of EAB presence were observed. Where present, the ash observed was generally healthy and showed no symptoms or signs of EAB. Declining ash (an average of 10 percent dieback or greater for all trees) was observed at $15 \%$ of the sampling sites with ash present (10 points). Due to the lack of EAB presence during the ground survey points, further analysis of the field data or comparison to the model predictions was not possible.

\subsection{Discussion}

The accuracy of the predictive model in both development and validation was $78 \%$ and $85 \%$ respectively, with $17 \%$ of the UP and northern LP at high risk (four or five) for EAB infestation. A comparable modeling effort was recently completed for EAB in Ohio (Prasad et al. 2010). Similar to our model, Prasad et al. (2010) predicted $62 \%$ of known EAB locations to be within what they classified as high or extreme risk classes, with $14 \%$ of Ohio at these risk levels. Our risk map shows areas of high risk across the extent of northern Michigan. The most obvious areas of risk appear where campgrounds occur in proximity to roads and suitable land cover types. The alternative models presented show similar accuracies. Selection of model weights should be dependent upon which parameters are perceived to contribute most to EAB infestation, and could vary among management areas. Roads were closely related to known EAB sites in our study area, and an increased weight given to this parameter may have increased accuracy of the model predictions. Prasad et al. (2010) gave a considerably greater weight to roads than other factors in their risk model (60 as opposed to 40 in our model). They also provided evidence to support that increased EAB infestations near roads are not merely the result of increased sampling effort along roads (Prasad et al. 2010). Roadsides may be linked to the presence of ash because drainage from roads provides suitable habitat for ash, which may not continue into the interior forest (Storer, Michigan Technological University, personal observation). Increasing the weight of land cover, such as in alternative model one, or decreasing the weight of campgrounds, such as in alternative model two, did not produce improved results for accuracy or percent area at risk. Further increasing the weight of roads may be another potential model to focus monitoring and ground surveys. However, although roads play a significant role in satellite infestations, road proximity may not be as influential in the further spread of the EAB infestation from satellite sites. 
In alternative model two, decreasing the weight of campgrounds while increasing roads and land cover improved both the development and validation accuracies. Despite improved accuracy, the percent of the area at risk also increased from $17 \%$ in the original model to $28 \%$. This substantial increase may indicate that the accuracy observed in alternative model two is due to over-prediction rather than improved precision. Because true absence data were lacking, the rate of false positives was unable to be determined, and this observation could not be verified further. Accordingly alternative model two was not considered an improvement over the original model. However, in future modeling efforts it may be appropriate to decrease the weight of campgrounds further, or remove this parameter completely. Campgrounds have been the site of a number of initial discoveries of EAB in the UP, and are thought to be destinations of firewood for long-distance dispersal events. Their importance as introduction points, however, may have been lessened as a result of firewood movement laws enforced within parks and campgrounds and between infested and uninfested counties and states. Furthermore, the influence of campgrounds on spread from established EAB sites is likely minimal.

Despite high accuracy in the multicriteria risk model, no EAB or signs of EAB were found during our ground survey. This lack of detection could be due, in part, to the difficulty in locating ash, as only $22 \%$ of survey points had ash present. Comparison of the ground survey points to the predicted risks found that $83 \%$ of points with ash present were in high risk areas, however due to a biased sampling effort this was not statistically significant $\left(\chi^{2}=0.91, P=0.63\right)$. Two additional spatial ash datasets were assessed for incorporation into this model, though neither proved to accurately predict the distribution of ash observed during the ground survey or in related projects (Frederick 2008). Ash tends to be only a minor component of many wetland and upland forest types in northern Michigan, and this trait seems to be a limiting factor in many spatial modeling efforts. Although the land cover data included in the model was useful, a comprehensive ash layer would decrease the need for larger sampling effort while increasing the accuracy of the predictions. The low percentage of sites with ash suggests that the model likely overpredicts the area at high risk for EAB invasion. Accounting for the limited occurrence of ash at sampling sites (present at $22 \%$ of sites), it may be more realistic to assume that only $3 \%\left(1,456 \mathrm{~km}^{2}\right)$ of the UP, rather than $15 \%$, is at high risk. This contrasts markedly with other regions of Michigan and the Midwest where ash seems to be more dominant, and thus the effects of EAB more severe.

Another possible reason for the lack of EAB detection during the ground survey could be the rarity of undiscovered EAB populations in the UP. It is not likely that EAB has reached its full potential in the UP, and thus satellite invasion sites are rare and randomly located within high risk areas. An increased sampling effort or incorporation of ancillary information could be used to increase the precision of the ground survey (Dixon et al. 2005). Ultimately, the accuracy of any spatial model is dependent on the quality of the spatial data and source data used in the assignment of risks (Store and Kangas 2001). Inclusion of other data, such as parameters limiting occurrence and those for which spatial data need to be developed, would also improve success of the predictions and ground survey. Additional parameters, including road type, road density, 
urban areas, and distance to and age of nearest EAB infestation, were assessed for our model, but these were found to be unimportant or were correlated with other included parameters.

The detection of satellite invasion sites of emerald ash borer is an important step in the future management of EAB. Slowing the spread of EAB has proven to be a feasible and cost-effective control strategy when EAB is at low densities, as it typically is at these sites (McCullough et al. 2009; Kovacs et al. 2010). Additionally, biological control species are expected to become available for release at satellite sites, and may prove successful at reducing EAB populations and thereby spread (Bauer et al. 2009). Those sites, from the ground survey, with declining ash may be important sites to monitor in the future for EAB invasion. The accuracy of the model to predict known locations of EAB suggests that it may be of use in guiding future surveys and monitoring efforts, such as the placement of widely used "purple traps" to attract EAB. The model predictions could also be used to locate infested trees when detection is made on traps and aid in the determination of infestation extent. Future use of this spatial model should involve refinement of the model and further verification before incorporation into survey and monitoring efforts.

\subsection{Conclusions}

As the focus of management for emerald ash borer shifts more towards satellite invasions and slowing spread from these sites (Mercader et al. 2009), methods for detecting satellite invasion sites will become increasingly important. The use of landscape characteristics to predict high risk areas for EAB has the potential to enhance survey methods and focus efforts. The multicriteria model created here should prove useful for monitoring, especially if improved ash distribution data can be incorporated. The model predictions correlate well with presently known satellite sites in the UP and northern LP. Continued assessment of the model as additional satellite EAB sites are discovered will improve the predictions and its use. Hopefully, these efforts will lead to improved monitoring and management of $\mathrm{EAB}$, limiting long distance dispersal and suppressing spread from satellite populations.

\section{Literature Cited}

Ayersman W, Strager MP, Strager JM. 2009. Modeling emerald ash borer establishment and spread using GIS. Proceedings of the 2009 ESRI Users Conference.

Bauer LS, Liu H, Miller DL. 2009. Emerald ash borer biological control: rearing, releasing, establishment, and efficiency of parasitoids. Proceedings of the 2009 USDA Research Forum on Invasive Species. January 13-16, Annapolis, MD. 
Cappaert D, McCullough DG, Poland TM, Siegert NW. 2005. Emerald ash borer in North America: a research and regulatory challenge. American Entomologist. 51:152165.

Dixon PM, Ellison AM, Gotelli NJ. 2005. Improving the precision of estimates of the frequency of rare events. Ecology. 86:1114-1123.

Emerald Ash Borer (EAB) Info. 2011. http://emeraldashborer.info. Accessed 1 April 2011.

Environmental Systems Research Institute (ESRI). 2008. ArcGIS Desktop 9.3. Redlands, CA.

Environmental Systems Research Institute (ESRI). 2011. ArcGIS Desktop: Release 10. Redlands, CA.

Forman RTT, Alexander LE. 1998. Roads and their major ecological effects. Annual Review of Ecological Systems. 29:207-231.

Francese JA, Oliver JB, Fraser I, Lance DR, Youssef N, Sawyer AJ, Mastro VC. 2008. Influence of trap placement and design on capture of the emerald ash borer (Coleoptera: Buprestidae). Journal of Economic Entomology. 101:1831-1837.

Frederick J. 2008. Ash resources threatened by the emerald ash borer (Agrilus planipennis Fairmaire) in recreational areas throughout Michigan. MS Thesis, Michigan Technological University, Houghton, MI.

Kovacs KF, Haight RG, McCullough DG, Mercader RJ, Siegert NW, Liebhold AM. 2010. Cost of potential emerald ash borer damage in U.S. communities, 2009-2019. Ecological Economics. 69:569-578.

Liebhold AM, Tobin PC. 2008. Population ecology of insect invasions and their management. Annual Review of Entomology. 53:387-408.

MacFarlane DW, Meyer SP. 2005. Characteristics and distribution of potential ash tree hosts for emerald ash borer. Forest Ecology and Management. 213:15-24.

McCullough DG, Poland TM, Cappaert D. 2009. Attraction of the emerald ash borer to ash trees stressed by girdling, herbicide treatment, or wounding. Canadian Journal of Forest Research. 39:1331-1345.

Mercader RJ, Siegert NW, Liebhold AM, McCullough DG. 2009. Dispersal of the emerald ash borer, Agrilus planipennis, in newly-colonized sites. Agricultural and Forest Entomology. 11:421-424. 
Millers I, Lachance D, Burkman WG, Allen DC. 1991. North American sugar maple decline project: organization and field methods. US Department of Agriculture Forest Service, Northeastern Forest Experiment Station. Gen. Tech. Rep. NE-154.

Minnesota Department of Agriculture. 2006. Emerald ash borer introduction risk model for Minnesota. MDA Plant Protection Division, Invasive Species Exclusion Unit. 11 p.

Muirhead JR, Leung B, van Overdijk C, Kelly DW, Nandakumar K, Marchant KR, MacIsaac HJ. 2006. Modeling local and long-distance dispersal of invasive emerald ash borer Agrilus planipennis (Coleoptera) in North America. Diversity and Distributions. 12:71-79.

Poland TM, McCullough DG. 2006. Emerald ash borer: invasion of the urban forest and the threat to North America's ash resource. Journal of Forestry. 104: 118-124.

Poland TM, McCullough DG. 2010. SLAM: A multi-agency pilot project to SL.ow A.sh M.ortality caused by emerald ash borer in outlier sites. Newsletter of the Michigan Entomological Society. 55:4-8.

Prasad AM, Iverson LR, Peters MP, Bossenbroek JM, Matthews SN, Sydnor TD, Schwartz MW. 2010. Modeling the invasive emerald ash borer risk of spread using a spatially explicit cellular model. Landscape Ecology. 25:353-369.

Ruiz GM, Carlton JT (Editors). 2003. Invasive species: vectors and management strategies. Island Press, Washington, D.C.

State of Michigan. 2007. Michigan Geographic Data Library (http://mcgi.state.mi.us/mgdl/). Center for Geographic Information, Department of Information Technology.

Store R, Kangas J. 2001. Integrating spatial multi-criteria evaluation and expert knowledge for GIS-based habitat suitability modeling. Landscape and Urban Planning. 55:79-93.

United States Geological Survey (USGS). 2011. National Land Cover Database 2006 (http://www.mrlc.gov/nlcd2006_update). 


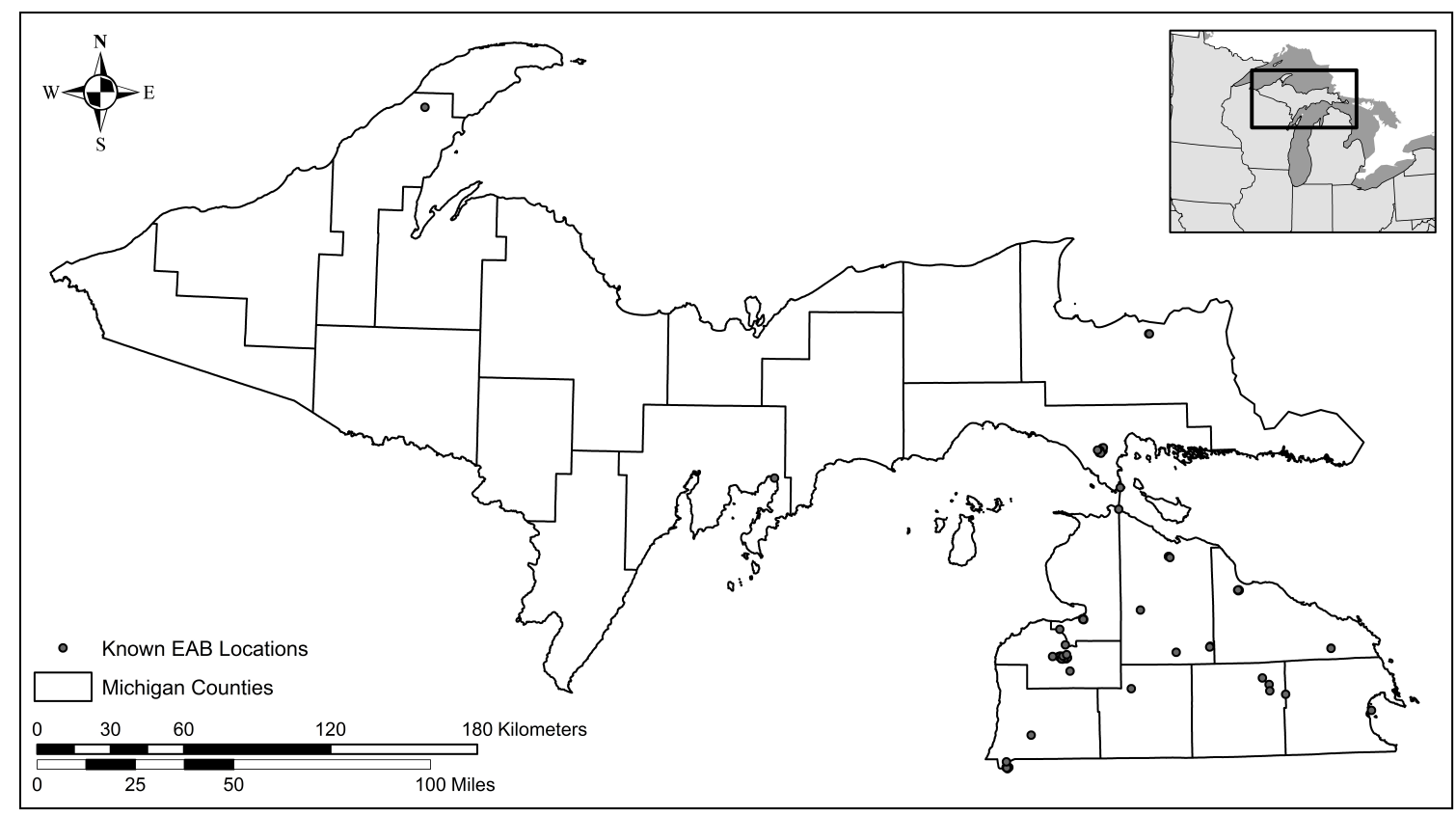

Figure 2.1 The locations of known emerald ash borer (EAB) satellite invasion sites used in the development and validation of the multicriteria risk model predicting invasion risk for emerald ash borer across northern Michigan. 


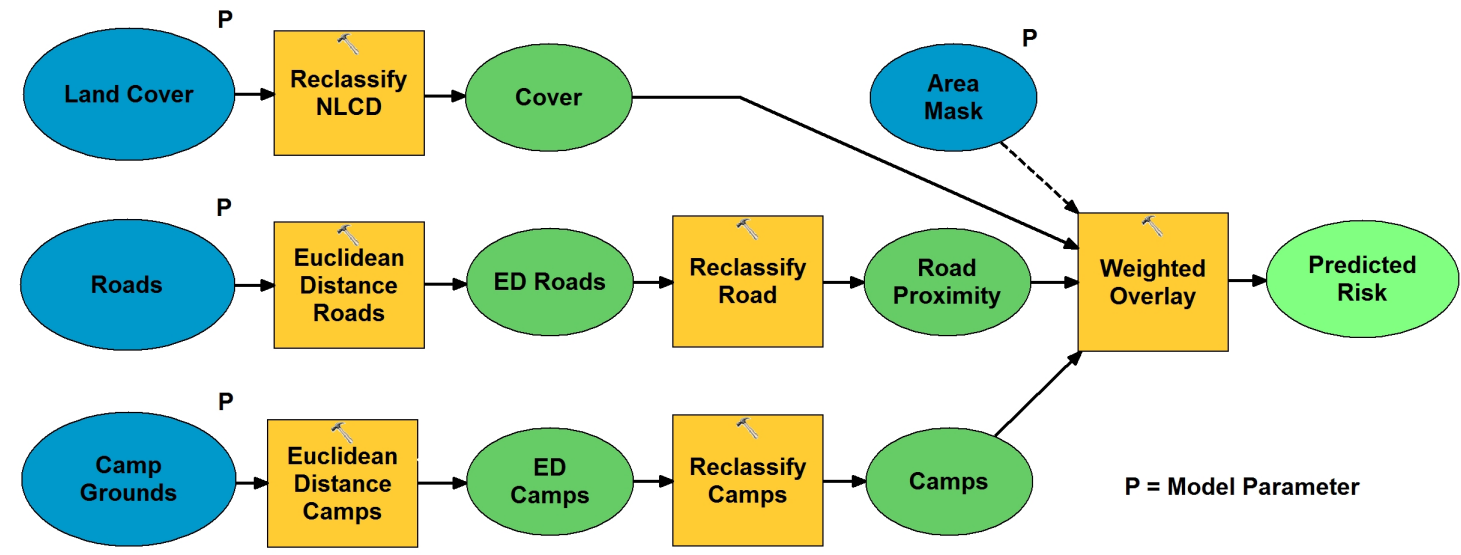

Figure 2.2 Design and layout of the multicriteria risk model predicting invasion risk for emerald ash borer across northern Michigan. The model was produced using ArcGIS ModelBuilder (ESRI 2011). 


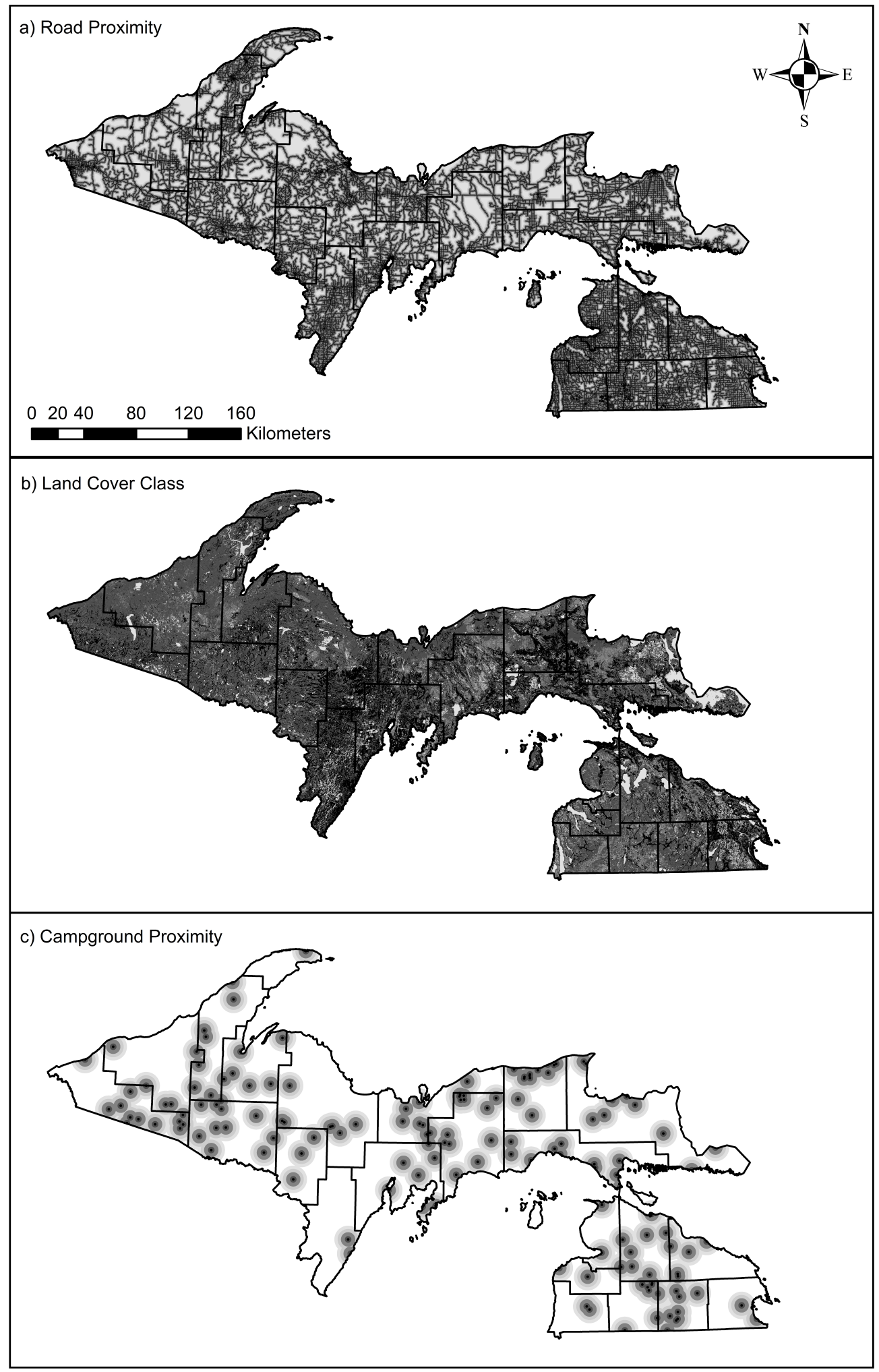

Figure 2.3 Risks assigned to the model parameters a) road proximity, b) land cover class, and c) campground proximity used in the multicriteria risk model to predict emerald ash borer invasion risk across northern Michigan. Darker color indicates higher risk. 


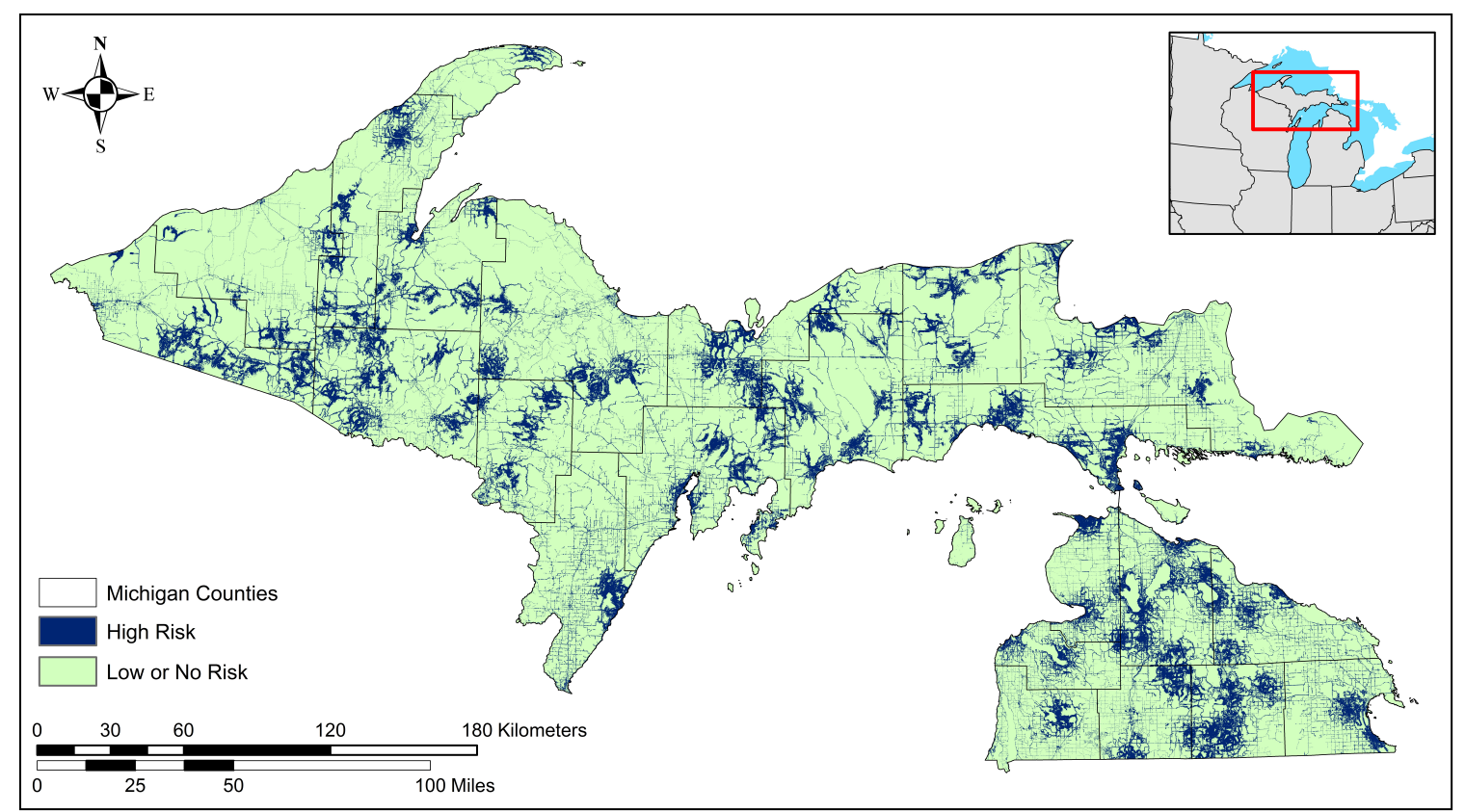

Figure 2.4 Predicted risk of early-stage emerald ash borer invasion across the Upper Peninsula and northern portion of the Lower Peninsula of Michigan. Areas of dark blue indicate high risk. 


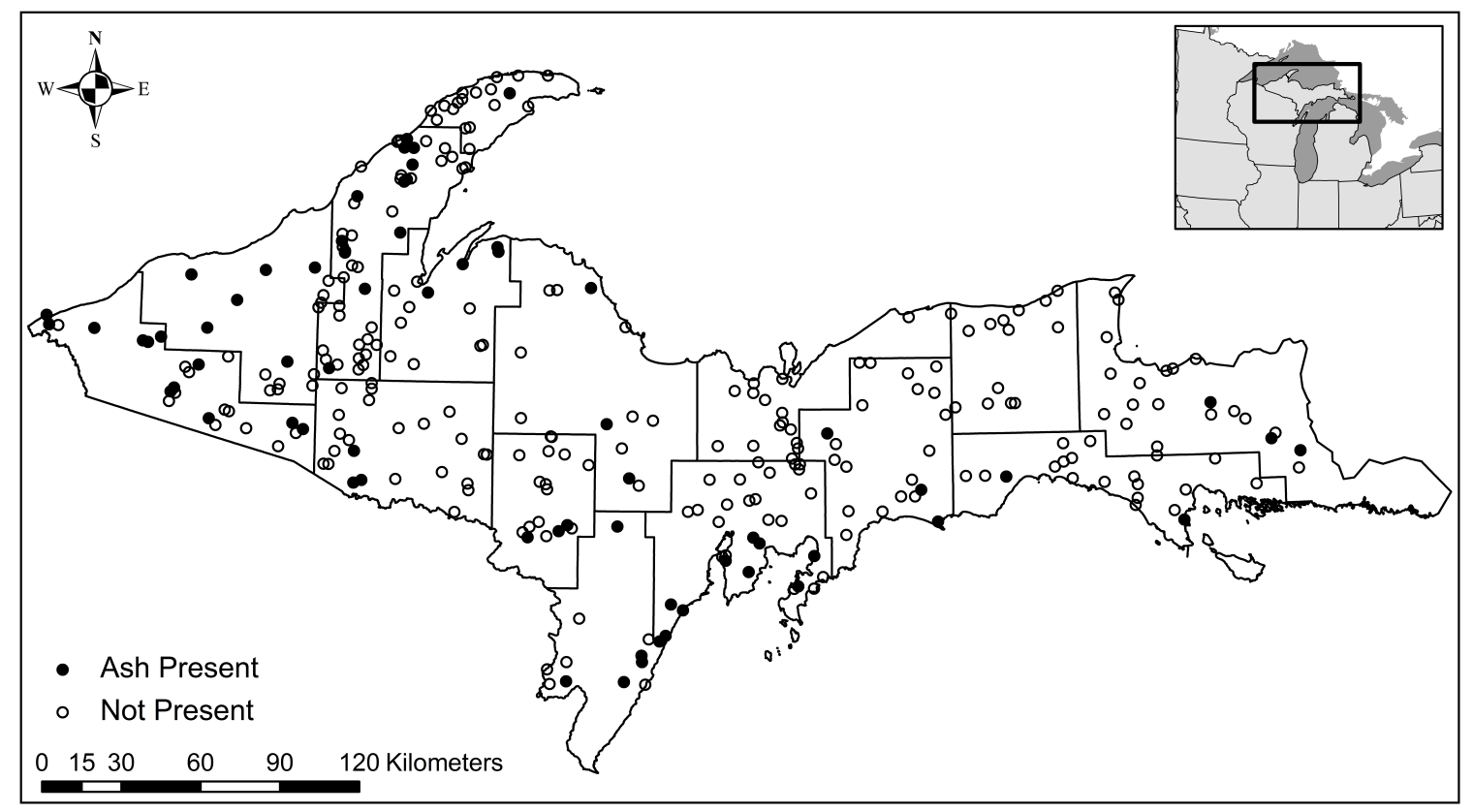

Figure 2.5 Emerald ash borer ground survey locations, indicating the presence of ash. Ash was found at only $22 \%$ of the sample points visited. 
Table 2.1

Description of parameters used in the multicriteria risk model developed to predict satellite invasion sites of emerald ash borer across northern Michigan.

\begin{tabular}{|c|c|c|}
\hline Parameter & Descriptor & Data Source \\
\hline Roads & Distance To & $\begin{array}{l}\text { Michigan Geographic Framework } \\
\text { (State of Michigan 2007) }\end{array}$ \\
\hline Land Cover & Class & $\begin{array}{l}\text { National Land Cover Data } \\
\text { (USGS 2001) }\end{array}$ \\
\hline Campgrounds & Distance To & $\begin{array}{l}\text { State Forest, State Park, and National Forest } \\
\text { Campgrounds }\end{array}$ \\
\hline
\end{tabular}


Table 2.2

Risk values assigned to National Land Cover Data classes. Assignment is based on the development subsample of emerald ash borer presence points.

\begin{tabular}{lcc}
\hline Cover Class & No. of Points & Assigned Risk \\
\hline Woody Wetlands & 18 & 5 \\
Developed, Open Space & 16 & 5 \\
Developed, Low Intensity & 12 & 5 \\
Deciduous Forest & 8 & 4 \\
Mixed Forest & 8 & 4 \\
Grassland/Herbaceous & 6 & 3 \\
Coniferous Forest & 3 & 3 \\
Cultivated Crops & 3 & 3 \\
Emergent Wetlands & 2 & 2 \\
Shrub/Scrub & 2 & 2 \\
Pasture/Hay & 1 & 1 \\
Open Water & 1 & 1 \\
Barren Land & 1 & 1 \\
Developed, Medium Intensity & 0 & 1 \\
Developed, High Intensity & 0 & 1 \\
\hline
\end{tabular}


Table 2.3

Comparison of the original and two alternative multicriteria risk models for predicting risk of emerald ash borer invasion across northern Michigan.

\begin{tabular}{|c|c|c|c|c|c|c|}
\hline & \multicolumn{3}{|c|}{ Parameter Weights } & \multirow{2}{*}{$\begin{array}{c}\text { Development } \\
\text { Accuracy }\end{array}$} & \multirow{2}{*}{$\begin{array}{l}\text { Validation } \\
\text { Accuracy }\end{array}$} & \multirow{2}{*}{$\begin{array}{c}\text { Area at } \\
\text { Risk }\end{array}$} \\
\hline & Roads & Cover & Camps & & & \\
\hline Original Model & 40 & 30 & 30 & $78 \%$ & $85 \%$ & $17 \%$ \\
\hline Alternative One & 30 & 40 & 30 & $76 \%$ & $81 \%$ & $19 \%$ \\
\hline Alternative Two & 40 & 40 & 20 & $85 \%$ & $93 \%$ & $28 \%$ \\
\hline
\end{tabular}




\section{Chapter 3. Patterns and Predictions of Exotic Earthworm Distribution in the Huron Mountains of the Upper Peninsula, Michigan}

\subsection{Introduction}

Exotic European earthworms (family Lumbricidae) are becoming established in previously earthworm free areas of the Great Lakes region. These invaders have the potential to alter forest ecosystem structure and function causing a wide variety of cascading ecological effects (Bohlen et al. 2004a; Frelich et al. 2006). Evidence from agricultural settings suggests that earthworms are beneficial organisms, particularly to plant productivity (Scheu 2003). In forested sites devoid of native earthworms, however, exotic earthworms can significantly alter natural ecosystem features, patterns, and processes, leading to detrimental effects. Earthworms have been shown to decrease the thickness of the forest floor, alter soil through compaction, and increase erosion and nutrient leaching (Scheu and Parkinson 1994; Bohlen et al. 2004a; Hale et al. 2008). They also have the potential to cause declines in native plants, arthropods, salamanders, ground-nesting birds, and small mammal populations (Hale 2008; Maerz et al. 2009; Loss and Blair 2011). As ecosystem engineers (Jones et al. 1994), earthworms can influence the major processes that underlie ecosystems and their health, making invasion by exotic earthworms a critical concern for the persistence and health of forest ecosystems as they are now (Frelich et al. 2006). Understanding the factors controlling earthworm distribution and abundance across the landscape will aid efforts to assess their impact and consequences, and increase the potential for forest management solutions.

The invasion of exotic earthworms from Europe, in particular, tends to be most common due to the high level of transport of people and goods from Europe to North America, and because of the similarities in climate and habitat (Hendrix and Bohlen 2002). Though relatively rare in the Great Lakes region, earthworms from Africa, Asia, and South America have also been introduced into North America with similar detrimental effects in forested ecosystems (Hendrix and Bohlen 2002). Early introductions of exotic earthworms were both accidental, such as in soils used for ballast in ships, and intentional, for use in gardening and agriculture (Barley 1961). Further spread of earthworms, both short and long distances, has been facilitated by human activity. Human-mediated spread of earthworms occurs through the release of fishing bait and in the movement of soil containing earthworms and/or cocoons (Hendrix and Bohlen 2002). Earthworm cocoons, or egg capsules, are able to survive cold temperatures and desiccation over long periods of time (Holmstrup and Westh 1995). Consequently any movement of soil, including unintentional movement on shoes, tire treads, and other equipment, can spread earthworms via cocoons. Thus it is thought that the transport of cocoons on vehicles, including all-terrain vehicles (ATVs), is the leading mechanism for the spread of earthworms into relatively undisturbed forested ecosystems (Cameron et al. 2008). Furthermore, earthworm cocoons can be transported in waterways, facilitating spread along lakes, streams and rivers or in conjunction with 
floodwaters (Schwert and Dance 1979). These mechanisms exert a dynamic influence on the patterns of earthworm introduction across the landscape, and offer opportunities for multiple introductions, which can increase the genetic diversity of earthworm populations and potentially increase invasion success (Cameron et al. 2008). While dispersal can have a substantial effect on introduction, these effects should lessen as the invasion process proceeds to establishment and spread, particularly as earthworms move into areas where modes and mechanisms for dispersal are lacking.

Of the European earthworms identified in the Great Lakes region, Lumbricus terrestris (an anecic species, commonly known as the night crawler) has had a large impact in forested ecosystems (Frelich et al. 2006). This is partly attributable to their larger size (adults range from 80 to $150 \mathrm{~mm}$ ) and thus large consumption of litter and substantial soil alteration. In forests, L. terrestris preferentially feeds on fresh fallen leaf litter and large populations have the potential to consume all of the fresh litter present in one season (Hale et al. 2005). However, additional impacts result from their deep burrowing habit which transports surface organic matter deep into the mineral soil. It is thought that the presence of L. terrestris in combination with other earthworm species, whose feeding and burrowing habits have differing effects, will contribute to increased alteration of the forest floor, soil, and ultimately the flora and fauna of an ecosystem (Hale et al. 2008). For example, the commonly associated species L. rubellus feeds on older organic matter that has accumulated on the soil surface, while L. terrestris feeds on fresh litter, together rapidly decreasing the existing forest floor. Furthermore, other epigeic and endogeic earthworm species tend to be present in sites where Lumbricus spp. are present, further contributing to forest floor and soil alteration (Hale et al. 2005).

While some research on exotic earthworm invasion has focused on population and species dynamics, the majority of research has been concerned with the effect of earthworms on forest characteristics. How forest and landscape characteristics shape earthworm distributions and promote or limit invasion, has rarely been explored in detail. Exotic earthworm presence can be related to many factors including climate, habitat, soil, landscape features, and dispersal mechanisms (Hendrix and Bohlen 2002; Bohlen et al. 2004c). In the Great Lakes, the distribution of earthworms is thought to correspond mainly to source populations, modes of dispersal, and soil and litter properties (Tiunov et al. 2006). While human activity is known to drive short and long distance dispersal, earthworm presence and abundance at later stages of invasion is dependent primarily on site conditions such as litter type, litter availability, and soil properties. These can be considered static effects or factors because they function at all stages of the invasion process, as opposed to dispersal mechanisms which can be considered dynamic. Litter feeding earthworm species prefer materials that are calcium-rich, with a low C:N ratio and low concentration of phenols and tannins (Hendriksen 1990; Reich et al. 2005). For example, species in the genus Lumbricus were found to prefer litter from basswood (Tilia), ash (Fraxinus) and alder (Alnus) to oak (Quercus) and beech (Fagus) (Hendriksen 1990). Earthworm populations can also be limited by unfavorable soil conditions, such as low $\mathrm{pH}$, low moisture, and/or coarse texture (Tiunov et al. 2006). These soil conditions in turn influence forest composition, and thus litter and organic matter 
availability. In addition, landscape characteristics such as aspect and slope are expected to influence forest composition and soils, as well as earthworm dispersal ability, ultimately affecting earthworm invasion.

The objectives of this research were to uncover factors influencing the distribution and abundance of earthworms in northern forested landscapes, using the land of the Huron Mountain Club (hereafter referred to as the Huron Mountains) in the Upper Peninsula of Michigan as a target for detailed modeling efforts. Presence of earthworms at a site can be confirmed without extraction by documentation of signs such as mixed or missing soil layers, castings, and middens created by the deep burrowing L. terrestris. Additionally, the counting of middens is an effective and non-destructive way to estimate the abundance of $L$. terrestris at a given site (Clapperton et al. 2008). It is expected that earthworm signs and midden abundance will be most common in those sites that have a high probability of introduction (assuming that earthworms are at an early stage of invasion), as well as optimal conditions for survival. Those sites closest to roads and water bodies used for fishing should be more likely to have earthworms present due to increased opportunity for dispersal to these sites. Sites with high basal area of preferred tree species that provide favorable litter for consumption can support larger earthworm populations, and therefore are expected to have a greater number of middens present. Earthworm presence and abundance is expected to be related to soil characteristics such as drainage index and soil $\mathrm{pH}$, with earthworms preferring moist (though not saturated) and high $\mathrm{pH}$ sites. It is also expected that earthworms will be influenced by site characteristics including aspect, slope, and elevation, with largest populations occurring in north-facing, low, flat areas because of their tendency to be more accessible for dispersal and generally wetter sites. Thus, it is hypothesized that earthworm signs and middens are positively related to the following characteristics favoring earthworm dispersal and survival: proximity to human activity (distance to roads and waterways), forest structure and composition (using basal area of preferred species), and soil and site conditions (warm, mesic, slightly acidic to calcareous soils on flat sites at low elevation). After determination of the importance of these variables, they were used to create a predictive model identifying high risk areas for earthworm invasion.

\subsection{Study Area}

Earthworm invasion was assessed within the Huron Mountains located in Marquette County in the Upper Peninsula of Michigan (Figure 3.1). The land is a limited access private club used primarily as a remote area for hunting and fishing. According to the 2006 National Land Cover Dataset (NLCD, USGS 2011), the area is mainly forested land, consisting of $27 \%$ evergreen forest, $24 \%$ mixed forest, $19 \%$ deciduous forest, and $12 \%$ woody wetlands. The site contains a series of inland lakes and streams $(12 \%$ of the area) and is bordered by Lake Superior to the north. There is currently very little developed land (3\% of the area), and thus relatively limited human activity beyond a small network of roads and fishing access points. Portions of the land, however, have been farmed in the past. A wide range of soil conditions exist across the area, from 
excessively drained sandy soils to very poorly drained muck and peat (Soil Survey Geographic data, SSURGO, NRCS 2006), and the variable topography provides a range of elevations, slopes, and aspects.

\subsection{Methods}

A preliminary GIS-based spatial risk model for earthworm invasion was developed based on potential factors affecting earthworm dispersal and habitat suitability as indicated in recent literature, and limited by data availability (Figure 3.2). The intent of developing this model was to direct field data collection by identifying varying risk levels within the study area, to guide the selection of variables to be measured in the field, and to establish an initial invasion prediction that could be improved based on field data. Parameters incorporated into this model were land cover type, drainage index, slope, and distance to hydrological features. Land cover type was represented by the Integrated Forest Monitoring, Assessment, and Prescription (IFMAP) Gap Land Cover dataset (MI DNR 2001). Each land cover type was assigned a risk based on its potential to provide habitat and favorable litter for earthworms (Table 3.1). Drainage index, which is a measure of the soil water available to plants (Schaetzl et al. 2009), was linked to SSURGO data (NRCS 2006) to create a spatial drainage index layer. Drainage index incorporates aspects of soil taxonomy including moisture regime, drainage class, water table depth, soil volume, and secondarily, soil texture (Schaetzl et al. 2009). Slope was calculated from a digital elevation model (DEM) available from the Michigan Geographic Data Library (State of Michigan 2009). Steeper slopes were expected to have a lower risk for invasion. Hydrological features (including lakes, rivers, and streams) were obtained from Michigan Geographic Framework data (State of Michigan 2009). These variables were incorporated into the model, which was built using ArcGIS ModelBuilder (ESRI 2011). Distance to the nearest hydrological feature was determined using Euclidean distance. Since fishing is popular in the Huron Mountains, release of bait may be an important source for earthworm invasion, and it is expected that this type of introduction would take place within close proximity to lakes, rivers, and streams. Parameters were combined using a weighted overlay with the following percent weights assigned to each: land cover 30 , drainage index 30 , slope 20, and hydrology 20 . A spatial resolution (pixel size) of $30 \mathrm{~m}$ was used for the model output. The result was a risk map with values from 1 to 5 indicating lowest to highest probability of earthworm invasion (Figure 3.3).

The model predictions were used to locate random sample points within the Huron Mountains study area. Sample points were stratified among the hypothesized risk levels to focus the sampling effort on high risk areas, but also to ensure that all risk levels were represented. Actual GPS coordinates at each plot were recorded in the field and location was updated using this information for spatial analyses. At each sample plot, site characteristics of slope, aspect, position (top, mid, or base), curvature (concave, flat, or convex), and drainage type (hillside, wetland, river edge, etc.) were determined. Drainage type was later separated into two binary presence/absence variables, drainage- 
wet which indicated plots in wetlands or along water edges and drainage-hillside which indicated plots located on a hillside, which consequently were drier sites. A mineral soil punch from 0 to $10 \mathrm{~cm}$ was collected, from which soil $\mathrm{pH}$ was determined using both the $\mathrm{H}_{2} \mathrm{O}$ and $\mathrm{CaCl}_{2}$ methods (Thomas 1996) for verification ( $\mathrm{pH} \mathrm{CaCl} \mathrm{Cl}_{2}$ results are presented hereafter). Forest composition was assessed at the center point using a basal area factor 2 metric prism to count trees by species. Each species was ranked by its suitability as a food source for earthworms based on available assays or literature (Reich et al. 2005; Yatso and Lilleskov in prep.). Preferred species present in our study area were basswood (Tilia americana), maple (Acer spp.), ash (Fraxinus spp.), and balsam fir (Abies balsamea, Table 3.2). Using this information the basal area $\left(\mathrm{BA}, \mathrm{m}^{2} / \mathrm{ha}\right)$ of preferred trees was calculated for each point. Aspects of earthworm invasion were measured in four $0.25 \mathrm{~m}^{2}$ plots, one in each cardinal direction from the center point. The number of middens present was counted in each plot. Middens were recognized by the distinctive mounding of residual plant material, castings, a central plug composed of leaf litter, and an underlying burrow. Forest floor condition was ranked from 1-lowest quality (most altered) to 5-highest quality (minimally altered, Table 3.3, Lilleskov, USDA Forest Service, personal communication). Signs of earthworms other than middens (castings, admixture of $\mathrm{Oa}$ and $\mathrm{E}$ horizons, missing $\mathrm{Oa}$ and Oe horizons) were noted, as well as the presence of any earthworms. Additional landscape characteristics were obtained using GIS and spatial data layers, including road proximity, hydrologic features, and topographic metrics from a DEM. Private roads within the study area were digitized based on aerial photographs and ground-truthing. Proximity to roads and waterways was calculated using Euclidean distance.

To assess patterns of the distribution and abundance of earthworms, site and landscape characteristics (referred to as environmental variables, Table 3.4) were related to the presence or absence of earthworm signs, as well as the presence or absence of middens and the average middens per sample plot (indicating patterns specific to $L$. terrestris distribution and abundance). Statistical analyses were performed using R ( R Development Core Team 2011) and SigmaPlot 11 (Systat Software 2008). Pearson correlation was used to test environmental variables for multicollinearity, as well as to assess predictive model parameters. Variables were first assessed independently using the Mann-Whitney-Wilcoxon test (for continuous independent variables) or a chi-squared test (for categorical independent variables) to identify significant differences in variables between plots with and without earthworm signs and with and without middens. The Mann-Whitney-Wilcoxon test was selected due to identification of non-normal distributions in the environmental variables, since this test is appropriate for data that do not follow a normal distribution. Road proximity was transformed by taking the square root, however back-transformed values are reported for means and standard deviations. For assessment of forest floor condition plots were grouped into three categories: absent, earthworm signs only, and middens, and analysis was done using pairwise comparisons and the Holm's correction (Holm 1979). Logistic regression was used to combine significant variables to explain the presence and absence of earthworm signs and middens. The resulting predictions were assessed by determining an optimal cutoff value for which the minimum overall accuracy (for the prediction of both presence and 
absence) was $70 \%$ (if obtainable) and the success was thereafter optimized for predicting plots with presence of earthworm signs or middens. Linear and nonlinear regressions were used to explore relationships to midden abundance data. Spatial autocorrelation in the environmental variables was expected and tested using Moran's I in ArcGIS. This test was also used to assess spatial autocorrelation in the standardized residuals. Akaike's Information Criterion (AIC) and $\mathrm{R}^{2}$ values were used to compare and assess model fit. For all other tests, significance was determined at $\alpha \leq 0.05$ for $P$-values.

Following statistical analysis, improvements to the spatial GIS model were made through the incorporation of important parameters and removal of unnecessary parameters. In addition, risk assignment within the model was adjusted if necessary based on the findings. Finally, the model weights were reassigned to favor those variables with the strongest correlations to earthworm and midden presence. Spatial datasets representing the Huron Mountain area were obtained when available or created where needed. The resulting risk values were compared to the field data to assess model accuracy, and the final model was compared to the preliminary model to assess the success of improvements. A chi-square test was used to identify differences in risk levels between points with and without middens. In addition to this "current" model of earthworm invasion, a future predictive model was created by incorporating only those variables that were considered static. These variables were those that have a consistent effect (whether constraining or promoting) on earthworm populations without regard to stage of invasion (i.e. introduction, establishment, or spread).

\subsection{Results}

A total of 235 points were sampled over one field season in 2009 (Figure 3.4). Signs of earthworm activity were observed at $58 \%(\mathrm{~N}=135)$ of the plots visited. Middens (exclusive to L. terrestris) were observed at $20 \%(\mathrm{~N}=47)$ of plots. When present, the average number of middens was 3 per $0.25 \mathrm{~m}^{2}$ sample area. The preliminary GIS model predicted a high risk of invasion (value of 4 or 5) for $56 \%$ of plots with earthworm signs present and for $57 \%$ of plots with middens present. An additional $26 \%$ of plots with earthworm signs and $30 \%$ of plots with middens were predicted to have a moderate risk of invasion (value of 3). Significant correlations between environmental variables were found in some cases, particularly for elevation (correlated with five other variables) and drainage-wet (correlated with six other variables, Table 3.5).

Plots with earthworm signs present, including those with middens, significantly differed from plots without middens in basal area of preferred species and soil $\mathrm{pH}$ (Table 3.6). Mean basal area of preferred tree species was significantly greater in plots with earthworm signs $\left(12.3 \pm 9.3 \mathrm{~m}^{2} / \mathrm{ha}\right)$ than without $\left(8.9 \pm 8.6 \mathrm{~m}^{2} / \mathrm{ha}, P<0.01\right)$. Mean soil $\mathrm{pH}$ was also significantly higher in plots with earthworm signs $(4.05 \pm 0.57)$ than in those without $(3.86 \pm 0.58, P<0.01)$. Proximity to roads, proximity to water, drainage index, aspect, slope or elevation did not significantly differ, nor did position, curvature, drainage-wet, or drainage-hillside (Table 3.6). However, aspect did show a weak 
relationship $(P=0.06)$, in which earthworm signs were present on more northern facing sites. The best multivariate model was produced using logistic regression and the variables preferred species and soil $\mathrm{pH}(P<0.001$, Table 3.7). Using the predicted values, optimization to an overall accuracy of $70 \%$ was not possible, thus a standard cutoff value of 0.5 was used resulting in an overall accuracy of $61 \%$. The logistic regression model had a producer's accuracy (the percent of plots with earthworm signs predicted correctly) of 79\%, and a user's accuracy (the percent of positive predictions that did have earthworm signs) of $63 \%$. Despite this, absence was correctly predicted in only $37 \%$ of cases, and the rate of false negatives (percent of plots predicted absent that had earthworm signs) was $44 \%$.

Where middens were present, road proximity, basal area of preferred species, soil $\mathrm{pH}$, and drainage-wet were significant (Table 3.8). Plots with middens present had significantly lower mean road proximity $(237.7 \pm 262.9 \mathrm{~m})$ than those without $(538.3 \pm$ $502.8 \mathrm{~m}, P<0.001)$. Mean basal area of preferred species was significantly greater in plots with middens $\left(14.2 \pm 9.4 \mathrm{~m}^{2} / \mathrm{ha}\right)$ than in those without middens $\left(10.0 \pm 8.9 \mathrm{~m}^{2} / \mathrm{ha}, P\right.$ $<0.01)$. Plots with middens present also had significantly higher mean soil $\mathrm{pH}(4.25 \pm$ $0.58)$ than those without $(3.90 \pm 0.56, P<0.001)$. Drainage-wet was found to be significant in that those plots with middens were less likely to be associated with wet sites $(P<0.01)$. There were no significant differences in water proximity, drainage index, aspect, slope, elevation, position, curvature, or drainage-hillside (Table 3.8). The best combination model was a logistic regression with the variables road proximity, preferred species, soil pH, and drainage-wet $(P<0.001$, Table 3.9). Optimization of the model resulted in a cutoff value of 0.237 to achieve an overall accuracy of $76 \%$. The producer's accuracy was $72 \%$ for the prediction of plots with middens present and user's accuracy (the percent of positive predictions with middens) was 44\%. Midden absence was correctly predicted in $77 \%$ of cases, and the rate of false negatives for midden presence was $8 \%$.

When examining midden abundance (including plots without middens present), linear regression showed that average midden abundance had significant relationships with the same four environmental variables: road proximity $(P<0.001)$, basal area of preferred species $(P<0.01)$, soil pH $(P<0.001)$, and drainage-wet $(P=0.02$, Table 3.10). Aspect showed a weak relationship $(P=0.10)$ with midden abundance, with middens being associated with more southern facing sites. Despite these correlations, examining midden abundance among only those plots with middens (zeros removed) showed no significant relationships (Table 3.10). Aspect, however, retained a weak relationship with midden abundance $(P=0.06)$. These results suggest that the absence of middens was driving the observed associations, and that a logistic regression approach was most appropriate. Furthermore, the observed $\mathrm{R}^{2}$ values were also low, signifying the weakness of these variables in predicting midden abundance. For these reasons, multivariate linear regression based on the midden abundance data was not used, and the best statistical model was the logistic regression model describing midden presence and absence. For this model, significant spatial autocorrelation was present in all of the environmental variables $(P \leq 0.01$ in all cases, Table 3.11). Spatial autocorrelation was 
also present in the logistic regression model residuals (Moran's $\mathrm{I}=0.26, \mathrm{Z}=4.61, P<$ $0.001)$.

As expected, forest floor condition (scaled from 1-lowest quality to 5-highest quality, Table 3.1) was indicative of earthworm invasion (Table 3.12). Plots lacking any signs of earthworms had a mean forest floor rating of $4.98( \pm 0.12)$. Those plots with earthworm signs present, but no middens (suggesting the presence of earthworm species other than $L$. terrestris $)$ had significantly lower forest floor ratings $(3.76 \pm 0.46)$ than plots without any indication of earthworm presence $(P<0.001)$, but had significantly higher ratings than did those plots with middens present $(1.63 \pm 0.69, P<0.001)$. Forest floor condition was strongly related to midden abundance, and was best described by an exponential regression model $\left(P<0.001, \mathrm{R}^{2}=0.85\right.$, Figure 3.5$)$. Those plots with higher midden abundance had lower quality forest floors as altered by L. terrestris. And average midden abundance significantly differed among forest floor ranks $(P<0.001$, Table $3.13)$.

The preliminary GIS model was recreated to incorporate those variables that were significantly related to midden presence. Three parameters in the preliminary model, drainage index, slope, and hydrology, were not found significant and were removed from the model. The fourth variable, land cover, remained in the model as basal area of preferred species wat found to be significant. Land cover was again represented by IFMAP data (MDNR 2001) with the risk values altered slightly from that assigned in the preliminary model (Table 3.1). Basal area of preferred species was significantly positively correlated $(P<0.001)$ with the risk values assigned to IFMAP land cover classes, demonstrating that the IFMAP layer was satisfactory in representing the basal area of preferred species. Road proximity, calculated using Euclidean distance, was included in the updated model using the road layer created from aerial photographs of the Huron Mountains. Soil pH measured in the field was significantly related to midden presence, however SSURGO soil data (NRCS 2006) was not found to be correlated to midden presence $(P=0.44)$. SSURGO data also very poorly matched the measured soil $\mathrm{pH}$ values $\left(\mathrm{R}^{2}=0.02\right)$, which is likely due to the high variability in soil $\mathrm{pH}$ across the Huron Mountains. For this reason, soil $\mathrm{pH}$ sampled in the field was interpolated across the study area using ordinary kriging (ArcGIS 10 Spatial Analyst, ESRI 2011) of the 235 field sample points (Figure 3.6). This layer was used to represent soil $\mathrm{pH}$ in the model. This also limited the predictive map to only the study area within the Huron Mountains.

An improved final model was created using the variables road proximity, soil $\mathrm{pH}$, and land cover (Figures 3.7 and 3.8). The assigned weights in the model were 40 for road proximity, 30 for soil $\mathrm{pH}$, and 30 for land cover. The final model predicted a high risk of invasion (value of 4 or 5 ) for $55 \%$ of plots with earthworm signs and $81 \%$ of plots with middens present, compared to $56 \%$ for earthworm signs and $57 \%$ for middens as predicted by the preliminary model. Chi-square analysis indicated that risk level significantly differed between points with and without middens $\left(\chi^{2}=20.0, d f=4, P<\right.$ 0.001 ). The user's accuracy for predicting midden presence (percent of all sample points at risk of 4 or 5 with middens present) was $30 \%$ compared to $21 \%$ for the preliminary 
model. By including the dynamic variable road proximity, this model and risk map represent the current risk of invasion by $L$. terrestris. Removing road proximity and taking into account only static variables creates a model and risk map that show the potential future distribution of L. terrestris across the Huron Mountains (Figure 3.9). In comparing the current and future model predictions, the current model assigned the highest risk (value of 5) to $4 \%$ of the study area, while the future model assigned highest risk to $10 \%$ of the study area. Although in general high risk (value of 4 or 5) covered a similar area, $47 \%$ for the current model and $48 \%$ for the future model, the risk maps show variation in the locations and patterns of high risk areas. Based on the current distribution of earthworms, the future model had a user's accuracy of $25 \%$, which would be expected to increase over time as the full distribution was met.

\subsection{Discussion}

For predicting the presence of earthworm signs, the variables preferred species and soil $\mathrm{pH}$ were found to be significant. Soil $\mathrm{pH}$ is known to limit earthworm activity, particularly in low $\mathrm{pH}$ conditions. Here earthworm signs were rarely present in soils with $\mathrm{pH}\left(\mathrm{CaCl}_{2}\right)$ less than 3.5 and were nearly always present in soils with $\mathrm{pH}$ above 4.0. Basal area of preferred tree species was also higher in plots with earthworms, which is attributable to both the availability of food and the associated suitability of other habitat conditions. Though preferred tree species exclude those that are common on acidic sites or produce acidic litter, there was no significant correlation between soil $\mathrm{pH}$ and preferred species. The lower predictive ability for earthworm signs as opposed to midden presence and abundance is due in part to the variation in earthworm functional and feeding groups present. Those species that feed on microorganisms or partially decomposed organic matter are less influenced by the basal area of preferred tree species, especially since this ranking was developed specifically for $L$. terrestris, which feeds on fresh leaf litter. Furthermore, earthworm species differ in their tolerance of extremes in soil $\mathrm{pH}$, soil moisture, and other conditions.

Midden presence and abundance could be predicted using the variables road proximity, preferred species, soil $\mathrm{pH}$, and drainage-wet. Preferred species was significant in predicting midden presence and was also related to midden abundance. Increased basal area of preferred trees should provide for an increased amount of leaf litter and be able to support larger earthworm populations. Soil $\mathrm{pH}$ limited the presence of middens to plots with $\mathrm{pH}\left(\mathrm{CaCl}_{2}\right)$ of 3.35 or greater, and only rarely did middens occur at plots with $\mathrm{pH}$ less than 3.6. The linear relationship between midden abundance and $\mathrm{pH}$, though significant, was weak and highly influenced by zero values. There was a particularly large increase in $P$-value, from $P<0.001$ for all plots to $P=0.66$ for non-zero plots, suggesting that soil $\mathrm{pH}$ represents a threshold for presence rather than having an effect on earthworm abundance. Similarly, drainage-wet was also highly influenced by zero midden plots, indicating that sites saturated with water (e.g. open water, wetlands, river edges) were less likely to have middens present at all, which agrees with our hypothesis that soil moisture (in this case overly wet soils) will limit the presence of $L$. terrestris. 
Spatial autocorrelation was observed in the significant environmental variables and the logistic regression residuals, suggesting that a geographically weighted approach could be beneficial for this dataset. Geographically weighted regression (GWR) models allow for coefficients to vary over the area, creating a more specified prediction at each location. A GWR model would be beneficial for predicting the probability of midden presence or abundance within the Huron Mountains. The use of geographically weighted logistic regression (necessary for presence/absence data) or other methods such as autologistic regression, however, is uncommon and requires further examination of applicability and validity before application (Dormann 2007).

Road proximity, which serves as a proxy for dispersal potential, was important only for the presence of $L$. terrestris rather than for all earthworm signs. This may indicate that other species of earthworms are at a later stage of invasion than L. terrestris. This is consistent with the theory of invasion waves, where there is an orderly procession of earthworm species and/or functional group invasion, beginning with epigeic species such as Dendrobaena octaedra, and ending with L. terrestris (James and Hendrix 2004; Hale et al. 2005). Accordingly, D. octaedra was by far the most widespread species in the Huron Mountains (Lilleskov, personal observation), and may demonstrate steadystate distribution patterns, limiting the predictive ability of roads, which are associated with invading species. It is important to understand how the effect of these variables as predictors may differ depending on whether they are static constraints on earthworm distribution or dynamic variables related to the stage of invasion (i.e. introduction, establishment, or spread). The ability to identify the current stage of invasion would help explain the importance (or unimportance) of dynamic variables, such as road proximity, in a predictive model.

Forest floor condition showed a close relationship with both earthworm activity and midden presence and abundance. This result, however, should serve only in support of the efficacy of the rating system, as earthworm signs and middens are a component. Nevertheless, alteration of the forest floor organic layer and soil was identifiable under earthworm invasion and most severe where there was a high abundance of middens, and therefore a larger population of $L$. terrestris. This demonstrates the increased impact of L. terrestris over that of other earthworm species. The close relationship between earthworm activity and forest floor condition, especially in the case of presence and abundance of $L$. terrestris, also suggests that a simple visual rating of the forest floor is a feasible option for rapid assessment of earthworm activity and impact, and could easily be incorporated into other forest monitoring efforts. Accordingly, Loss et al. (in prep.) have adapted a similar rating scale for use as a rapid assessment tool for earthworm invasion severity. The significant relationship between forest floor condition and measures of earthworm activity found in this study support the use of rapid assessment via forest floor and soil condition rating for efficient and accurate estimation of earthworm invasion.

Many of the variables assessed to test relationships with earthworm presence and abundance were not significant despite having reasonable theoretical associations. For 
example, studying the genetic diversity of earthworm populations has shown that multiple introductions are likely to occur at boat launches and fishing sites, making these sites important points of introduction and further spread (Cameron et al. 2008). However, in this study hydrology was not related to earthworm distribution. It may be that differences in earthworm species dispersal patterns and habitat preferences are confounding the observed results and significance of environmental variables. None of the topographic characteristics (aspect, slope, elevation, position, curvature) were found to be significantly related to earthworm or midden presence. However, aspect did show some indication of association with earthworm distribution, with earthworm presence occurring on more northern facing sites. On the other hand, midden abundance (both with and without zeros removed) showed some association with more southern facing sites. In this case it could be that earthworm species differ in their association with aspect.

The preliminary GIS model was developed without use of field data and included only readily available spatial data. The model correctly assigned high risk levels to approximately half of the points with earthworm signs or middens. The lack of accuracy could be attributed to the inclusion of parameters that were found to be insignificant in the assessment of the field data. Of the four parameters included in the model, three (slope, drainage index, and water proximity) were not significantly related to the presence of earthworm signs or middens. Land cover, which in this case served as a proxy for preferred species, may have been the only parameter driving the limited success that was observed. Because of data limitations at the time of creation, road proximity and soil $\mathrm{pH}$, which were both significant variables during field data assessment, were not included in the preliminary model. In the final model, road proximity and soil $\mathrm{pH}$ were able to be included along with land cover to improve the accuracy of the predictions. Low user accuracy in the case of the final model should not be a concern in this case considering that earthworm invasion has not yet fully progressed. At the earlier, introduction stage of invasion a predictive model would be expected to have many false positives or plots where earthworm presence is predicted but because of limitations in the speed of dispersal earthworms have not yet reached. Alternatively, the user accuracy could be viewed as the percent of the potential or predicted distribution that has become invaded. Thus by extrapolating beyond the sample points to the entire study area, $30 \%$ of the area predicted to have high risk of invasion by earthworms in the current model has been invaded, and only $25 \%$ of the area predicted to be high risk in the future model has been invaded.

\subsection{Conclusions}

Earthworm invasion within the Huron Mountains appears to be at varying stages dependent upon species. A lack of correlation between measures of dispersal and the presence of earthworm signs suggests that epigeic and endogeic species have reached a further stage of invasion than the anecic species L. terrestris. For both general earthworm signs, and L. terrestris specifically, soil $\mathrm{pH}$ and basal area of preferred tree 
species were the best predictive variables. Thus, high $\mathrm{pH}$ sites with a substantial basal area of basswood, maples, ash, and/or balsam fir have the highest likelihood for invasion by European earthworms. Likewise, these conditions within close proximity to roads are most likely to contain earthworm species at the introduction stage of invasion, such as was the case for L. terrestris within the Huron Mountains. Because of high variability in important site characteristics at a fine scale, specifically soil $\mathrm{pH}$, using spatial data to expand these models beyond the Huron Mountains may present difficulties. While there is optimism for management approaches to prevent earthworms from invading earthworm-free or minimally invaded forests (Hale 2008), implementation will rely on identification of current populations and can be further focused using predictive models to determine invasion potential.

\section{Literature Cited}

Barley KP. 1961. Abundance of earthworms in agricultural land and their possible significance in agriculture. Advances in Agronomy. 13:249-268.

Bohlen PJ, Groffman PM, Fahey TJ, Fisk MC, Suarez E, Pelletier DM, Fahey RT. 2004a. Ecosystem consequences of exotic earthworm invasion of north temperate forests. Ecosystems. 7:1-12.

Bohlen PJ, Scheu S, Hale CM, McLean MA, Migge S, Groffman PM, Parkinson D. 2004c. Non-native invasive earthworms as agents of change in northern temperate forests. Frontiers in Ecology and the Environment. 2:427-435.

Cameron EK, Bayne EM, Coltman DW. 2008. Genetic structure of invasive earthworms Dendrobaena octaedra in the boreal forest of Alberta: insights into introduction mechanisms. Molecular Ecology. 17:1189-1197.

Clapperton MJ, Baker GH, Fox CA. 2008. Earthworms. In: Carter MR, Gregorich EG, editors. Soil Sampling and Methods of Analysis. $2^{\text {nd }}$ ed. Boca Raton, FL: CRC Press. p. 427-444.

Dormann CF. 2007. Assessing the validity of autologistic regression. Ecological Modeling. 207:234-242.

Environmental Systems Research Institute (ESRI). 2011. ArcGIS Desktop: Release 10. Redlands, CA: Environmental Systems Research Institute.

Frelich LE, Hale CM, Scheu S, Holdsworth AR, Heneghan L, Bohlen PJ, Reich PB. 2006. Earthworm invasion into previously earthworm-free temperate and boreal forests. Biological Invasions. 8:1235-1245. 
Hale CM. 2008. Evidence for human-mediated dispersal of exotic earthworms: support for exploring strategies to limit further spread. Molecular Ecology. 17:1165-1169.

Hale CM, Frelich LE, Reich PB. 2005. Exotic earthworm invasion dynamics in northern hardwood forests of Minnesota, USA. Ecological Applications 15:848-860.

Hale CM, Frelich LE, Reich PB, Pastor J. 2008. Exotic earthworm effects on hardwood forest floor, nutrient availability and native plants: a mesocosm study. Oecologia. 155:509-518.

Hendriksen NB. 1990. Leaf litter selection by detritivore and geophagous earthworms. Biology and Fertility of Soils. 10:17-21.

Hendrix PF, Bohlen PJ. 2002. Exotic earthworm invasions in North America: ecological and policy implications. BioScience. 52:801-811.

Holm S. 1979. A simple sequentially rejective multiple test procedure. Scandinavian Journal of Statistics. 6:65-70.

Holmstrup M, Westh P. 1995. Effects of dehydration on water relations and survival of lumbricid earthworm egg capsules. Journal of Comparative Physiology. 165:377-383.

James SW, Hendrix PF. 2004. Invasion of exotic earthworms into North America and other regions. In: Edwards CA, editor. Earthworm Ecology. Boca Raton: CRC Press. p. $75-88$.

Jones CG, Lawton JH, Shachak M. 1994. Organisms as ecosystem engineers. Oikos. 69:373-386.

Loss SR, Blair RB. 2011. Reduced density and nest survival of ground-nesting songbirds relative to earthworm invasions in northern hardwood forests. Conservation Biology. 25:983-992.

Loss SR, Hueffmeier RM, Hale CM, Frelich LE, Host GE, Sjerven G. In Prep. A visual method for rapidly assessing earthworm invasions in northern hardwood forests.

Maerz JC, Nuzzo VA, Blossey B. 2009. Declines in woodland salamander abundance associated with non-native earthworm and plant invasions. Conservation Biology. 23:975-981.

Michigan Department of Natural Resources (MI DNR). 2001. Michigan 2001 Integrated Forest Monitoring, Assessment, and Prescription (IFMAP) Gap Land Cover dataset. (http://www.mcgi.state.mi.us/mgdl). 
Natural Resources Conservation Service (NRCS). 2006. Soil Survey Geographic (SSURGO) Database. (http://soildatamart.nrcs.usda.gov).

R Development Core Team. 2011. R: A language and environment for statistical computing. R Foundation for Statistical Computing, Vienna, Austria. (http://Rproject.org).

Reich PB, Oleksyn J, Modrzynski J, Mrozinski P, Hobbie SE, Eissenstat DM, Chorover J, Chadwick OA, Hale CM, Tjoelker MG. 2005. Linking litter calcium, earthworms and soil properties: a common garden test with 14 tree species. Ecology Letters. 8:811-818.

Schaetzl RJ, Krist FJ, Stanley K, Hupy CM. 2009. The natural soil drainage index: an ordinal estimate of long-term soil wetness. Physical Geography. 30:383-409.

Scheu S. 2003. Effects of earthworms on plant growth: patterns and perspectives. Pedobiologia. 47:846-856.

Scheu S, Parkinson D. 1994. Effects of earthworms on nutrient dynamics, carbon turnover and microorganisms in soils from cold temperate forests of the Canadian Rocky Mountains - laboratory studies. Applied Soil Ecology. 1:113-125.

Schwert DP, Dance KW. 1979. Earthworm cocoons as a drift component in a southern Ontario stream. Canadian Field Naturalist. 93:180-183.

State of Michigan. 2009. Michigan Geographic Data Library. Center for Geographic Information, Department of Information Technology. (http://mcgi.state.mi.us/mgdl).

Systat Software. 2008. SigmaPlot 11. User's Guide. San Jose, CA: Systat Software Inc.

Thomas GW. 1996. Soil pH and Soil Acidity. In: Sparks DL, editor. Methods of Soil Analysis, Part 3 - Chemical Methods. Madison, Wisconsin: Soil Science Society of America. p. 475-490.

Tiunov AV, Hale CM, Holdsworth AR, Vsevolodova-Peral TS. 2006. Invasion patterns of Lumbricidae into previously earthworm-free areas of northeastern Europe and the western Great Lakes region of North America. Biological Invasions. 8:1223-1234.

United States Geological Survey (USGS). 2011. National Land Cover Database 2006. Multi-Resolution Land Characteristics (MRLC) Consortium. (http://www.mrlc.gov/nlcd2006_update).

Yatso K, Lilleskov E. In Prep. Effects of tree litter type and soil type on growth of an introduced earthworm (Lumbricus terrestris): implications for invasion dynamics. 


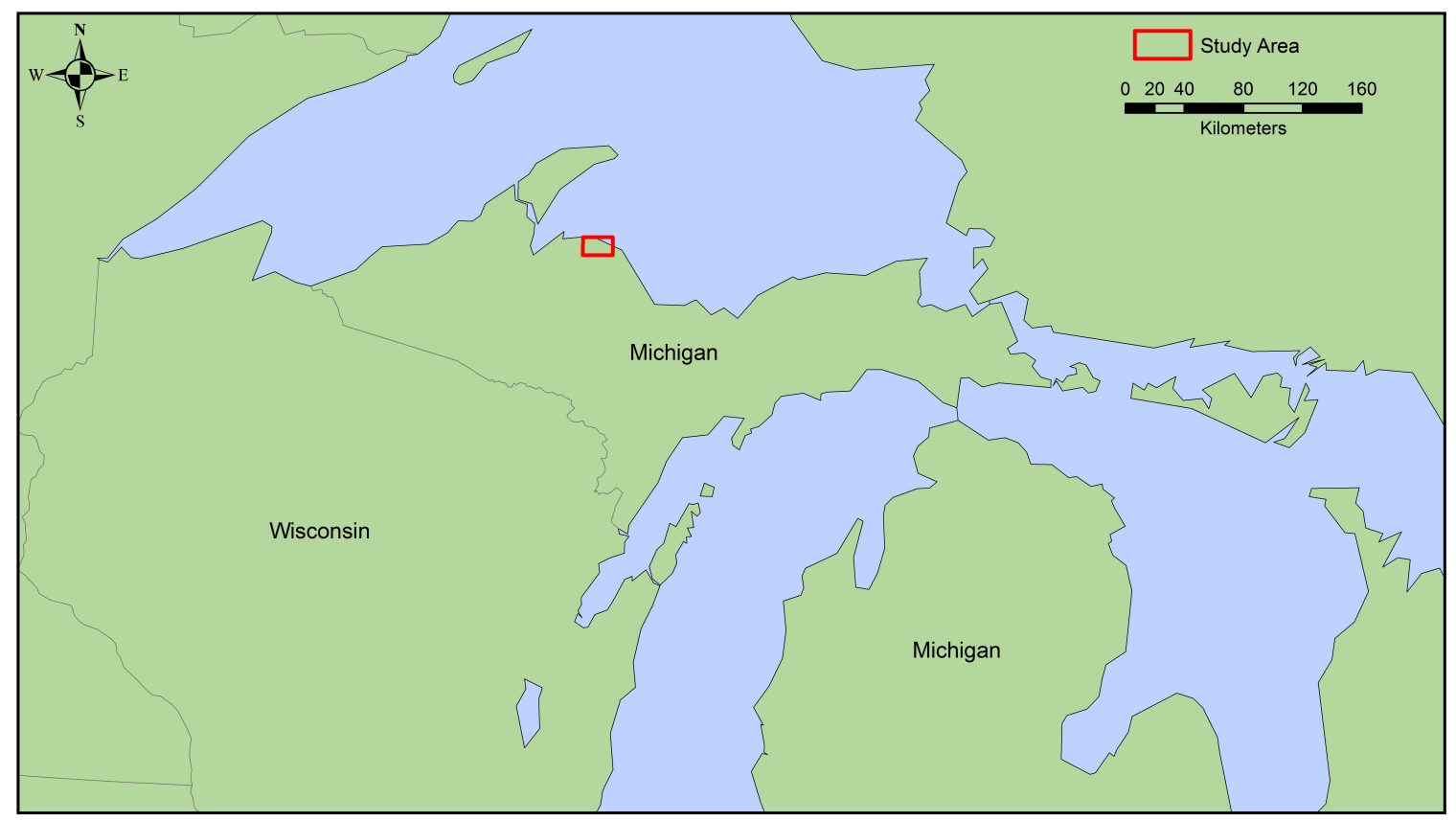

Figure 3.1 Locator map for the area of study, the Huron Mountains, located in Marquette County in the Upper Peninsula of Michigan. The study area is indicated by the red rectangle. 


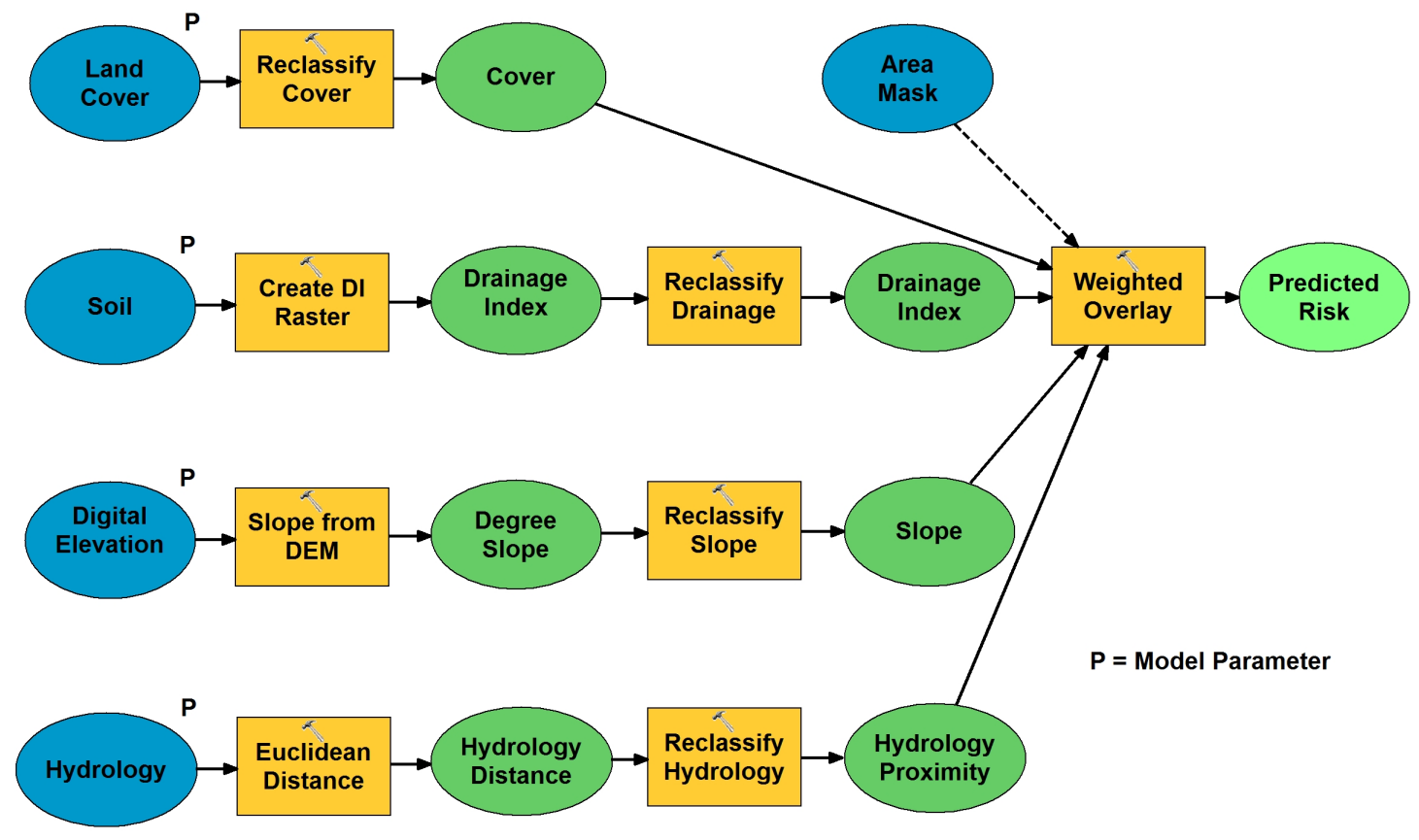

Figure 3.2 Design and layout of the preliminary GIS model developed to predict risk of invasion by exotic earthworms within the Huron Mountains, Upper Peninsula, Michigan. The model was created using ArcGIS ModelBuilder (ESRI 2011). Model inputs (parameters) include land cover, soil drainage index, slope (derived from a Digital Elevation Model), and proximity to hydrologic features. The model output, predicted risk, is a combination of these parameters calculated by use of a weighted overlay. 


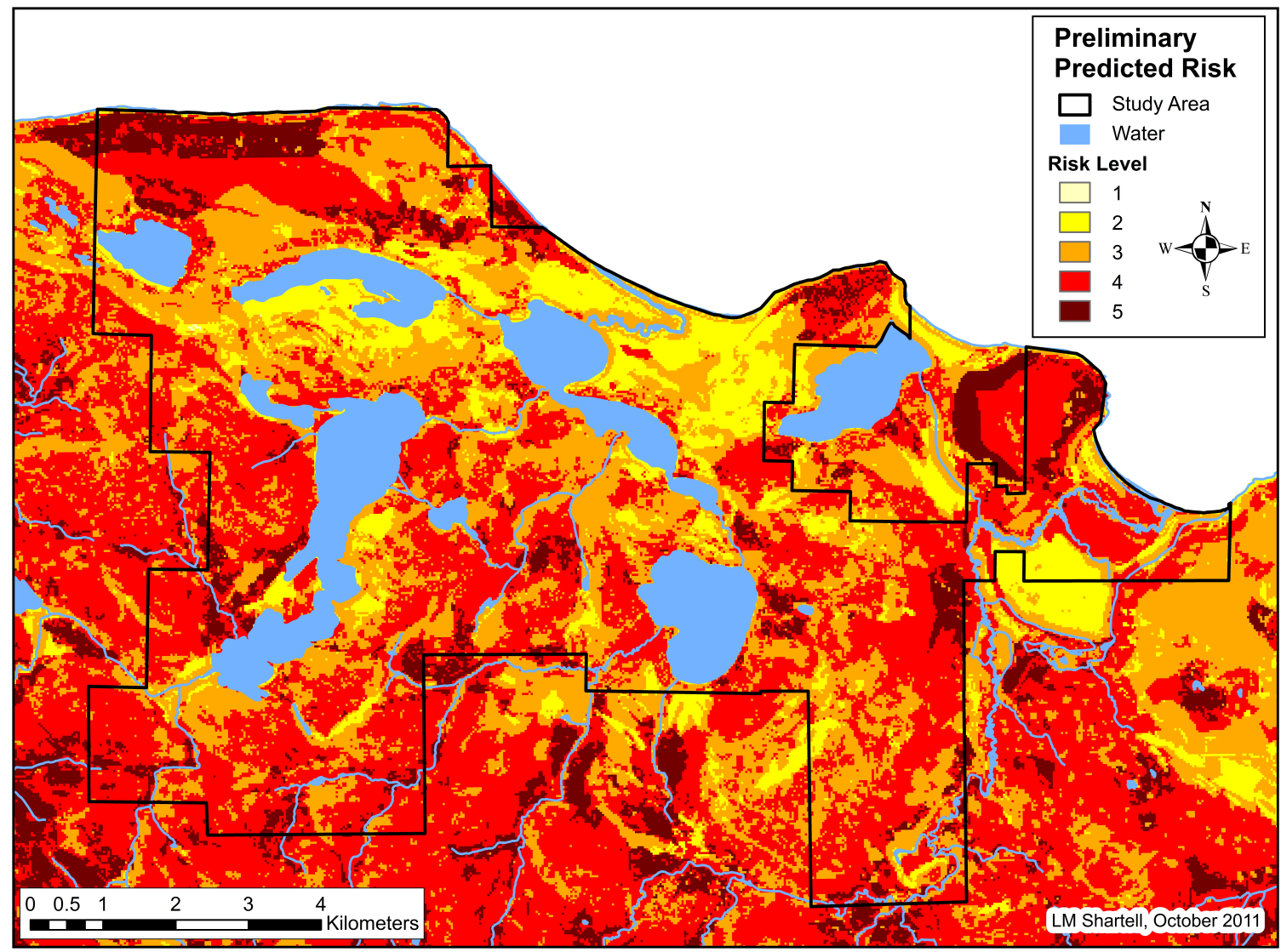

Figure 3.3 Preliminary predicted risk of invasion by earthworms across the study area in the Huron Mountains, Upper Peninsula, Michigan. Model parameters included land cover, soil drainage index, slope, and proximity to hydrologic features. Risk is displayed on a scale from 1-lowest risk to 5-highest risk. 


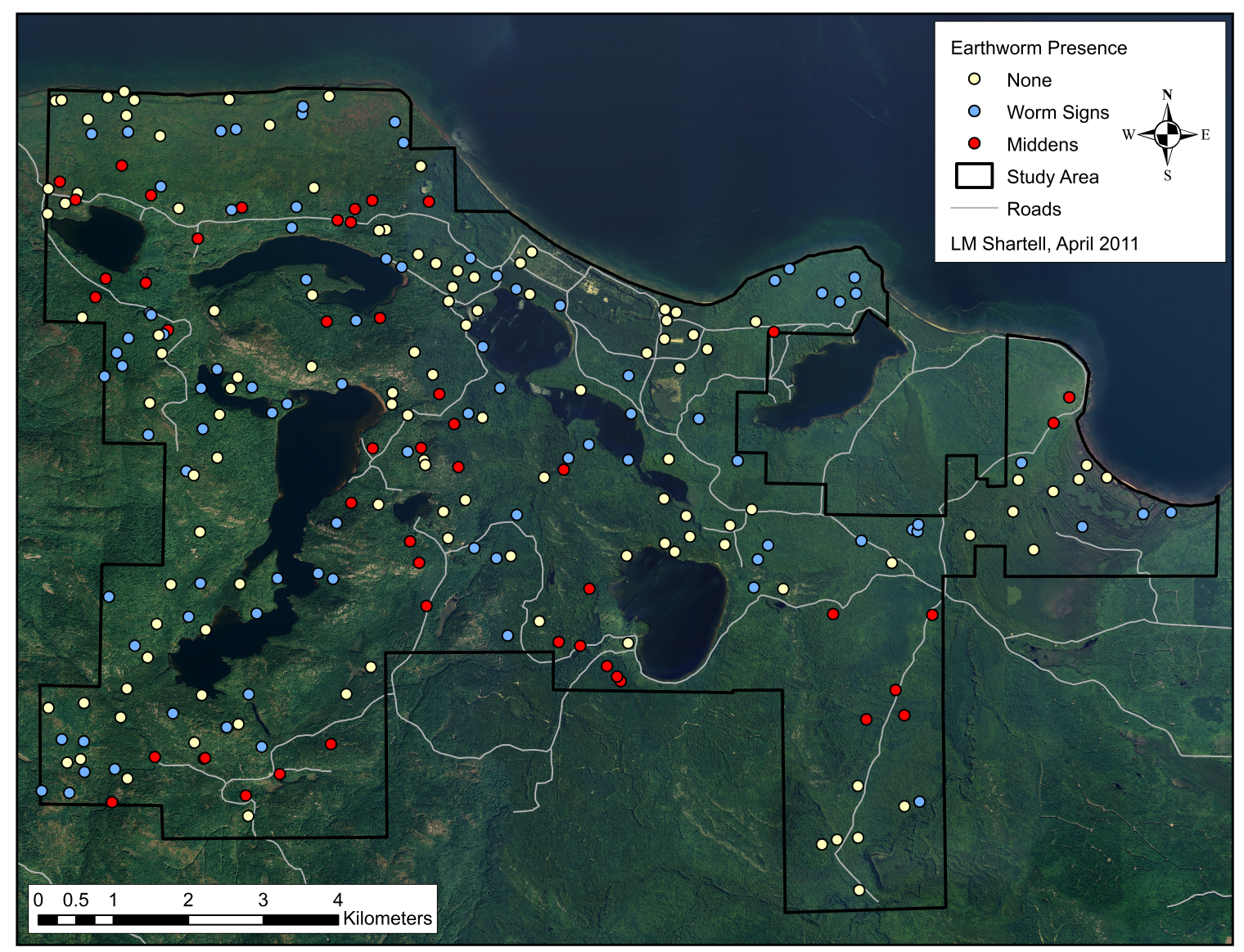

Figure 3.4 The distribution of earthworm signs and middens at sample points across the Huron Mountains, Upper Peninsula, Michigan. Background imagery is from the 2005 National Agriculture Imagery Program (NAIP). Signs of earthworm presence were observed at $58 \%$ of points, and middens (exclusive to L. terrestris) were observed at $20 \%$ of points. 


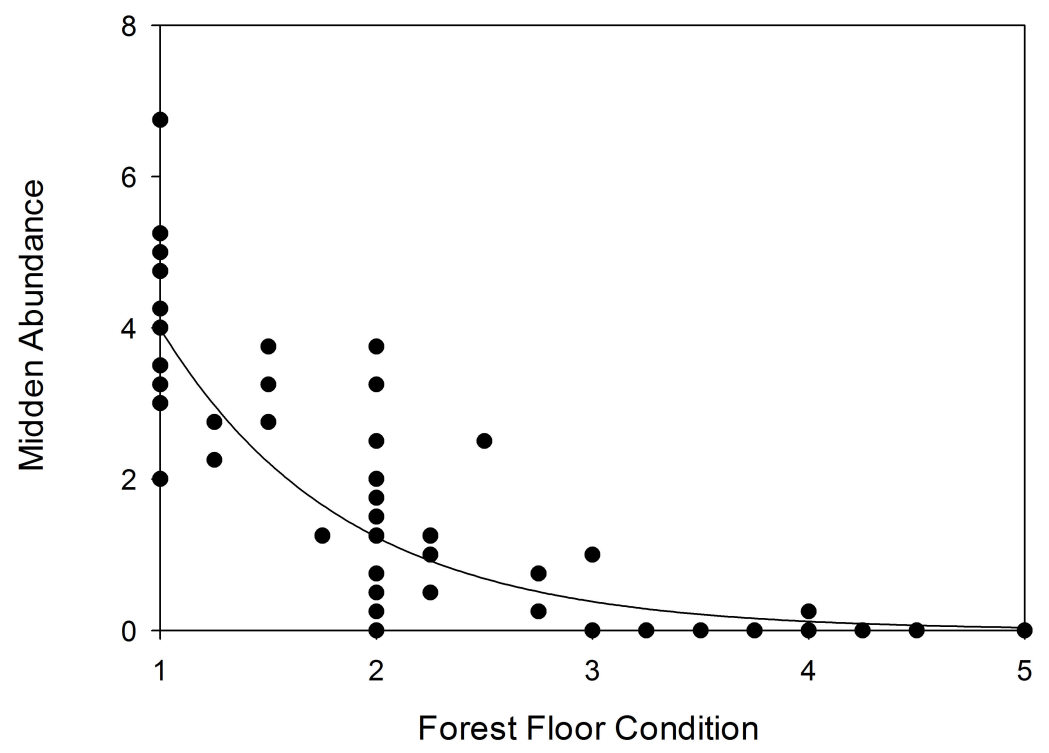

Figure 3.5 The relationship between forest floor condition and earthworm midden abundance. Forest floor condition is rated from 1-lowest quality to 5-highest quality (Table 3.3). Forest floor condition was significantly related to midden abundance and was best explained by an exponential regression model $\left(P<0.001, \mathrm{R}^{2}=0.85\right)$. 


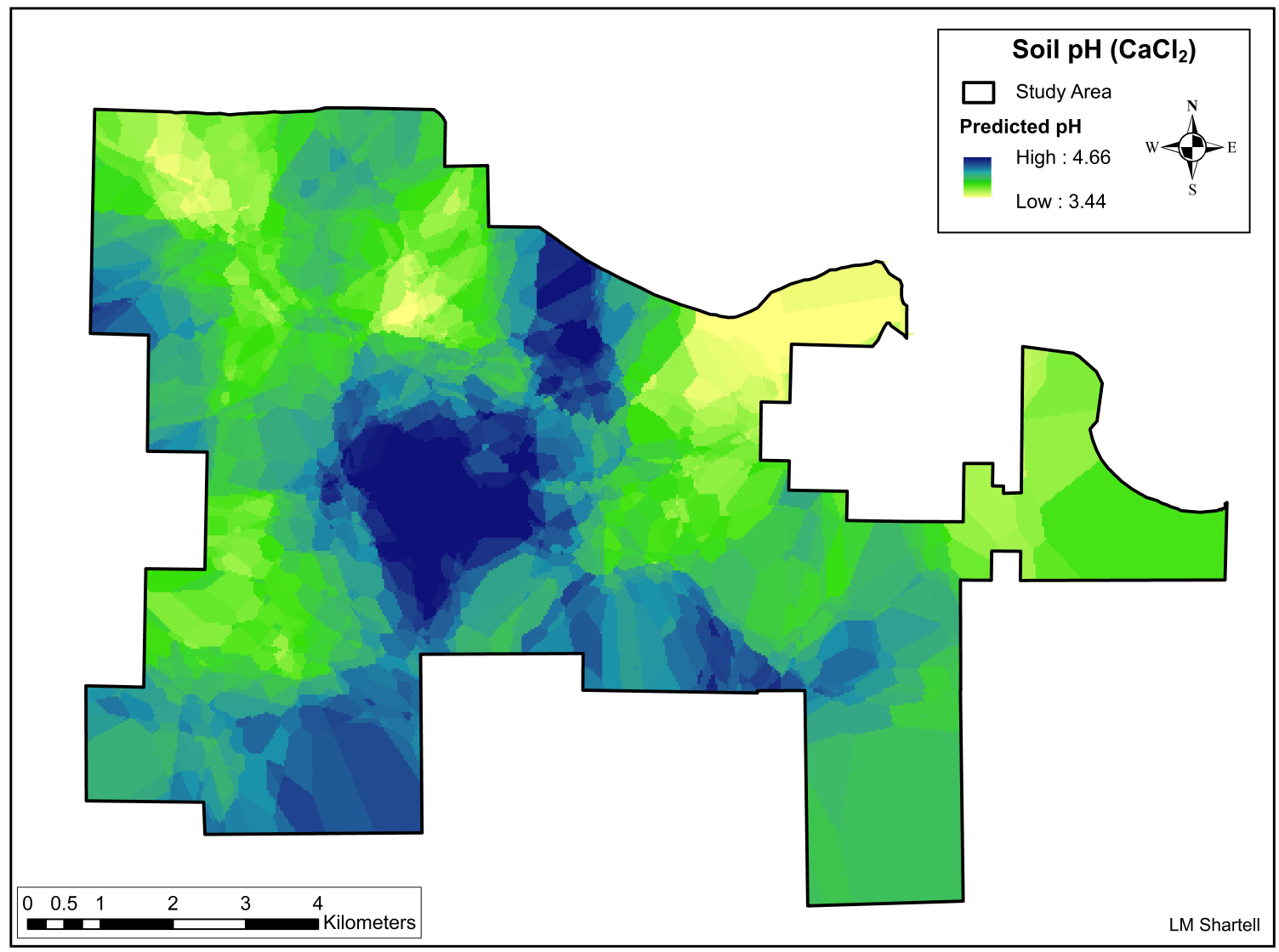

Figure 3.6 Interpolated soil $\mathrm{pH}\left(\mathrm{CaCl}_{2}\right)$ across the Huron Mountains created using ordinary kriging (ArcGIS 10 Spatial Analyst, ESRI 2011) of the 235 field sample points. 


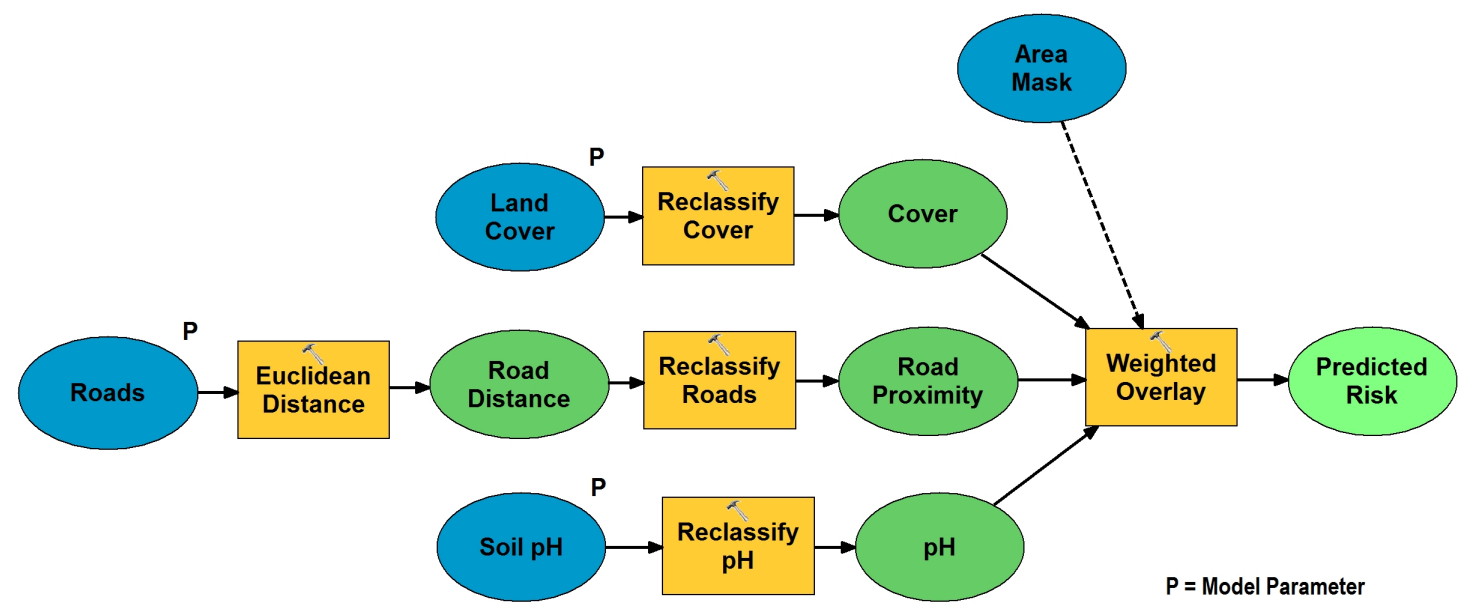

Figure 3.7 Design and layout of the final (current) GIS model developed to predict risk of invasion by exotic earthworms within the Huron Mountains, Upper Peninsula, Michigan. The model was created using ArcGIS ModelBuilder (ESRI 2011). Model inputs (parameters) include land cover, road proximity, and soil $\mathrm{pH}$. The model output, predicted risk, is a combination of these parameters calculated by use of a weighted overlay. 


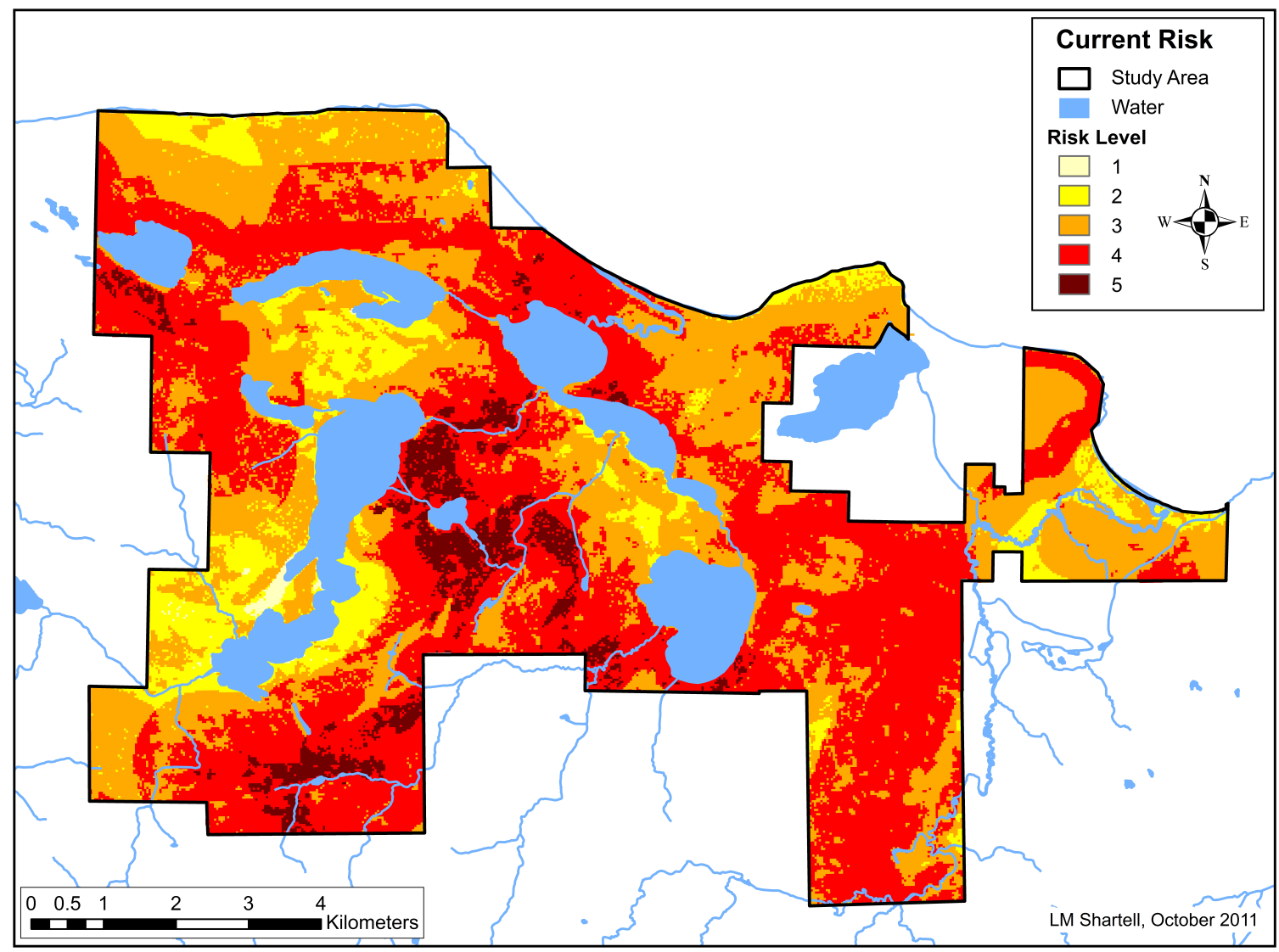

Figure 3.8 Current predicted risk of invasion of Lumbricus terrestris across the study area in the Huron Mountains, Upper Peninsula, Michigan. Parameters include soil pH, land cover, and road proximity. Risk is displayed on a scale from 1-lowest risk to 5highest risk. 


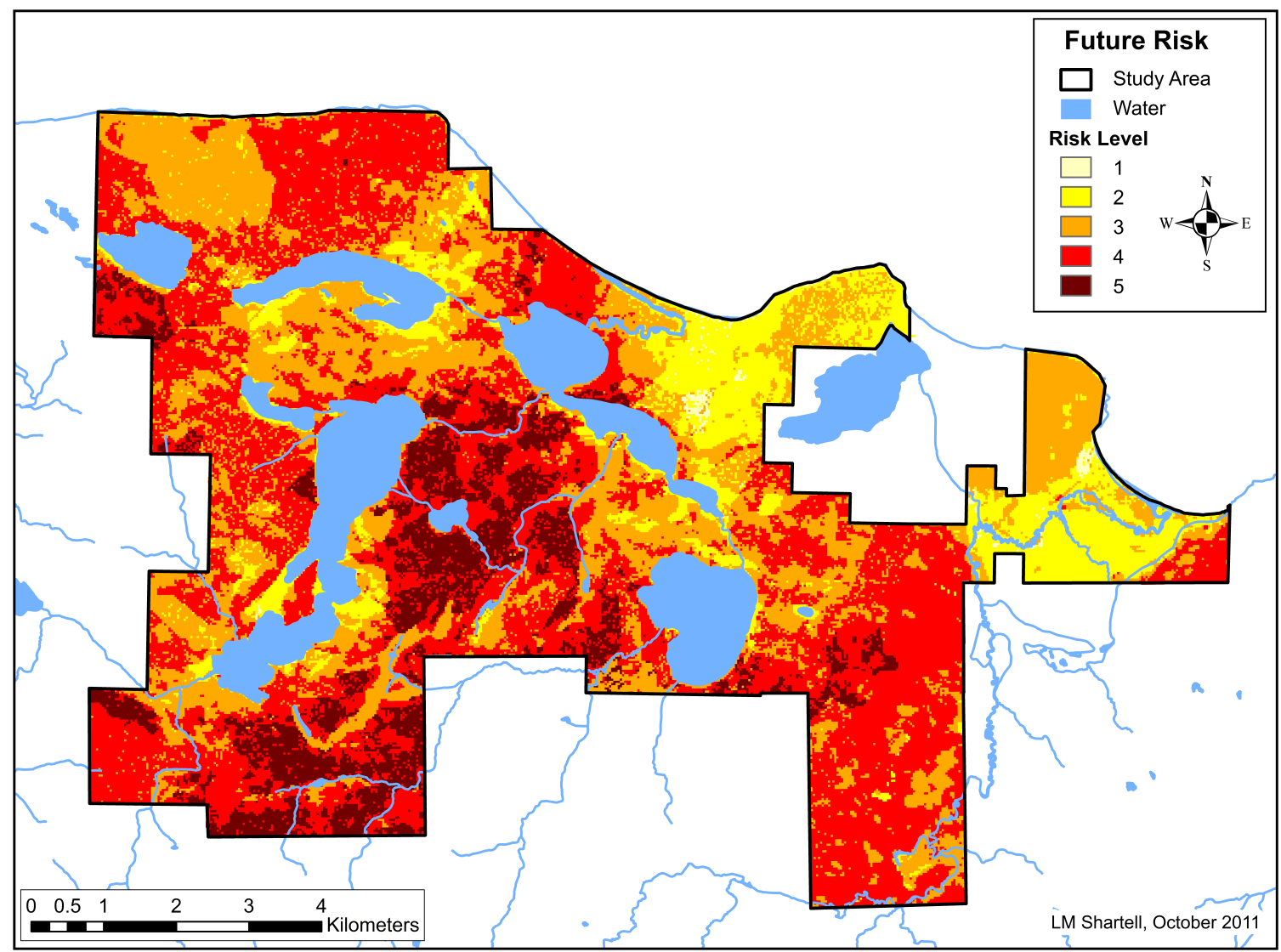

Figure 3.9 Future predicted distribution of Lumbricus terrestris across the study area in the Huron Mountains, Upper Peninsula, Michigan. Parameters include soil pH and land cover. Risk is displayed on a scale from 1-lowest risk to 5-highest risk. 


\section{Table 3.1}

Risk values assigned to IFMAP (MI DNR 2001) land cover types within the Huron Mountains for the preliminary and final (both current and future) predictive GIS models. Risks were assigned from 0 -no risk to 5 -highest risk based on the potential to provide earthworm favorable habitat and litter for a food source, as indicated in the literature.

\begin{tabular}{lcc}
\hline Cover Type & Preliminary Risk & Final Risk \\
\hline Northern Hardwood Association & 5 & 5 \\
Mixed Upland Deciduous & 4 & 5 \\
Upland Mixed Forest & 4 & 5 \\
Aspen Association & 4 & 4 \\
Lowland Deciduous Forest & 3 & 4 \\
Mixed Upland Conifers & 1 & 4 \\
Forage Crops & 5 & 3 \\
Low Intensity Urban & 5 & 3 \\
Herbaceous Openland & 4 & 3 \\
Upland Shrub & 3 & 3 \\
Lowland Mixed Forest & 2 & 3 \\
Lowland Shrub & 2 & 3 \\
Other Upland Conifers & 1 & 3 \\
Pines & 1 & 3 \\
Bare/Sparsely Vegetated & 2 & 2 \\
Lowland Coniferous Forest & 1 & 2 \\
Sand/Soil & 1 & 2 \\
High Intensity Urban & 3 & 1 \\
Emergent Wetland & 1 & 1 \\
Mixed Non-Forest Wetland & 1 & 1 \\
Oak Association & 1 & 1 \\
Roads/Paved & 1 & 1 \\
Water & 0 & 1 \\
\hline
\end{tabular}




\section{Table 3.2}

Earthworm preference for leaf litter from tree species encountered during field sampling within the Huron Mountains. Highest ranked species are most preferred, based on earthworm growth and/or consumption under leaf litter from these or similar species. Species ranked as 3 or 4 were considered preferred species for the purpose of the study.

\begin{tabular}{lcl}
\hline Species & Ranking & Basis \\
\hline Acer saccharum & 4 & Yatso and Lilleskov (in prep) \\
Tilia americana & 4 & Yatso and Lilleskov (in prep) \\
Abies balsamea & 3 & Reich et al 2005, congeners \\
Acer pennsylvanicum & 3 & Yatso and Lilleskov (in prep) \\
Acer rubrum & 3 & Yatso and Lilleskov (in prep) \\
Fraxinus americana & 3 & provisional \\
Betula alleghaniensis & 2 & Yatso and Lilleskov (in prep) \\
Betula papyrifera & 2 & Yatso and Lilleskov (in prep) \\
Ostrya virginiana & 2 & Yatso and Lilleskov (in prep) \\
Picea glauca & 2 & Reich et al 2005, congeners \\
Picea mariana & 2 & Reich et al 2005, congeners \\
Populus grandidentata & 2 & provisional \\
Populus tremuloides & 2 & provisional \\
Pinus banksiana & 1 & Reich et al 2005, congeners \\
Pinus resinosa & 1 & Reich et al 2005, congeners \\
Pinus strobus & 1 & Reich et al 2005, congeners \\
Quercus rubra & 1 & Yatso and Lilleskov (in prep) \\
Thuja occidentalis & 1 & provisional \\
Tsuga canadensis & 1 & Yatso and Lilleskov (in prep) \\
\hline
\end{tabular}


Table 3.3

Description of forest floor condition ratings from 1-lowest quality to 5-highest quality (Lilleskov, USDA Forest Service, personal communication).

\section{Rating Forest Floor Condition}

$1 \quad$ No forest floor. Previous year's litter over mineral soil. Worm casting and/or L. terrestris middens abundant.

No humus or small leaf fragments present; larger old leaves may be

2 present under litter. Worm castings present. L. terrestris middens present or absent. Roots absent from forest floor.

No humus. Small leaf fragments and larger old leaves present. Sparse

3 to no roots in the forest floor. Some worm casting may be present. $L$. terrestris likely to be absent or very sparse.

Humus present in patches, may be slightly mixed with mineral soil, the

4 rest of the forest floor is intact. Some roots in the forest floor, but not thick. Small worms may be found in the forest floor, but no large castings or L. terrestris middens.

Humus fully intact. Roots present in humus and leaf fragments. Forest

5 floor coherent when picked up with intact recognizable layers. No worms or worm sign present. 
Table 3.4

Description of environmental variables selected to test associations with exotic earthworm presence and abundance.

\begin{tabular}{|c|c|c|c|}
\hline Variable & Code & Units & Description \\
\hline Road Proximity & RD & $\mathrm{m}$ & Distance to the nearest road \\
\hline Water Proximity & WA & $\mathrm{m}$ & Distance to nearest waterway \\
\hline Preferred Species & PS & $\mathrm{m}^{2} / \mathrm{ha}$ & $\begin{array}{c}\text { Basal area of earthworm preferred } \\
\text { overstory tree species }\end{array}$ \\
\hline Soil pH & $\mathrm{pH}$ & $\mathrm{pH}$ & Soil pH \\
\hline Drainage Index & DI & & Drainage index (Schaetzl et al. 2009) \\
\hline Aspect & AS & $\circ$ & Deviation from north \\
\hline Slope & $\mathrm{SL}$ & $\%$ & Percent slope \\
\hline Elevation & EL & $\mathrm{m}$ & Elevation at plot center \\
\hline Position & $\mathrm{PO}$ & & $\begin{array}{l}\text { Position of the plot relative to } \\
\text { surrounding land (top, mid, or base) }\end{array}$ \\
\hline Curvature & $\mathrm{CU}$ & & $\begin{array}{l}\text { Topography of the plot (convex, flat, or } \\
\text { concave) }\end{array}$ \\
\hline Drainage-Wet & DW & binary & $\begin{array}{c}\text { Indicates a wet site (wetland, lake or } \\
\text { river edge, etc.) }\end{array}$ \\
\hline Drainage-Hillside & DH & binary & Indicates a hillside site \\
\hline
\end{tabular}




\section{Table 3.5}

Correlation matrix showing Pearson's correlation coefficients for environmental variables. For code descriptions see Table 3.2. Significant correlation $(P \leq 0.05)$ is indicated by $*$.

\begin{tabular}{lccccccccc}
\hline & RD & WA & PS & pH & DI & AS & SL & EL & DW \\
\hline WA & $-0.15^{*}$ & & & & & & & & \\
PS & 0.05 & 0.09 & & & & & & & \\
pH & -0.07 & -0.09 & 0.05 & & & & & & \\
DI & $0.15^{*}$ & -0.01 & 0.03 & 0.10 & & & & & \\
AS & -0.10 & -0.12 & -0.03 & 0.03 & -0.03 & & & & \\
SL & 0.01 & -0.03 & $-0.20^{*}$ & $0.15^{*}$ & $-0.14^{*}$ & 0.08 & & & \\
EL & $0.18^{*}$ & 0.21 & -0.11 & $0.14^{*}$ & -0.01 & -0.09 & $0.37^{*}$ & & \\
DW & 0.12 & $-0.38^{*}$ & $-0.18^{*}$ & 0.06 & $0.16^{*}$ & $0.15^{*}$ & 0.06 & $-0.14^{*}$ & \\
DH & 0.00 & -0.02 & -0.06 & 0.06 & -0.09 & 0.01 & $0.55^{*}$ & $0.19^{*}$ & $-0.18^{*}$ \\
\hline
\end{tabular}




\section{Table 3.6}

Results (mean \pm standard deviation and significance) of analyses testing differences between plots with earthworm signs $(\mathrm{N}=135)$ and plots without $(\mathrm{N}=100)$. Significant difference $(P \leq 0.05)$ is indicated by *.

\begin{tabular}{lccc}
\hline & \multicolumn{2}{c}{ Earthworm Signs } & \\
\cline { 2 - 3 } Variable & \multicolumn{1}{c}{ Present } & Absent & P-Value \\
\hline Road Proximity & $481.0( \pm 475.0)$ & $474.4( \pm 488.4)$ & 0.86 \\
Water Proximity & $322.4( \pm 247.8)$ & $269.1( \pm 216.8)$ & 0.11 \\
Preferred Species & $12.3( \pm 9.3)$ & $8.9( \pm 8.6)$ & $<0.01 *$ \\
Soil pH & $4.05( \pm 0.57)$ & $3.86( \pm 0.58)$ & $0.01 *$ \\
Drainage Index & $37.0( \pm 18.3)$ & $36.9( \pm 18.4)$ & 0.78 \\
Aspect & $70.2( \pm 49.7)$ & $82.7( \pm 52.0)$ & 0.06 \\
Slope & $6.2( \pm 6.7)$ & $6.7( \pm 8.1)$ & 0.48 \\
Elevation & $821.6( \pm 178.5)$ & $793.8( \pm 178.0)$ & 0.07 \\
Position & - & - & 0.08 \\
Curvature & - & - & 0.81 \\
Drainage-Wet & - & - & 0.25 \\
Drainage-Hillside & - & - & 0.37 \\
\hline
\end{tabular}




\section{Table 3.7}

Summary statistics (coefficients, significance, and odds ratios) for the logistic regression model analyzing presence of earthworm signs.

\begin{tabular}{lccc}
\hline Predictor & Coefficient & $\boldsymbol{P}$-Value & Odds Ratio \\
\hline Constant & -2.48 & 0.01 & \\
Preferred Species & 0.04 & $<0.01$ & 1.04 \\
Soil pH & 0.59 & 0.02 & 1.80 \\
& & & \\
& $\boldsymbol{\chi}^{\mathbf{2}}$ & $\boldsymbol{d f}$ & $\boldsymbol{P}$-Value \\
Likelihood Ratio Test & 14.39 & 2 & $<0.001$ \\
\hline
\end{tabular}




\section{Table 3.8}

Results (mean \pm standard deviation and significance) of analyses testing differences in environmental variables between plots with middens present $(\mathrm{N}=47)$ and plots without middens $(\mathrm{N}=188)$. Significant difference $(P \leq 0.05)$ is indicated by *.

\begin{tabular}{|c|c|c|c|}
\hline \multirow[b]{2}{*}{ Variable } & \multicolumn{2}{|c|}{ Middens } & \multirow[b]{2}{*}{$P$-Value } \\
\hline & Present & Absent & \\
\hline Road Proximity & $237.7( \pm 262.9)$ & $538.3( \pm 502.8)$ & $<0.001 *$ \\
\hline Water Proximity & $346.6( \pm 247.7)$ & $288.0( \pm 232.3)$ & 0.13 \\
\hline Preferred Species & $14.2( \pm 9.4)$ & $10.0( \pm 8.9)$ & $<0.01 *$ \\
\hline Soil pH & $4.25( \pm 0.58)$ & $3.90( \pm 0.56)$ & $<0.001 *$ \\
\hline Drainage Index & $36.5( \pm 18.4)$ & $36.6( \pm 18.2)$ & 0.97 \\
\hline Aspect & $81.0( \pm 48.6)$ & $74.1( \pm 51.5)$ & 0.31 \\
\hline Slope & $6.3( \pm 6.6)$ & $6.4( \pm 7.5)$ & 0.69 \\
\hline Elevation & $810.1( \pm 109.7)$ & $809.7( \pm 192.0)$ & 0.08 \\
\hline Position & - & - & 0.34 \\
\hline Curvature & - & - & 0.36 \\
\hline Drainage-Wet & - & - & $<0.01 *$ \\
\hline Drainage-Hillside & - & - & 0.38 \\
\hline
\end{tabular}




\section{Table 3.9}

Summary statistics (coefficients, significance, and odds ratios) for the logistic regression model analyzing presence of middens.

\begin{tabular}{lccc}
\hline Predictor & Coefficient & $\boldsymbol{P}$-Value & Odds Ratio \\
\hline Constant & -5.04 & $<0.001$ & \\
Road Proximity & -0.09 & $<0.001$ & 0.92 \\
Preferred Species & 0.04 & 0.03 & 1.04 \\
Soil pH & 1.18 & $<0.001$ & 3.26 \\
Drainage-Wet & -1.27 & 0.02 & 0.28 \\
& & & \\
& $\boldsymbol{\chi}^{\mathbf{2}}$ & $\boldsymbol{d f}$ & $\boldsymbol{P}$-Value \\
Likelihood Ratio Test & 45.70 & 4 & $<0.001$ \\
\hline
\end{tabular}




\section{Table 3.10}

Results of linear regression analyses testing relationships between environmental variables and midden abundance. Analyses were performed for all plots $(\mathrm{N}=235)$ and then for only those plots with middens present (non-zero plots, $N=47$ ). Significant difference $(P \leq 0.05)$ is indicated by $*$. $\mathrm{R}^{2}$ values are reported for significant variables.

\begin{tabular}{lcccc} 
& \multicolumn{2}{c}{ All Plots } & & Non-Zero Plots \\
\cline { 2 - 3 } Variable & $\boldsymbol{P}$-Value & $\mathbf{R}^{\mathbf{2}}$ & & $\boldsymbol{P}$-Value \\
\hline Road Proximity & $0.001 *$ & 0.07 & & 0.18 \\
Water Proximity & 0.41 & - & & 0.46 \\
Preferred Species & $<0.01 *$ & 0.04 & \\
Soil pH & $<0.001 *$ & 0.05 & & 0.13 \\
Drainage Index & 0.56 & - & 0.66 \\
Aspect & 0.10 & - & 0.29 \\
Slope & 0.61 & - & 0.06 \\
Elevation & 0.71 & - & 0.38 \\
Position & 0.39 & - & 0.27 \\
Curvature & 0.55 & - & 0.18 \\
Drainage-Wet & $0.02 *$ & 0.02 & 0.75 \\
Drainage-Hillside & 0.14 & - & 0.81 \\
\hline
\end{tabular}




\section{Table 3.11}

Results (Moran's Index, significance and pattern) of tests for spatial autocorrelation in significant environmental variables. Significant spatial autocorrelation $(P \leq 0.05)$ is indicated by *.

\begin{tabular}{lcccc}
\hline Variable & Moran's Index & Z Score & $\boldsymbol{P}$-Value & Pattern \\
\hline Road Proximity & 0.68 & 12.15 & $<0.01 *$ & Clustered \\
Preferred Species & 0.26 & 4.72 & $<0.01 *$ & Clustered \\
Soil pH & 0.21 & 3.73 & $<0.01 *$ & Clustered \\
Drainage-Wet & 0.14 & 2.57 & $0.01 *$ & Clustered \\
\hline
\end{tabular}


Table 3.12

Results (sample size, mean \pm standard deviation and significance) of analyses of forest floor condition in relation to the presence and absence of earthworm signs and middens. Significant difference $(P \leq 0.05)$ is indicated by *.

\begin{tabular}{lccc}
\hline Condition & Sample Size & Forest Floor Rank & $P$-Value \\
\hline Absent & 100 & $4.98( \pm 0.12)$ & $<0.001 *$ \\
Earthworm Signs & 88 & $3.76( \pm 0.46)$ & $<0.001^{*}$ \\
Middens & 47 & $1.63( \pm 0.69)$ & $<0.001^{*}$ \\
\hline
\end{tabular}




\section{Table 3.13}

Average midden abundance (mean \pm standard deviation) at each forest floor rating, and analysis of variance table comparing midden abundance among ratings. Forest floors were rated from 1-lowest quality to 5-highest quality (Table 3.3). Significant difference $(P \leq 0.05)$ is indicated by *.

\begin{tabular}{|c|c|c|c|c|c|}
\hline Forest Floor Rating & \multicolumn{2}{|c|}{ Middens } & & & \\
\hline 1 & \multicolumn{2}{|c|}{$3.8( \pm 1.2)$} & & & \\
\hline 2 & \multicolumn{2}{|c|}{$1.7( \pm 1.1)$} & & & \\
\hline 3 & \multicolumn{2}{|c|}{$0.1( \pm 0.3)$} & & & \\
\hline 4 & \multicolumn{2}{|c|}{$0.003( \pm 0.03)$} & & & \\
\hline \multirow[t]{2}{*}{5} & \multicolumn{2}{|c|}{0} & & & \\
\hline & $d f$ & SS & MSE & F Statistic & $P$-Value \\
\hline Forest Floor Rating & 4 & 311.50 & 77.88 & 300.93 & $<0.001 *$ \\
\hline Residuals & 230 & 59.52 & 0.26 & & \\
\hline
\end{tabular}




\section{Chapter 4. Invasion Patterns of Exotic Earthworms in Forest Ecosystems across the Upper Great Lakes Region}

\subsection{Introduction}

The term ecosystem can be defined as "a spatially explicit, relatively homogenous unit of the earth that includes all interacting organisms and components of the abiotic environment within its boundaries" (Helms 1998). The protection of interconnected components of ecosystems, both biotic and abiotic, is key to maintaining ecosystem function. Exotic species currently threaten the health and persistence of many natural ecosystems and their individual components. The presence of exotic earthworms in forests of the Upper Great Lakes region, for example, has been linked to decreased plant species richness, changes in plant community composition, altered forest floor and soil conditions, shifts in nutrient cycling, and potential indirect impacts to wildlife and other ecosystem components (Alban and Berry 1994; Bohlen et al. 2004c; Holdsworth et al. 2007a). An improved understanding of the invasion patterns, potential impacts, and cascading effects of exotic species, such as earthworms, is necessary to manage, protect, and restore ecosystems and the services they provide.

Ecosystems are characterized within a hierarchical framework in which higherlevel drivers regulate the ecological structure and function at successively lower levels (Turner et al. 2001; Bailey 2009). Landscape level patterns and attributes, as quantified by landscape metrics, may influence ecosystem processes and act as ecosystem drivers. Landscape metrics are often used as a tool to help land managers make informed decisions regarding the management and restoration of natural landscape features (Forman and Godron 1986). Landscape patterns associated with human activity (e.g., road, urban, and agricultural development) can be particularly important in promoting the introduction and spread of invasive species (Lodge and Shrader-Frechette 2003; Shartell et al. 2011). There is evidence that the dispersal of exotic earthworms is closely associated with human activity (Cameron et al. 2007). Increased presence of anthropogenic habitats and specific patterns of their distribution may be driving earthworm invasion or promoting individual species at differing rates, affecting community composition and ultimately invasion severity and impact. It is also true, however, that lower-level environmental characteristics of forests (e.g., overstory species composition, basal area, soil type) also influence susceptibility to, and suitability for, invasion by exotic earthworms. In the Upper Great Lakes region, studies have been completed that describe the impact of exotic earthworms on forest ecosystems, with most published studies having been conducted in communities dominated by deciduous tree species (Bohlen et al. 2004a; Hale et al. 2005; Frelich et al. 2006). However, how landscape scale patterns, in combination with specific forest and soil characteristics, control earthworm abundance and community composition has not been fully addressed.

In general and as a whole, exotic earthworms in the Upper Great Lakes region tend to have similar long-term effects on invaded ecosystems, however, the target, mode 
of action, and degree of their impact can vary by functional group (Bouché 1977). Epigeic (litter and surface dwelling) species feed on microorganisms, organic matter, and/or relatively fresh plant litter on the surface or in the top layers of the organic horizon. They live and burrow within the organic horizon and top portion of the mineral soil. Their feeding and burrowing activity can cause alteration of the forest floor and soil structure through the breakdown of litter and organic matter and the mixing of the organic and soil horizons (Edwards and Bohlen 1996). Endogeic (soil dwelling) species feed on soil organic matter and create horizontal, non-permanent burrows within the mineral soil. These actions disrupt fungal communities and alter soil nutrient cycling, which can have cascading ecosystem effects, such as decreased native plant productivity (Bohlen et al. 2004c). Epi-endogeic species feed in the litter layer and organic horizon, but live mainly in the mineral soil. Finally, anecic (deep burrowing) species form deep, permanent burrows and feed on surface litter. The permanent burrows can be identified by the presence of a midden, a mound of residual plant material and earthworm castings with a central plug composed of leaf litter. Anecic species transport organic material into the mineral soil contributing to mixing of these layers and alter soil structure by increasing porosity, which can increase nutrient leaching (Subler et al. 1997). Large populations of the anecic species Lumbricus terrestris (L.), commonly known as the night crawler, can remove the forest floor completely each season (Hale et al. 2005). Litter feeding epi-endogeic and anecic species contribute most to changes seen in the forest floor litter layer and understory community, while endogeic and epigeic species exhibit less influence (Frelich et al. 2006). A high diversity of earthworm species and functional groups, however, tends to result in increased site alteration and impact. For example, Hopfensperger et al. (2011) found that high earthworm species diversity was linked to decreases in understory plant species cover and diversity. Earthworms may also facilitate invasion by exotic plant species. One example is the co-facilitation of L. terrestris and European buckthorn (Rhamnus cathartica), in which earthworms create opportunities for buckthorn invasion by decreasing native understory cover and buckthorn provides highquality litter to support and increase the earthworm population (Heneghan et al. 2007; Heimpel et al. 2010).

The objective of this research was to examine patterns of earthworm distribution, abundance, and community composition to deduce potential higher-level drivers and constraints of earthworm invasion and identify specific lower-level environmental correlates. In addition, the impact of earthworms was examined to determine observable effects (e.g., forest floor and understory alteration) and identify potential differences in impact related to earthworm community composition. Thus three main hypotheses are presented: 1) earthworm impact will be most pronounced in sites with high earthworm biomass and presence of epi-endogeic and anecic species, 2) stand level environmental variables related to earthworm habitat suitability and dispersal opportunity will be correlated with earthworm biomass and community composition, and 3) landscape level patterns dominated by anthropogenic cover types will promote increased earthworm biomass and diversity. 
Earthworm abundance and community composition, particularly the presence of high impact species, should drive changes in forest floor condition, litter depth, understory cover, and invasive exotic plant presence. Earthworm abundance and community composition, however, should be driven by environmental variables. These variables can be either static, having a consistent effect across varying stages of invasion (e.g., habitat suitability), or dynamic, having varying effects across stages of invasion (e.g., dispersal opportunities). Those forests consisting of earthworm preferred tree species (i.e., stands comprised of species of basswood, maple, and associates), with favorable soil conditions, in close proximity to roads or agricultural fields should have the greatest earthworm abundance and diversity. At a larger scale, natural landscape patterns (e.g., high natural patch richness, high Shannon's diversity, large mean patch area, high largest patch index, and high landscape shape index) should translate to lower earthworm biomass and less diverse earthworm communities, while anthropogenic land cover patterns (e.g., high percent anthropogenic cover, large mean patch area of anthropogenic cover, high largest patch index for anthropogenic cover, and low landscape shape index ) should promote earthworm invasion. Addressing these hypotheses is important as the findings will improve our understanding of the invasion patterns, habitat preferences, and impacts of exotic earthworms, which in turn will drive forest management decisions to mitigate negative impacts and sustain ecosystem health.

\subsection{Study Sites}

The study sites consisted of six National Wildlife Refuges located within the Laurentian Mixed Forest-Great Lakes Biological Network (GLBN) of the U.S. Department of the Interior Fish and Wildlife Service National Wildlife Refuge System (Figure 4.1). Specifically, sampling was done at most of the larger, non-island refuges of the GLBN: Tamarac, Rice Lake, Shiawassee, Seney, Horicon, and Ottawa. Sampling occurred within forest Rapid Ecological Assessment (REA) monitoring plots established within refuges concurrent to this study (Petrillo and Corace 2011). Among refuges, considerable variation is found in existing and historic land cover and landscape patterns (Corace et al. 2012). Tamarac National Wildlife Refuge (NWR) encompasses 17,770 ha in northwestern Minnesota and is dominated by deciduous forests, with $66 \%$ of the refuge being forested (i.e., deciduous forest, evergreen forest, mixed forest, or woody wetlands from 2006 National Land Cover Data, USGS 2011). Rice Lake NWR (7,316 ha in northeast Minnesota) and Shiawassee NWR (3,882 ha in Michigan's Lower Peninsula) are both dominated by woody wetlands. Forests at these refuges make up $51 \%$ of the land at Rice Lake and 53\% at Shiawassee. The largest refuge in the study, Seney NWR, covers 38,626 ha in Michigan's Upper Peninsula. Seney is dominated by a mix of woody and emergent herbaceous wetlands, with $57 \%$ of the refuge being forested. Horicon NWR covers 8,849 ha in southeast Wisconsin and Ottawa NWR (including Cedar Point NWR) covers 3,480 ha in northeast Ohio. Both these refuges are dominated by emergent herbaceous wetlands. Horicon and Ottawa have limited forested land of $11 \%$ and $<1 \%$ respectively. 


\subsection{Methods}

Earthworm populations and related measures were sampled within REA plots where forest composition, structure, and health were quantified and assessed using methods similar to the U.S. Department of Agriculture Forest Service Forest Inventory and Assessment Program (Bechtold and Patterson 2005; Petrillo and Corace 2011). The REA plots were established within forest stands selected by refuge staff as management and/or monitoring priorities for each refuge. Stand selection also reflected the variability of forest types across each refuge, and as such was not thought to be biased by the selection methods. Within stands, transects were established to minimize edge effect, maximize length, and provide efficient sampling. Plots were established a minimum of $20 \mathrm{~m}$ apart along each transect, with transect length being dependent upon stand size. A 1/100-hectare circular plot was established around the center point, with three transects running from plot center to plot edge at 0,135 , and 225 degrees, and one $1 \mathrm{~m}^{2}$ quadrat subplot placed along each transect (Figure 4.2). Distance from center point to subplot edge was staggered along the three transects with subplots at $1 \mathrm{~m}, 2 \mathrm{~m}$, and $4 \mathrm{~m}$. Within the REA plots forest composition, structure, and health were quantified, as well as understory cover, coarse woody debris, and invasive exotic plant presence (Petrillo and Corace 2011). From these data four metrics were identified as potential correlates with earthworm communities (total basal area, number of overstory species, percent canopy cover, and presence of coarse woody debris), and two additional variables were created based on the forest composition data (basal area of earthworm preferred species and percent of basal area composed of coniferous species).

Within the three REA subplots, earthworm community and impact were sampled. The forest floor was characterized by rating the condition on a scale of 1-lowest quality (most altered) to 5-highest quality (minimally altered, see Table 3.1) and by measuring the litter depth $(\mathrm{cm})$. Earthworm species composition and abundance were quantified using the mustard extraction method (Gunn 1992; Lawrence and Bowers 2002) within an area of $0.11 \mathrm{~m}^{2}(33 \mathrm{~cm}$ by $33 \mathrm{~cm})$. Before sampling earthworms, the surface litter was cleared and any earthworms encountered in the litter or on the surface were collected. During clearing, the number of middens present was also recorded to confirm and supplement $L$. terrestris presence and abundance data. Midden counts were used to supplement biomass of $L$. terrestris in cases where middens occurred without the collection of $L$. terrestris individuals. The mustard solution was premade by mixing water and ground yellow mustard (Sinapis alba) powder at a ratio of $10 \mathrm{~g}$ per L of water. A box was built and used to contain the mustard solution and keep the sampling area consistent. The amount of mustard solution applied varied depending on soil moisture and drainage speed, however no more than $3.8 \mathrm{~L}$ of solution was used in the $0.11 \mathrm{~m}^{2}$ area. All earthworms that emerged within five minutes were collected and preserved in $70 \%$ isopropyl alcohol. Earthworms were identified to genus or species (when possible) and measured within 24 hours of collection. Earthworm biomass was calculated as ash-free dry mass (AFDg) using earthworm lengths and allometric equations developed by Hale et al. (2004). Soil cores approximately $27 \mathrm{~cm}$ deep were taken at each subplot for assessment of soil properties related to earthworm presence. Soils were dried to a 
constant weight at $105^{\circ} \mathrm{C}$ (a minimum of 48 hours, maximum of 72 hours in the oven), and then ground and sieved using a $2 \mathrm{~mm}$ (\#10 mesh) sieve. Rocks and roots $>2 \mathrm{~mm}$ were discarded. Soil $\mathrm{pH}$ was measured using a $\mathrm{pH}$ meter and $15 \mathrm{~g}$ of sieved soil mixed with $15 \mathrm{ml}$ of deionized water. Organic matter content was determined by loss on ignition (LOI) over 4 hours at $500^{\circ} \mathrm{C}$.

Eleven environmental variables were selected based on our present understanding of earthworm invasion patterns for comparison to earthworm abundance and community composition (Table 4.1). In addition to the six REA variables and two soil variables, three variables related to anthropogenic activity were created. Spatial data provided by the refuges were used to calculate road proximity and agricultural proximity, and National Land Cover data was used to calculate the percent anthropogenic cover within a $500 \mathrm{~m}$ buffer surrounding each transect. In addition, forest floor condition, litter depth, herbaceous understory cover, woody understory cover, and invasive exotic plant presence were designated as variables dependent upon earthworm invasion. As such, they were assessed as potential correlates of earthworm abundance. Plot level measurements were pooled and averaged by transect resulting in a total sample size of 64 transects, with each sample representing an individual forest stand at a given refuge. Additionally, trends in road or agriculture proximity among plots within transects were assessed. Earthworm species diversity was represented both by taxa and by functional group.

Landscape metrics were calculated for refuges and associated ecoregion(s) (Table 4.2, Cleland et al. 1997). The 2006 National Land Cover Dataset (NLCD, USGS 2011) was used to characterize the landscape, and metrics were calculated for refuges and ecoregions using these data. Previous studies have shown that National Wildlife Refuges are two to five times the size of their largest patch (Corace et al. 2012) and thus landscape metric calculation is not biased by the non-natural political boundaries of the refuges (O’Neill et al. 1996). The spatial analysis program FRAGSTATS (McGarigal et al. 2002) was used to calculate landscape metrics (Table 4.3). To avoid including redundant metrics, those metrics that were highly correlated to others were excluded. For example, because patch density and mean patch area were highly correlated, only one of these two variables, in this case mean patch area, was selected for analysis. Rather than using standard patch richness (the total number of land cover types present), a natural patch richness was calculated by taking the ratio of number of natural land cover types to number of anthropogenic land cover types for only those cover types occupying at least $1 \%$ of the refuge or ecoregion. This provided better valuation of the degree of natural land cover at a given refuge. Six NLCD land cover types were considered to be anthropogenic land covers: 1) developed open space, 2) developed low intensity, 3) developed medium intensity, 4) developed high intensity, 5) hay-pasture, and 6) cultivated crops. Landscape metrics were also calculated specifically for anthropogenic cover types within refuges and ecoregions. To allow evaluations of the influence of landscape patterns, earthworm plot data were pooled and averaged first by transect and then by refuge, yielding a sample size of six (one sample per refuge). 
Statistical analyses, except where noted below, were performed using R ( R Development Core Team 2011). Descriptive statistics were calculated for environmental variables. Pearson's correlation was used to test for significant correlations between environmental variables. Species richness, Shannon's diversity, and Shannon's equitability (evenness) of earthworm communities were calculated for each transect and for each refuge based on earthworm biomass within differing taxonomic groups. Analysis of variance (ANOVA) was used to test overall differences in total earthworm biomass among refuges, and multivariate analysis of variance (MANOVA) was used to test overall differences in community composition among refuges based on earthworm taxonomic and functional groups. Linear regression was used to compare landscape metrics and environmental variables to earthworm biomass. Stepwise regression based on Akaike information criterion (AIC) was used to select the best multivariate model. For all analyses, variables were assessed for normality and were transformed where necessary, in this case applying a square root transformation to road proximity and a log transformation to agriculture proximity. Canonical correspondence analysis (CCA) was performed in PC-ORD (McCune and Mefford 1999) using earthworm taxonomic group biomass data and environmental variables (excluding canopy cover due to a lack of data at Horicon). Before fitting the CCA model, road and agriculture proximity were transformed as above, and percent data were transformed by taking the arcsine square root. Environmental variables were then relativized by the maximum. Ordinations were plotted and significant variables were identified using a biplot vector cutoff value of 0.20 . For all statistical analyses, significance was determined at $\alpha \leq 0.05$.

\subsection{Results}

A total of 412 plots within 64 transects were sampled across the six refuges. Earthworms were present at all refuges in the study, and were found at $77 \%$ of the total plots and within $92 \%$ of the sampled stands (transects). Six European earthworm taxa and one lumped group were collected and identified during field sampling: Dendrobaena octaedra (Savigny), Dendrodrilus rubidus (Savigny), Eiseniella tetraedra (Savigny), Lumbricus rubellus (Hoffmeister), L. terrestris, a group consisting of Lumbricus juveniles, and Aporrectodea spp., which were not identified further due to morphological similarities. No native earthworm species were encountered at any of the sites. Individuals of Aporrectodea and L. rubellus were present at all refuges, however $D$. rubidus was present only at Horicon NWR and Rice Lake NWR, E. tetraedra was present only at Ottawa NWR and Shiawassee NWR, D. octaedra was absent from Ottawa, and $L$. terrestris was absent from Rice Lake. Earthworm species were assigned to the following functional groups: epigeic (D. octaedra, D. rubidus, E. tetraedra), epi-endogeic ( $L$. rubellus and Lumbricus juveniles), endogeic (Aporrectodea spp.), and anecic ( $L$. terrestris). Although the group Lumbricus juveniles likely contains individuals of $L$. terrestris, the juveniles usually live near the soil surface and feed on litter material, making them functionally more similar to epi-endogeic species (Asshoff et al. 2010). 
Earthworm biomass varied across each of the six refuges, with average biomass ranging from $0.40 \mathrm{AFDg} / \mathrm{m}^{2}$ at Seney NWR to $2.14 \mathrm{AFDg} / \mathrm{m}^{2}$ at Horicon NWR (Table 4.4, Figure 4.3). One way ANOVA revealed significant differences in earthworm biomass among refuges $\left(\mathrm{F}_{5,58}=3.76, P<0.01\right)$. Significant differences in pairwise comparisons were found between Seney and Horicon $(P<0.01)$ and Tamarac and Horicon $(P=0.05)$. Earthworm community diversity indices calculated for each stand varied among refuges (Table 4.4). Differences in both Shannon's diversity and Shannon's evenness among refuges were significant $\left(\mathrm{F}_{5,58}=4.75, P<0.01\right.$ and $\mathrm{F}_{5,58}=$ $4.27, P<0.01$ respectively). Individual pairwise comparisons between refuges indicated that Tamarac differed most often from the other refuges of study, having the lowest mean Shannon's diversity and lowest mean Shannon's evenness (Table 4.4). Within and among refuges, earthworm biomass differed by taxa and functional groups (Table 4.5). Differences in earthworm community composition were significant among all refuges as indicated by MANOVA by taxa $\left(\mathrm{F}_{35,221}=6.50\right.$, Wilks $\left.\lambda=0.05, P<0.001\right)$ and by functional group $\left(\mathrm{F}_{20,183}=10.17\right.$, Wilks $\left.\lambda=0.08, P<0.001\right)$. Pairwise comparisons indicated differences between refuges in some cases (Table 4.5). The dominant functional group varied among refuges with endogeic being dominant at Tamarac, anecic dominant at Horicon, and epi-endogeic dominant at the remaining four refuges (Figure 4.4).

\subsubsection{Earthworm Impact}

The impact of earthworms was represented by forest floor condition, litter depth, herbaceous understory cover, woody understory cover, and invasive exotic plant presence. A significant negative correlation was found between total earthworm biomass and forest floor condition $\left(P<0.001, \mathrm{R}^{2}=0.55\right)$, as well as between earthworm biomass and litter depth $\left(P<0.001, \mathrm{R}^{2}=0.21\right)$. Woody understory cover, herbaceous understory cover and invasive exotic plant presence did not show a significant relationship with earthworm biomass $(P=0.07, P=0.48$ and $P=0.20$ respectively).

Correlations between biomass and forest floor condition, litter depth, woody understory cover, and invasive exotic plant presence differed by earthworm functional groups (Table 4.6). Epi-endogeic, endogeic, and anecic earthworms were driving the relationship observed with forest floor condition, with only these functional groups showing a significant negative correlation where increased biomass resulted in lower quality, more altered forest floors $(P<0.001$ for all). Epi-endogeic and anecic biomass showed significant negative correlations $(P<0.001$ for both) with litter depth, while epigeic biomass showed a positive correlation with litter depth $(P=0.02)$. Woody understory cover was negatively correlated with epi-endogeic biomass $(P<0.001)$, and positively correlated with epigeic biomass $(P=0.04)$. Invasive exotic plant presence showed a significant positive correlation with epi-endogeic biomass $(P<0.01)$. No individual functional group showed correlations with herbaceous understory cover. 


\subsubsection{Stand Level Effects}

Significant correlations between variables were found for 15 of the 55 possible environmental variable pairs (Table 4.7). Of these, the most significant were positive correlations between loss on ignition (organic matter content) and soil $\mathrm{pH}$ and loss on ignition and anthropogenic cover, all other correlation coefficients remained below 0.40 . Of the eleven independent environmental variables, (Table 4.1, Appendix B) five were found to be significant predictors of earthworm biomass within stands (Table 4.8). A significant positive correlation was found between total earthworm biomass and increasing (more alkaline) soil $\mathrm{pH}(P<0.01)$, soil loss on ignition $(P<0.01)$, basal area of preferred species $(P=0.02)$, and percent anthropogenic cover $(P=0.01)$. A significant negative correlation was found between earthworm biomass and conifer dominance $(P<0.01)$, suggesting the unsuitable nature of conifer stands for many earthworms. Using stepwise multivariate regression based on AIC, the best significant model included the variables conifer dominance, anthropogenic cover, and basal area (for all species $)$ to predict earthworm biomass $\left(\mathrm{F}_{3,60}=6.39, P<0.001, \mathrm{AIC}=190.80\right.$, Table 4.9).

Canonical correspondence analysis (CCA) was conducted using earthworm taxa and 10 environmental variables (canopy cover was not included due to missing data at Horicon). The first axis of the CCA ordination explained $15 \%$ of the variance in earthworm community composition (Table 4.10). This axis was most strongly correlated with soil $\mathrm{pH}$, and represented a gradient from high $\mathrm{pH}$, high organic matter (loss on ignition), high anthropogenic cover, low or no conifer dominance on the left to low soil $\mathrm{pH}$, low organic matter, low anthropogenic cover, high conifer dominance on the right (Figure 4.5). Axis two explained an additional $6 \%$ of the variance, and was most closely correlated with overstory tree species and distance to agriculture (Table 4.10). This axis represented a gradient from high number of overstory species, close proximity to agriculture, high basal area of preferred species at the top of the graph to fewer overstory species, more distant from agriculture and low basal area of preferred species at the bottom (Figure 4.5). The locations of earthworm species within the biplot indicated the environmental conditions with which they are most associated. For example, Dendrobaena octaedra was associated with low $\mathrm{pH}$, low organic matter, low anthropogenic cover, and high conifer dominance sites, while Lumbricus spp. were associated with the opposite. A lack of earthworms was strongly associated with sites distant from agriculture with low basal area of preferred species and relatively high conifer dominance.

\subsubsection{Landscape Level Effects}

In assessing total earthworm biomass relative to landscape metrics (Appendix A), univariate linear regression indicated only one significant environmental variable (Tables 4.11 and Table 4.12). Earthworm biomass showed a positive correlation with refuge mean patch area for anthropogenic cover $\left(P=0.03, \mathrm{R}^{2}=0.74\right.$, Figure 4.6$)$. Biomasses of 
the earthworm functional groups were also compared to landscape metrics (Tables 4.13 and 4.14). Endogeic biomass had one significant environmental variable, a positive correlation with ecoregion Shannon's diversity index $\left(P=0.05, \mathrm{R}^{2}=0.66\right)$. For epiendogeic biomass, positive correlations were found with refuge largest patch index for anthropogenic cover $\left(P<0.01, \mathrm{R}^{2}=0.92\right)$, mean patch area for anthropogenic cover $(P=$ $\left.0.04, \mathrm{R}^{2}=0.69\right)$, and percent anthropogenic cover across the refuge $\left(P<0.01, \mathrm{R}^{2}=0.89\right)$. No significant relationships were found for epigeic or anecic biomass.

Landscape metrics were also compared to overall refuge earthworm community diversity (Shannon's diversity index) to identify any significant correlations (Tables 4.15 and 4.16). Significant negative correlations were found between earthworm community diversity and ecoregion largest patch index for anthropogenic cover $\left(P<0.01, \mathrm{R}^{2}=0.88\right)$ and percent anthropogenic cover across the ecoregion $\left(P<0.01, \mathrm{R}^{2}=0.89\right)$. A significant positive correlation was found with natural patch richness $\left(P<0.01, \mathrm{R}^{2}=\right.$ 0.94).

\subsection{Discussion}

Unlike past studies of patterns of exotic earthworm invasion in the Upper Great Lakes region (Gundale et al. 2005; Holdsworth et al. 2007b), this study involved analysis of potential constraints to earthworm distribution and community composition across a larger geographic area (spanning multiple ecoregions) and a greater range of forest and ecosystem types. Although European earthworms were encountered at all refuges, they were not encountered at all transects. Moreover, we found overall biomass and community composition differed among refuges, suggesting geographic or ecosystem variability in earthworm distribution and community patterns. In fact, it is proposed that patterns of earthworm distribution and abundance indicate that earthworm invasion into some refuges and specific forests is not yet complete, and thus stage of invasion is varied across refuges and forests.

The findings also suggest that earthworm invasion patterns may be constrained by broader ecological patterns of land cover and inferred land use. For instance, Seney NWR, the refuge (and associated ecoregion) least influenced by anthropogenic land cover types (covering only $2 \%$ of the refuge and $4 \%$ of the ecoregion), had the lowest mean earthworm biomass and earthworms present at $64 \%$ of plots visited. A similar association was seen at Tamarac NWR, which had low earthworm biomass, little anthropogenic cover within the refuge (2\%), and earthworms present at $53 \%$ of plots. Conversely, the highest earthworm biomass was encountered at Horicon NWR where $98 \%$ of plots had earthworms present and much of the ecoregion $(75 \%)$ is comprised of anthropogenic cover types. Shiawassee NWR also had high earthworm biomass and accordingly had earthworms present at $100 \%$ of plots and considerably more ecoregional anthropogenic land cover (73\%) than either Seney or Tamarac. The low earthworm biomass encountered at Ottawa was unexpected, but may be related to flooding and standing water conditions (and saturated soils) that occurred in the spring before 
earthworm sampling took place. This result may have contributed to the lack of correlation with refuge total area, and perhaps other landscape metrics and environmental variables, in relation to earthworm biomass, despite its probable importance at Seney and Tamarac, the two largest refuges in area. Other explanations for these earthworm patterns include the fact that Seney and Tamarac were more conifer-dominated refuges, which corresponds to lower soil $\mathrm{pH}$ and coarser textured soils, which could together with the large area contribute to a lower earthworm biomass due to limited or slowed immigration from outside the refuge. Rice Lake NWR, which had relatively low amounts of anthropogenic cover within the refuge and surrounding ecoregion, had higher earthworm biomass than Seney, Tamarac, or Ottawa but lacked L. terrestris. This may indicate that this refuge in general contains forests that are capable of supporting larger earthworm populations, but that earthworm introduction and community composition at Rice Lake is slowed or limited by the lack of anthropogenic cover.

The earthworm community composition patterns observed agree with the theory that earthworm invasion proceeds in waves, beginning with epigeic earthworm species and ending with increasing populations of L. terrestris (Hale et al. 2005). Horicon, the refuge with the overall greatest average earthworm biomass, also had the highest biomass of $L$. terrestris, which made up $56 \%$ of the total refuge earthworm biomass (not including Lumbricus juveniles). In addition, Horicon had low biomass of D. octaedra (less than $1 \%$ of the average biomass), thought to be the first invader. In contrast, Seney had only $2 \%$ of its average earthworm biomass in L. terrestris. These findings may indicate that Seney is in the early stage of colonization, while Horicon is in a later stage. Similar trends were seen at Shiawassee, where $16 \%$ of the total earthworm biomass was $L$. terrestris and less than $1 \%$ was D. octaedra. The observations also support the notion that the importance of environmental variables differs in relation to stage of invasion and that variables can be either dynamic (having varying effects dependent upon stage) or static (having consistent effects among stages). It was evident at Horicon that while few coniferous species were present, stands dominated by oak (Quercus spp.), which also has low palatability for earthworms, had the lowest earthworm biomasses, particularly of $L$. terrestris. This suggests that earthworms at Horicon are limited by static forest characteristics, rather than by dynamic factors that could indicate an earlier stage of invasion. Rice Lake, which lacked L. terrestris, had the highest biomass of D. octaedra, and tended to have high earthworm biomass at those sites in closest proximity to roads. This supports two theories, first that D. octaedra invasion precedes L. terrestris, and second that at the introduction stage, earthworm presence and abundance is strongly related to dynamic variables such as anthropogenic dispersal mechanisms, in this case roads.

Tamarac, despite having low overall biomass, had some stands with high densities of L. terrestris, which made up $28 \%$ of the total refuge biomass. Looking among transects within Tamarac, it appeared that each forest stand differed in stage of invasion, and thus in the importance of variables. For example, three transects at Tamarac were similar deciduous-dominated forest stands with high basal area of preferred species. Two of these transects had high earthworm biomass dominated by L. terrestris, while the other 
transect had no earthworms present. One difference in these stands was that those with earthworms present were immediately adjacent to roads, while the other was located within a large forested patch that was distanced from roads. Absent or low earthworm biomass in areas that would theoretically be highly suitable for earthworm invasion may indicate an early stage of invasion. This and other findings suggest that earthworm populations at Tamarac have not yet reached their full potential distribution across the refuge, but within the most accessible stands, have become well established. Thus the multivariate regression and canonical correspondence models presented include a combination of the most important dynamic and static environmental variables driving the current distribution of earthworms across the Upper Great Lakes region where stage of invasion varies. Of the eleven environmental variables assessed five were directly correlated with earthworm biomass (basal area of preferred species, conifer dominance, soil $\mathrm{pH}$, soil loss on ignition, and anthropogenic cover) and seven were strongly related to earthworm community composition (basal area of preferred species, conifer dominance, soil $\mathrm{pH}$, soil loss on ignition, anthropogenic cover, distance to agriculture, and overstory species). Of these, anthropogenic cover and distance to agriculture might be considered more dynamic variables that affect invasion most during the introduction stage. Thus the models presented may not represent the variables that would be most important in shaping the future or overall potential exotic earthworm distribution once well established in the Great Lakes region.

It was hypothesized that natural landscape patterns would translate to lower earthworm biomass and less diverse earthworm communities, while anthropogenic lands would promote earthworm invasion. Support for the hypothesis that anthropogenic lands would promote earthworm invasion was present in some cases though varied by earthworm functional group, yet there was little support that natural landscape patterns was associated with lower earthworm biomass. However, the low sample size $(\mathrm{N}=6)$ decreased the power of the analysis. Landscape metrics calculated for all cover types were not found to relate to earthworm biomass, except in the case of endogeic biomass which was positively correlated with Shannon's diversity. Anthropogenic cover types, however, revealed significant relationships in support of the hypothesis, such as the correlation of increased earthworm biomass with refuge mean patch area of anthropogenic cover. Epi-endogeic species (in this case L. rubellus and Lumbricus juveniles) were most closely associated with increased anthropogenic lands, specifically large patch area, high largest patch index, and high percent land cover within refuges. It should be consider, though, that anthropogenic lands, particularly agriculture, may be associated with higher quality sites that earthworms may prefer, such as those with higher $\mathrm{pH}$ and increased organic matter and nutrient levels. Contradictory to our hypothesis, the presence of anthropogenic lands in the surrounding ecoregion tended to decrease earthworm diversity. Specifically, earthworm community diversity decreased in relation to high largest patch index for anthropogenic cover and large percent anthropogenic cover in the ecoregion. Correspondingly, high natural patch richness within the ecoregion translated into more diverse earthworm communities. Thus it appears that earthworm community diversity is greatest in areas with a variety of natural land cover components rather than those areas that have been homogenized by anthropogenic lands. 
The first hypothesis presented was that earthworm impact, specifically altered forest floor condition, decreased litter depth, reduced understory cover, and increased presence of invasive exotic plants, would be most pronounced in sites with high earthworm biomass and presence of epi-endogeic and anecic species. Increased earthworm biomass was significantly correlated with lower quality forest floors, decreased litter depth, and reduced woody understory cover, and the effects did vary by earthworm functional group. The strong correlation found between forest floor condition and earthworm biomass further confirms the effectiveness of this rating system (see Chapter 3). It should be noted, however, that epigeic species biomass did not show a significant correlation with forest floor condition, emphasizing the low impact of this functional group. Decreased litter depth is one of the most often mentioned impacts of exotic earthworm invasion (e.g., Alban and Berry 1994; Frelich et al. 2006; Suarez et al. 2006). As hypothesized, epi-endogeic and anecic species were associated with decreased litter depth, while epigeic species showed a positive correlation with litter depth and endogeic species showed no correlation. This was expected since epigeic and endogeic species feed more commonly on microorganisms or organic matter in the mineral soil rather than on leaf litter. It is unlikely that epigeic species are promoting leaf litter accumulation, but probable that a lack of Lumbricus spp. promotes epigeic species, whether due to decreased competition or linked to an earlier stage of invasion. Like with leaf litter, woody understory cover was also positively correlated with epigeic earthworm biomass. Woody understory cover was significantly decreased, however, only in association with epi-endogeic species. The rapid alteration caused by the epi-endogeic $L$. rubellus might allow less time for native plant communities to adjust to changes as compared to the relatively slower alteration by the anecic $L$. terrestris (Frelich et al. 2006), which may be the case observed here. No significant associations were found with herbaceous understory cover, which others have found to decrease under increasing earthworm biomass, particularly of L. rubellus (Hale et al. 2006). Decreases or changes in woody and herbaceous understory cover in forests of this region can also result from other pressures such as invasion by exotic plant species (Stinson et al. 2006), harvesting techniques (Kraft et al. 2004), and herbivory by deer (Webster et al. 2005). In this study, however, invasive exotic plant presence was only noted and understory percent cover was not separated into native and exotic plant species, the first of which is expected to be diminished under increasing earthworm populations.

Though there was no trend among all earthworm taxa, invasive exotic plant presence was found to be positively correlated with epi-endogeic earthworm biomass. Other studies in forested ecosystems have shown that European earthworms are associated with the presence of invasive plant species, with each potentially cofacilitating the other (Nuzzo et al. 2009). Invasive plants have the ability to further change forest ecosystems by reducing biodiversity and altering structure and function in a multitude of ways, and may contribute to additional invasions. The presence of invasive exotic plants was not related to earthworm biomass as a whole in this study, however invasive exotic plant presence was found to be significantly related to Lumbricus juvenile biomass. It should be noted, though, that both Seney and Tamarac had no invasive exotic plants present in any of the sampled plots and low earthworm biomass. Whether the 
observed patterns of earthworms and exotic plants are linked or came about due to similar mechanisms is unknown. Nevertheless, the potential association between invasive exotic plants and earthworms should be considered for forest management. There has also been some evidence that removal of invasive plants may reduce earthworm biomass, and could potentially be used as a method for earthworm control (Madritch and Lindroth 2008).

Refuge managers are encouraged to restore wildlife habitat to historic conditions where and when possible (Schroeder et al. 2004; Meretsky et al. 2006). Despite there being few, if any, options for removing exotic earthworms from forests, management of forest ecosystems should take into consideration the short and long term effects that earthworms are expected to have on ecosystem patterns and processes. The 1997 Refuge Improvement Act stipulated that managers of National Wildlife Refuge System lands should, "where appropriate, restore and enhance healthy populations of fish, wildlife, and plants..." (Public Law 105-57), and the 2001 Biological Integrity Policy suggested favoring management practices based on natural ecological patterns and processes. Unfortunately, many refuges are far removed from their historic conditions (Scott et al. 2004), even in the more remote portions of the Upper Great Lakes region (Corace et al. 2012). Many refuges, for example, have incorporated agricultural cover types into their lands for wildlife forage or cover. This action may have aided the introduction and spread of earthworms. This suggests that managers should consider not only the effects of earthworms, but of associated patterns across the landscape. For instance, there may be benefits to converting old fields and wildlife forage areas on refuges to more native cover types. Along with changes in land use, other potential stressors, such as climate change (Griffith et al. 2009), should be expected to further exacerbate the impacts of earthworms and other exotic species in the future.

\subsection{Conclusions}

Exotic earthworm populations are indeed present within National Wildlife Refuges in the Upper Great Lakes region, and though similar species are present the earthworm communities vary among refuges. The results indicate that anthropogenic and agricultural lands promote the introduction of earthworms into forest ecosystems and that forest characteristics such as overstory composition, soil $\mathrm{pH}$, and soil organic matter influence the success of earthworm populations. This study also provides a baseline for earthworm invasion (e.g., abundance, community composition, impact, and stage of invasion) within the refuges of this region and will allow for better consideration of potential ecosystem alteration by earthworms in future management plans to restore and protect forest ecosystems in refuges. The discovery that earthworms are present in some forest stands but absent from others should encourage efforts to limit the movement of soil and equipment between sites or restrict the use of earthworms as fishing bait to reduce the potential for spread of earthworms. Moreover, the linkage (albeit tenuous at some refuges) between anthropogenic and agricultural covers and earthworm patterns suggests a potential benefit to reducing the dominance of these non-natural features on refuges and across the landscape. 


\section{Literature Cited}

Alban DH, Berry EC. 1994. Effects of earthworm invasion on morphology, carbon, and nitrogen of a forest soil. Applied Soil Ecology. 1:243-249.

Asshoff R, Scheu S, Eisenhauer N. 2010. Different earthworm ecological groups interactively impact seedling establishment. European Journal of Soil Biology. 14:330-334.

Bailey RG. 2009. Ecosystem Geography. 2nd ed. Springer, New York. 251 p.

Bechtold WA, Patterson PL. 2005. The enhanced forest inventory and analysis program: national sampling design and estimation procedures. USDA Forest Service Southern Research Station General Technical Report SRS-80. Asheville, NC.

Bohlen, PJ, Groffman PM, Fahey TJ, Fisk MC, Suarez E, Pelletier DM, Fahey RT. 2004a. Ecosystem consequences of exotic earthworm invasion of north temperate forests. Ecosystems. 7:1-12.

Bohlen PJ, Scheu S, Hale CM, McLean MA, Migge S, Groffman PM, Parkinson D. 2004c. Non-native invasive earthworms as agents of change in northern temperate forests. Frontiers in Ecology and the Environment. 2:427-435.

Bouché MB 1977. Strategies lombricienes. Soil organisms as components of ecosystems. In: Lohm U, Persson T, editors. Ecological Bulletins, Stockholm. p. 122-132.

Cameron EK, Bayne EM, Clapperton MJ. 2007. Human-facilitated invasion of exotic earthworms into northern boreal forests. Ecoscience. 14:482-490.

Cleland DT, Ayers RE, McNab WH, Jensen ME, Bailey RG, King T, Russell WE. 1997. National hierarchical framework of ecological units. In: Boyce MS and A Haney eds. Ecosystem management: applications for sustainable forest and wildlife resources. New Haven: Yale University Press.

Corace RG III, Shartell LM, Schulte LA, Brininger WL Jr., McDowell MKD, Kashian DM. 2012. An ecoregional context for forest management on National Wildlife Refuges of the Upper Midwest, USA. Journal of Environmental Management. 49:359-371.

Edwards CA, Bohlen PJ. 1996. Biology and Ecology of Earthworms. London, UK: Chapman \& Hall. 426 p.

Forman RTT, Godron M. 1986. Landscape Ecology. New York: Wiley \& Sons. 619 p. 
Frelich LE, Hale CM, Scheu S, Holdsworth AR, Heneghan L, Bohlen PJ, Reich PB. 2006. Earthworm invasion into previously earthworm-free temperate and boreal forests. Biological Invasions. 8:1235-1245.

Griffith B, Scott JM, Adamcik R, Ashe D, Czech B, Fischman R, Gonzalez P, Lawler J, McGuire AD, Pidgorna A. 2009. Climate change adaptation for the U.S. National Wildlife Refuge System. Environmental Management. 44:1043-1052.

Gundale MJ, Jolly WM, Deluca TH. 2005. Susceptibility of a northern hardwood forest to exotic earthworm invasion. Conservation Biology. 19:1075-1083.

Gunn A. 1992. The use of mustard to estimate earthworm populations. Pedobiologia. 36:65-67.

Hale CM, Frelich LE, Reich PB. 2004. Allometric equations for estimation of ash-free dry mass from length measurements for selected European earthworm species (Lumbricidae) in the western Great Lakes region. American Midland Naturalist. 15:179-185.

Hale CM, Frelich LE, Reich PB. 2005. Exotic European earthworm invasion dynamics in northern hardwood forests of Minnesota, USA. Ecological Applications. 15:848-860.

Hale CM, Frelich LE, Reich PB. 2006. Changes in hardwood forest understory plant communities in response to European earthworm invasions. Ecology. 87:1637-1649.

Heimpel GE, Frelich LE, Landis DA, Hopper KR, Hoelmer KA, Sezen Z, Asplen MK, Wu K. 2010. European buckthorn and Asian soybean aphid as components of an extensive invasional meltdown in North America. Biological Invasions. 12:29132931.

Helms JA, editor. 1998. The dictionary of forestry. Bethesda, MD: The Society of American Foresters. 210 p.

Heneghan L, Steffen J, Fagen K. 2007. Interactions of an introduced shrub and introduced earthworms in an Illinois urban woodland: impact on leaf litter decomposition. Pedobiologia. 50:543-551.

Holdsworth AR, Frelich LE, Reich PB. 2007a. Effects of earthworm invasion on plant species richness in northern hardwood forests. Conservation Biology. 21:997-1008.

Holdsworth AR, Frelich LE, Reich PB. 2007b. Regional extent of an ecosystem engineer: earthworm invasion in northern hardwood forests. Ecological Applications. 17:16661677. 
Hopfensperger KN, Leighton GM, Fahey TJ. 2011. Influence of invasive earthworms on above and belowground vegetation in a northern hardwood forest. American Midland Naturalist. 166:53-62.

Kraft LS, Crow TR, Buckley DS, Nauertz EA, Zasada JC. 2004. Effects of harvesting and deer browsing on attributes of understory plants in northern hardwood forests, Upper Michigan, USA. Forest Ecology and Management. 199:219-230.

Lawrence AP, Bowers MA. 2002. A test of the 'hot' mustard extraction method of sampling earthworms. Soil Biology and Biochemistry. 34:549-552.

Lodge DM, Shrader-Frechette K. 2003. Nonindigenous species: ecological explanation, environmental ethics, and public policy. Conservation Biology. 17:31-37.

Madritch, MD and RL Lindroth. 2008. Removal of invasive shrubs reduces exotic earthworm populations. Biological Invasions. 11:663-671.

McCune B, Mefford MJ. 1999. PC-ORD. Multivariate Analysis of Ecological Data. Version 5.0 Gleneden Beach, OR:MjM Software.

McGarigal K, Cushman SA, Neel MC, Ene E. 2002. FRAGSTATS: Spatial Pattern Analysis Program for Categorical Maps. Amherst MA: University of Massachusetts.

Meretsky VJ, Fischman RL, Karr JR, Ashe DA, Scott JM, Noss RF, Schroeder RL. 2006. New directions in conservation for the National Wildlife Refuge System. BioScience. 56:135-143.

Nuzzo VA, Maerz JC, Blossey B. 2009. Earthworm invasion as the driving force behind plant invasion and community change in northeastern American forests. Conservation Biology. 23:966-974.

O’Neill RV, Hunsaker CT, Timmins SP, Jackson BL, Jones KB, Riitters KH, Wickham JD. 1996. Scale problems in reporting landscape pattern at the regional scale. Landscape Ecology. 11:169-180.

Petrillo HA, Corace RG III. 2011. Rapid ecological assessment of forests in the Laurentian Mixed Forest-Great Lakes Coastal Biological Network, Midwest Region, National Wildlife Refuge System, US Fish \& Wildlife Service.

R Development Core Team. 2011. R: A language and environment for statistical computing. Vienna, Austria: R Foundation for Statistical Computing.

Schroeder RL, Holler JI, Taylor JP. 2004. Managing National Wildlife Refuges for historic and nonhistoric conditions: determining the role of the refuge in the ecosystem. Natural Resources Journal. 44:1185-1210. 
Scott JM, Loveland T, Gergely K, Strittholt J, Staus N. 2004. National Wildlife Refuge System:ecological context and integrity. Natural Resources Journal. 44:1041-1066.

Shartell LM, Nagel LM, Storer AJ. 2011. Multi-criteria risk model for garlic mustard (Alliaria petiolata) in Michigan's Upper Peninsula. American Midland Naturalist. 165:116-127.

Stinson KA, Campbell SA, Powell JR, Wolfe BE, Callaway RM, Thelen GC, Hallett SG, Prati D, Klironomos JN. 2006. Invasive plant suppresses the growth of native tree seedlings by disrupting belowground mutalisms. PLoS Biology. 4:727-731.

Suarez ER, Fahey TJ, Yavitt JB, Groffman PM, Bohlen PJ. 2006. Patterns of litter disappearance in a northern hardwood forest invaded by exotic earthworms. Ecological Applications. 16:154-165.

Subler S, Baranski CM, Edwards CA. 1997. Earthworm additions increased short-term nitrogen availability and leaching in two grain-crop agroecosystems. Soil Biology and Biochemistry. 29:413-421.

Turner MG, Gardner RH, O’Neill RV. 2001 Landscape ecology in theory and practice. New York: Springer. 401 p.

United States Geological Survey (USGS). 2011. National Land Cover Database 2006. Multi-Resolution Land Characteristics (MRLC) Consortium. (http://www.mrlc.gov/nlcd2006_update).

Webster CR, Jenkins MA, Rock JH. 2005. Long-term response of spring flora to chronic herbivory and deer exclusion in great Smoky Mountains National Park, USA.

Biological Conservation. 125:297-307. 


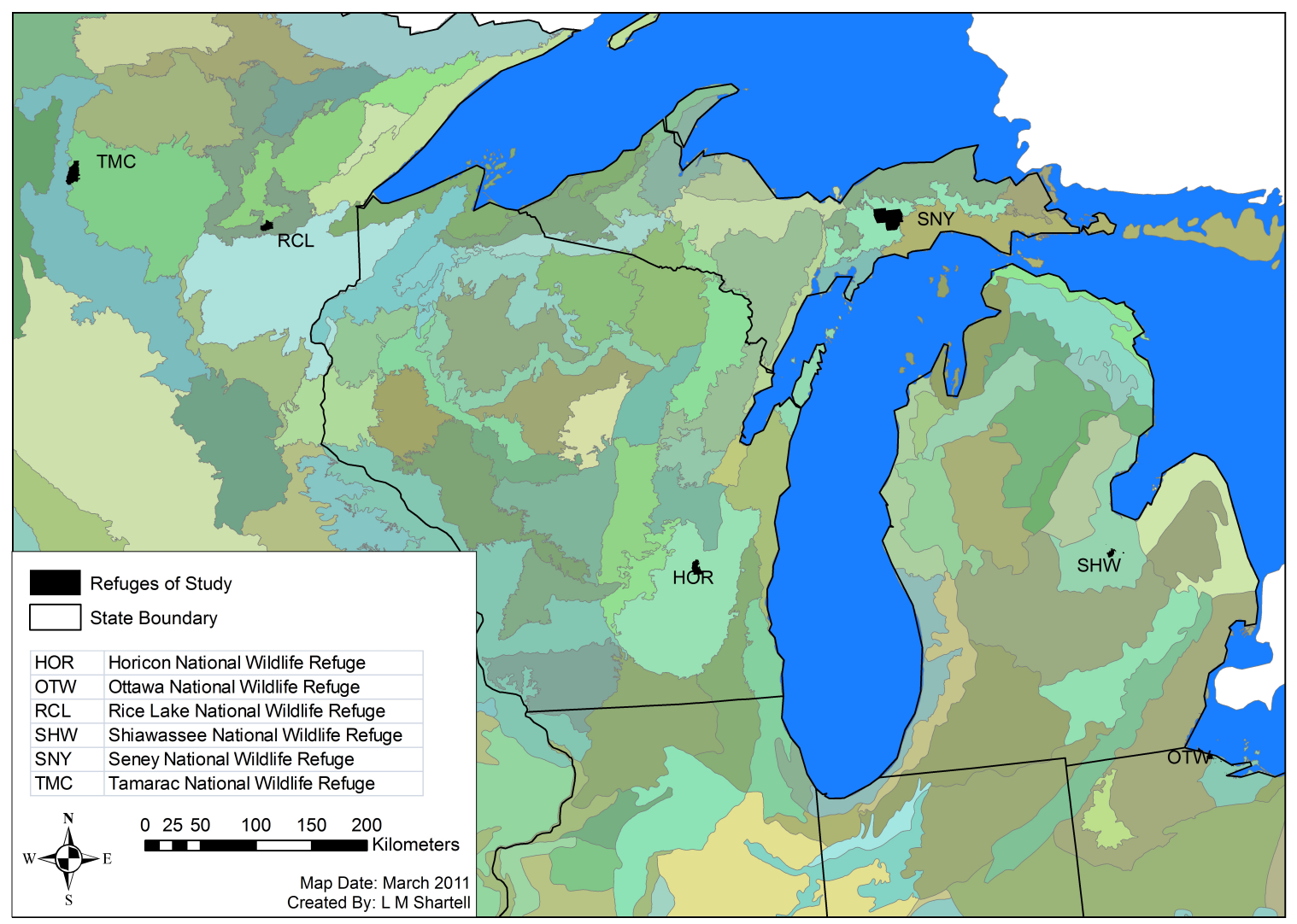

Figure 4.1 National Wildlife Refuges included in the study, located within the Upper Great Lakes region. Background polygons indicate differing ecoregion subsections (Cleland et al. 1997). Those ecoregions containing refuges of study are listed in Table 4.2. 


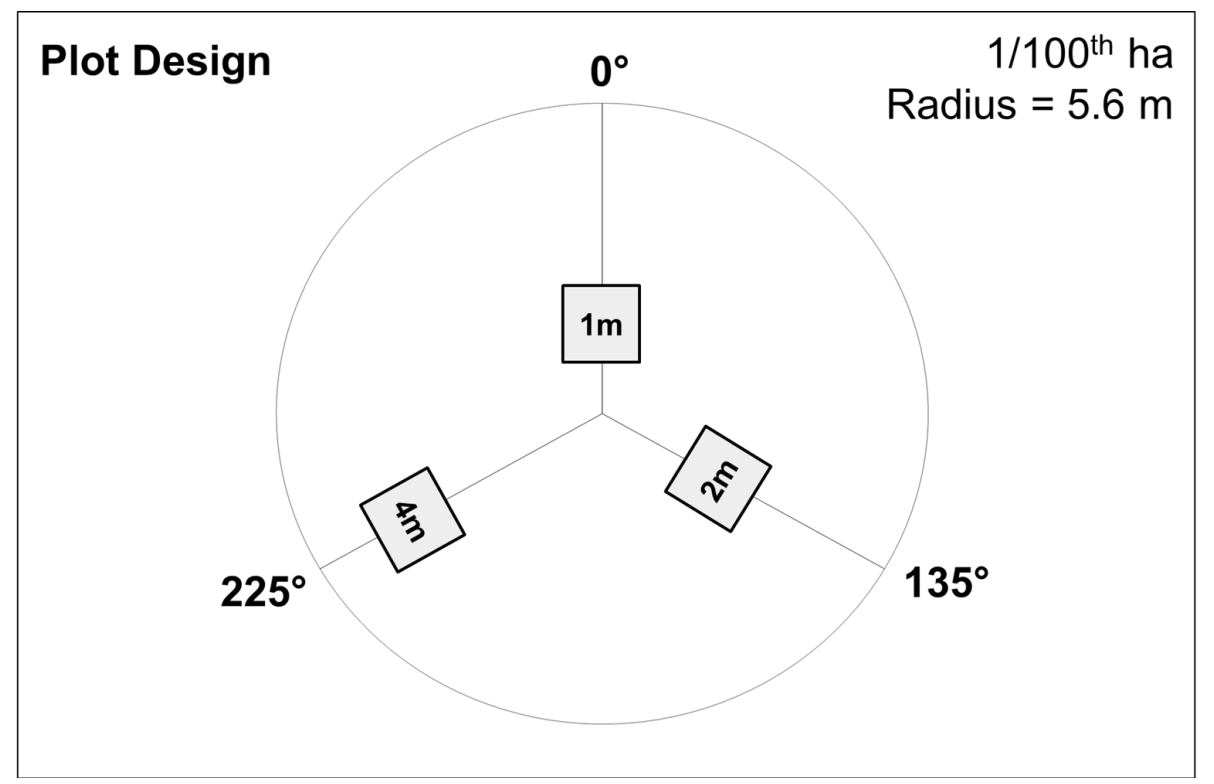

Figure 4.2 Forest rapid ecological assessment (REA) plot and subplot design. Adapted from Petrillo and Corace (2011). 


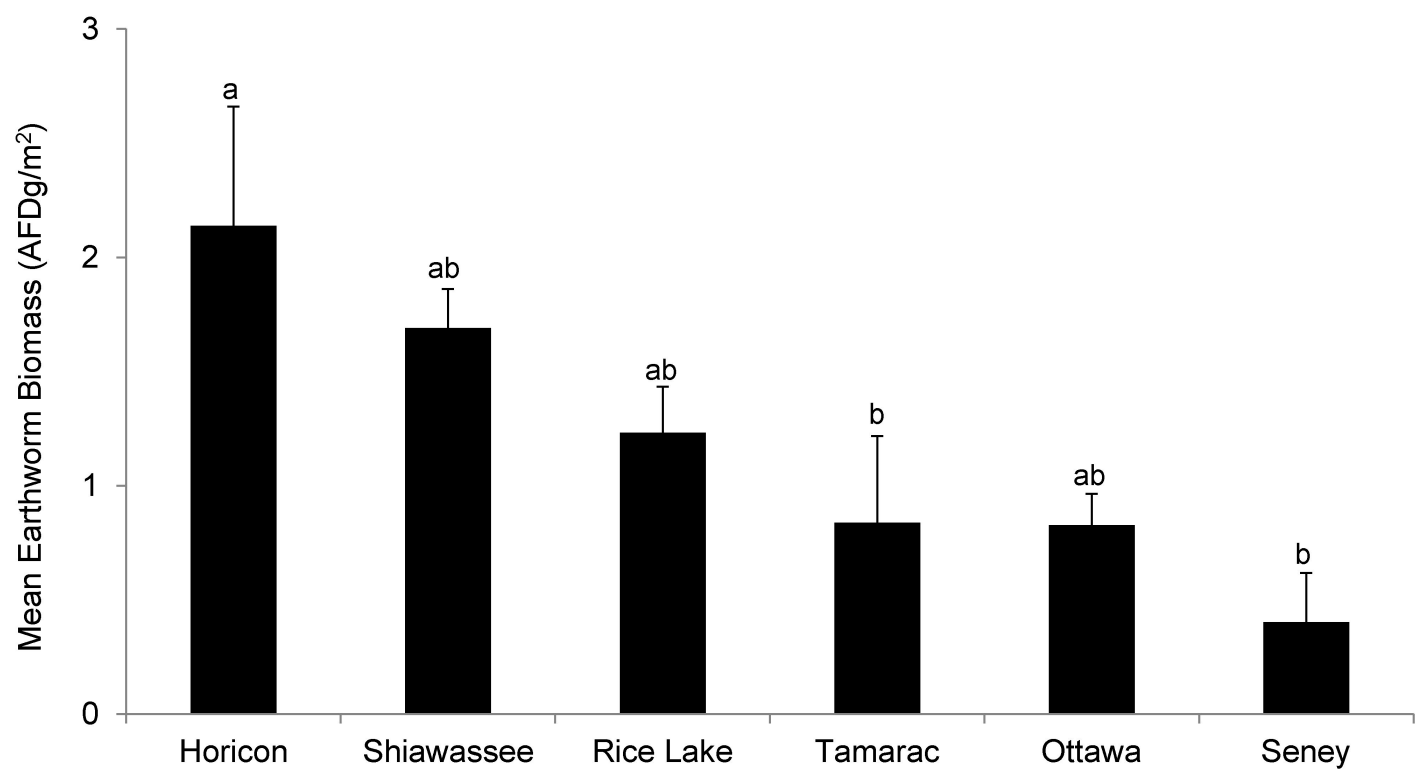

Figure 4.3 Mean (+SE) earthworm biomass $\left(\mathrm{AFDg} / \mathrm{m}^{2}\right)$ at six National Wildlife Refuges in the Great Lakes region. Different letters indicate significant differences $(P \leq 0.05)$ between refuges. 


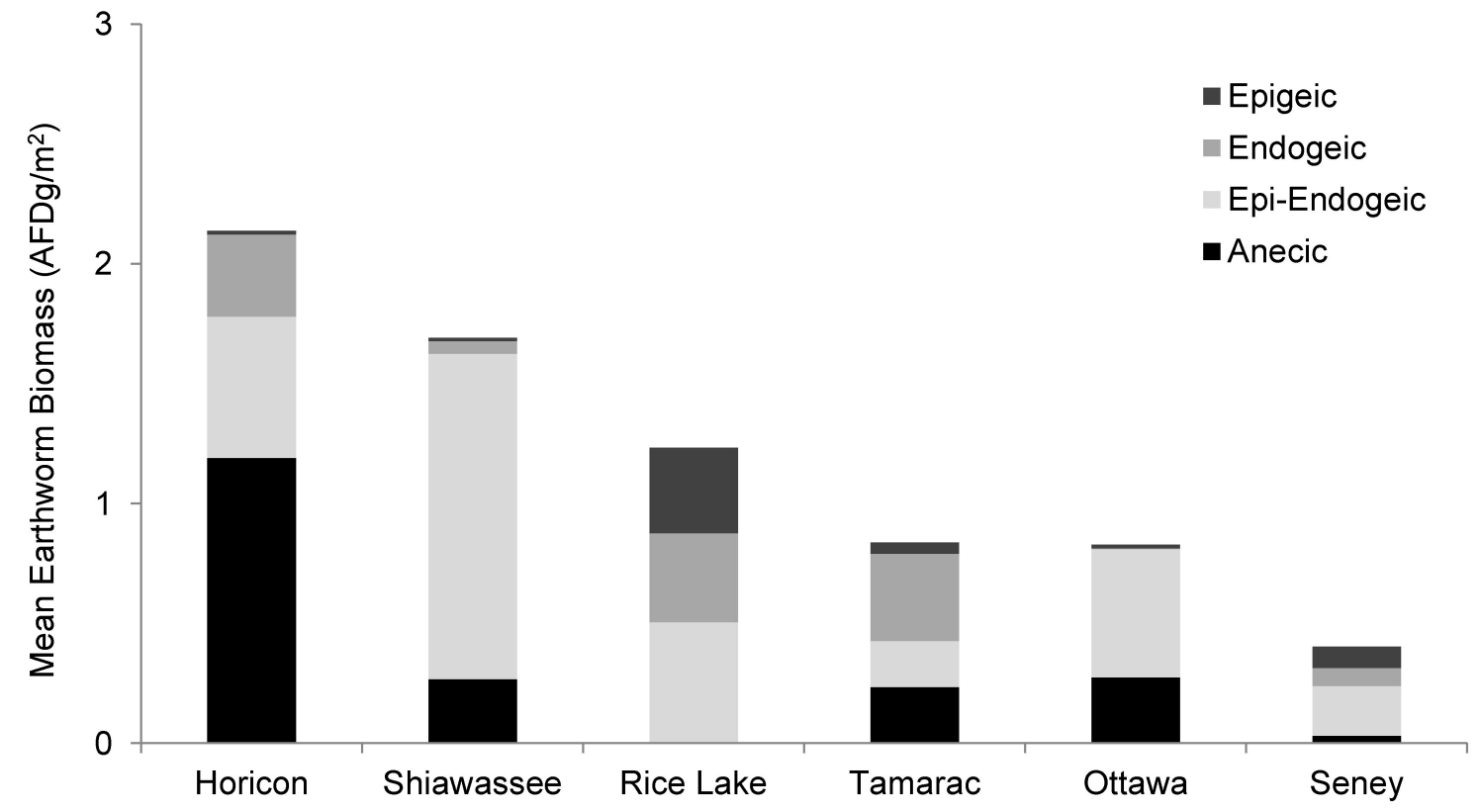

Figure 4.4 Variation in earthworm biomass (AFDg $/ \mathrm{m}^{2}$ ) by earthworm functional group at six National Wildlife Refuges in the Great Lakes region. 


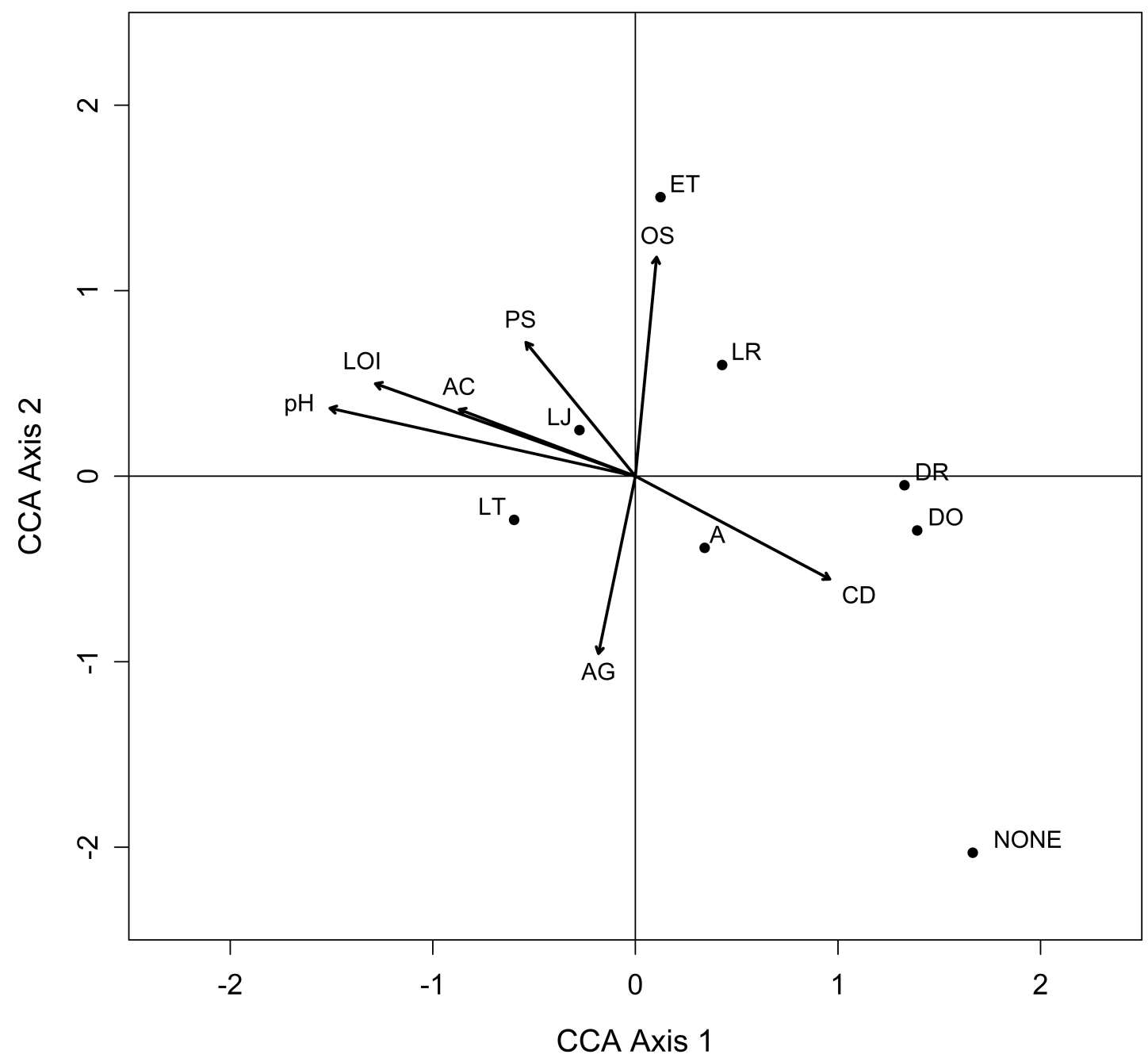

Figure 4.5 Canonical correspondence analysis (CCA) biplot relating earthworm community composition with environmental variables. Environmental variables are represented by arrows, which point to increasing values of that variable. Length of the arrow is proportional to the variable's importance in influencing earthworm community composition. Variables: $\mathrm{AC}=$ Anthropogenic Cover, $\mathrm{AG}=$ Agriculture Proximity, $\mathrm{CD}=$ Conifer Dominance, $\mathrm{LOI}=$ Loss on Ignition, $\mathrm{pH}=$ Soil $\mathrm{pH}, \mathrm{PS}=$ Basal Area Preferred Species, $\mathrm{OS}=$ Number of Overstory Species. Taxa: $\mathrm{A}=$ Aporrectodea spp., $\mathrm{DO}=$ Dendrobaena octaedra, $\mathrm{DR}=$ Dendrodrilus rubidus, $\mathrm{ET}=$ Eiseniella tetraedra, $\mathrm{LJ}=$ Lumbricus juveniles, $\mathrm{LR}=$ Lumbricus rubellus, $\mathrm{LT}=$ Lumbricus terrestris, and $\mathrm{NONE}=$ no earthworms present. 


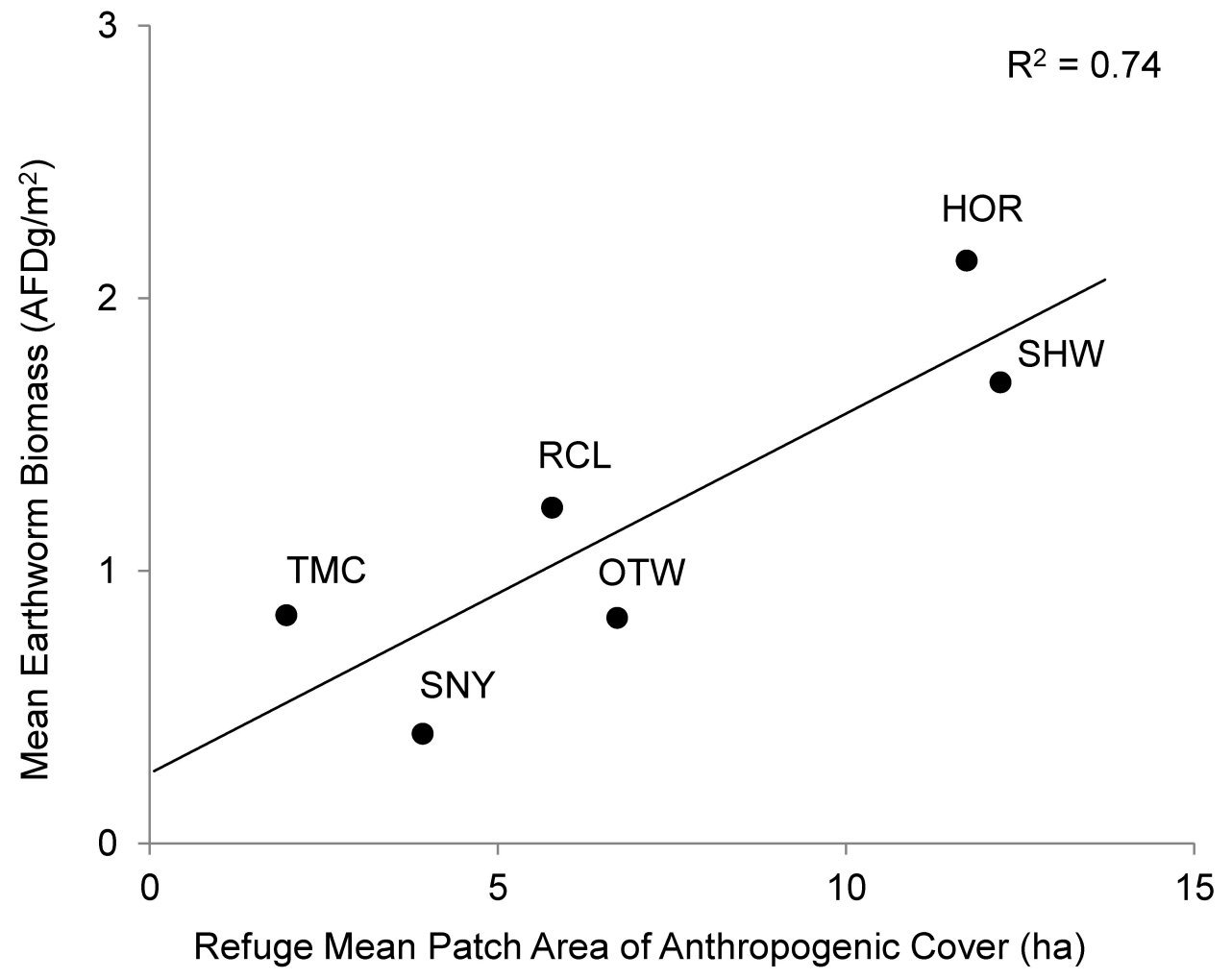

Figure 4.6 Correlation between refuge mean patch area of anthropogenic cover (ha, NLCD 2006) and mean earthworm biomass (AFDg/ $\mathrm{m}^{2}$ ). National Wildlife Refuges are labeled as follows: HOR $=$ Horicon, OTW = Ottawa, RCL = Rice Lake, SHW = Shiawassee, $\mathrm{SNY}=$ Seney, $\mathrm{TMC}=$ Tamarac. 


\section{Table 4.1}

Description of environmental variables assessed in association with earthworm abundance and community composition data. Within transect or stands variables represent the mean plot values, total for count data, or percent plots for presence/absence $(\mathrm{P} / \mathrm{A})$ data.

\begin{tabular}{|c|c|c|c|}
\hline Variable & Code & Units & Description \\
\hline Basal Area & BA & $\mathrm{m}^{2} / \mathrm{ha}$ & Basal area of live overstory species \\
\hline Preferred Species & PS & $\mathrm{m}^{2} / \mathrm{ha}$ & $\begin{array}{c}\text { Basal area of earthworm preferred live } \\
\text { overstory species }\end{array}$ \\
\hline Overstory Species & OS & \# & Number of overstory species present \\
\hline Canopy Cover & $\mathrm{CC}$ & $\%$ & Percent closed canopy \\
\hline Conifer Dominance & $\mathrm{CD}$ & $\%$ & $\begin{array}{c}\text { Percent of basal area consisting of } \\
\text { coniferous species }\end{array}$ \\
\hline Coarse Woody Debris & CWD & $\mathrm{P} / \mathrm{A}$ & Presence of coarse woody debris \\
\hline Soil pH & $\mathrm{pH}$ & $\mathrm{pH}$ & Soil pH \\
\hline Loss on Ignition & LOI & $\%$ & Percent loss on ignition from soil \\
\hline Road Proximity & RD & $\mathrm{m}$ & Distance to the nearest road \\
\hline Agriculture Proximity & $\mathrm{AG}$ & $\mathrm{m}$ & $\begin{array}{l}\text { Distance to the nearest cropland, hay } \\
\text { field, pasture, or old field }\end{array}$ \\
\hline Anthropogenic Cover & $\mathrm{AC}$ & $\%$ & $\begin{array}{l}\text { Percent of land within } 500 \mathrm{~m} \text { buffer } \\
\text { comprised of anthropogenic cover }\end{array}$ \\
\hline
\end{tabular}


Table 4.2

National Wildlife Refuges of study and their associated state and ecoregion subsection(s) (Cleland et al. 1997).

\begin{tabular}{lcc}
\hline Refuge & State & Ecoregion(s) \\
\hline Horicon & WI & Southern Green Bay Lobe \\
Ottawa & OH & Western Paleozoic Plateau \\
Rice Lake & MN & St. Louis Moraines \\
& & Toimi Uplands \\
Shiawassee & MI & Saginaw Clay Lake and Till Plain \\
Seney & MI & Seney Lake Plain \\
& & St. Ignace Lake Plain \\
Tamarac & MN & $\begin{array}{c}\text { Alexandria Moraine-Hardwood Hills } \\
\text { Pine Moraine and Outwash Plains }\end{array}$ \\
\hline
\end{tabular}


Table 4.3

Landscape metrics selected to represent patterns of composition and fragmentation within refuges and associated ecoregions.

\begin{tabular}{|c|c|c|}
\hline Metric & Description & Indication \\
\hline Natural Patch Richness (NPR) & $\begin{array}{l}\text { The ratio of natural to } \\
\text { anthropogenic land cover types }\end{array}$ & Composition \\
\hline Shannon's Diversity (SHDI) & $\begin{array}{l}\text { Value indicating relative species } \\
\text { richness and evenness }\end{array}$ & Composition \\
\hline Mean Patch Area (MPA) & $\begin{array}{c}\text { Mean patch size (ha) of all } \\
\text { patches on a landscape }\end{array}$ & Fragmentation \\
\hline Largest Patch Index (LPI) & $\begin{array}{l}\text { Percent of a landscape occupied } \\
\text { by the largest patch }\end{array}$ & Fragmentation \\
\hline Landscape Shape Index (LSI) & $\begin{array}{c}\text { Measure of class aggregation, } \\
\text { high values indicate less } \\
\text { aggregation }\end{array}$ & Fragmentation \\
\hline
\end{tabular}




\section{Table 4.4}

Mean earthworm biomass (AFDg/ $\mathrm{m}^{2} \pm \mathrm{SE}$ ), refuge earthworm taxa richness, mean earthworm Shannon's diversity $( \pm \mathrm{SE})$, and mean earthworm Shannon's evenness $( \pm \mathrm{SE})$. Different letters indicate significant differences in pairwise comparisons between refuges $(P \leq 0.05)$.

\begin{tabular}{lcccc}
\hline Refuge & Biomass & Richness & Diversity & Evenness \\
\hline Horicon & $2.14( \pm 0.52) \mathrm{a}$ & 5 & $1.01( \pm 0.05) \mathrm{a}$ & $0.81( \pm 0.04) \mathrm{a}$ \\
Ottawa & $0.83( \pm 0.14) \mathrm{ab}$ & 4 & $0.75( \pm 0.11) \mathrm{ab}$ & $0.70( \pm 0.09) \mathrm{ab}$ \\
Rice Lake & $1.23( \pm 0.20) \mathrm{ab}$ & 4 & $1.11( \pm 0.12) \mathrm{a}$ & $0.82( \pm 0.08) \mathrm{a}$ \\
Shiawassee & $1.69( \pm 0.17) \mathrm{ab}$ & 5 & $0.98( \pm 0.08) \mathrm{a}$ & $0.69( \pm 0.03) \mathrm{ab}$ \\
Seney & $0.40( \pm 0.21) \mathrm{b}$ & 4 & $0.70( \pm 0.20) \mathrm{ab}$ & $0.51( \pm 0.13) \mathrm{ab}$ \\
Tamarac & $0.84( \pm 0.38) \mathrm{b}$ & 4 & $0.38( \pm 0.13) \mathrm{b}$ & $0.34( \pm 0.11) \mathrm{b}$ \\
\hline
\end{tabular}




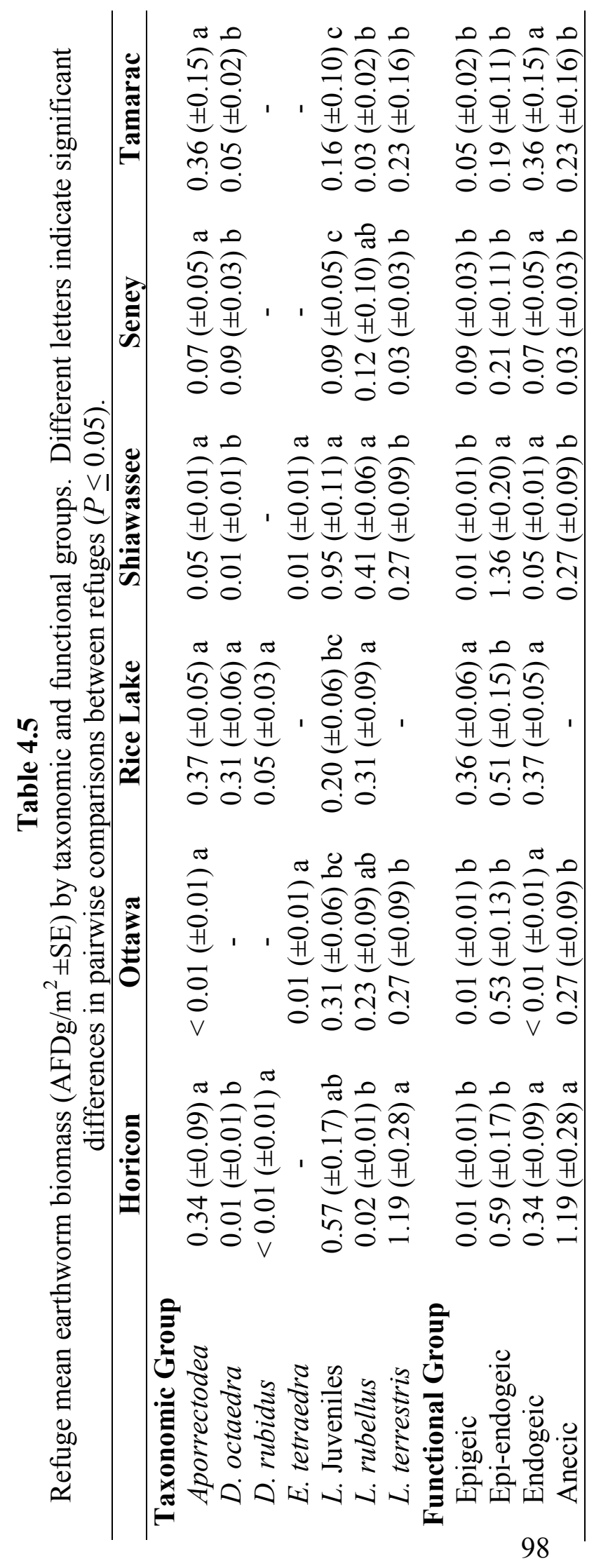




\section{Table 4.6}

Linear regression results by functional group for forest floor condition, litter depth, herbaceous understory cover, woody understory cover, and invasive exotic plant presence. Significance $(P \leq 0.05)$ is indicated by $* . \mathrm{R}^{2}$ values are reported for significant variables.

\begin{tabular}{lccc}
\hline Impact & Coefficient & P-Value & $\mathbf{R}^{2}$ \\
\hline Epigeic & & & \\
Forest Floor & -0.61 & 0.50 & - \\
Litter Depth & 3.31 & $0.02 *$ & 0.08 \\
Herbaceous Cover & 0.67 & 0.43 & - \\
Woody Cover & 1.55 & $0.04 *$ & 0.07 \\
Invasive Exotic Plants & -0.48 & 0.07 & - \\
Epi-Endogeic & & & \\
Forest Floor & -1.10 & $<0.001^{*}$ & 0.28 \\
Litter Depth & -1.62 & $<0.001^{*}$ & 0.23 \\
Herbaceous Cover & 0.17 & 0.49 & - \\
Woody Cover & -0.75 & $<0.001$ & 0.18 \\
Invasive Exotic Plants & 0.23 & $<0.01 *$ & 0.14 \\
Endogeic & & & \\
Forest Floor & -1.62 & $<0.001 *$ & 0.22 \\
Litter Depth & -0.44 & 0.54 & - \\
Herbaceous Cover & 0.58 & 0.15 & - \\
Woody Cover & 0.43 & 0.24 & - \\
Invasive Exotic Plants & -0.16 & 0.20 & - \\
Anecic & & & \\
Forest Floor & -1.25 & $<0.001^{*}$ & 0.42 \\
Litter Depth & -1.51 & $<0.001^{*}$ & 0.23 \\
Herbaceous Cover & -0.08 & 0.74 & - \\
Woody Cover & -0.31 & 0.12 & - \\
Invasive Exotic Plants & 0.07 & 0.34 & - \\
\hline
\end{tabular}




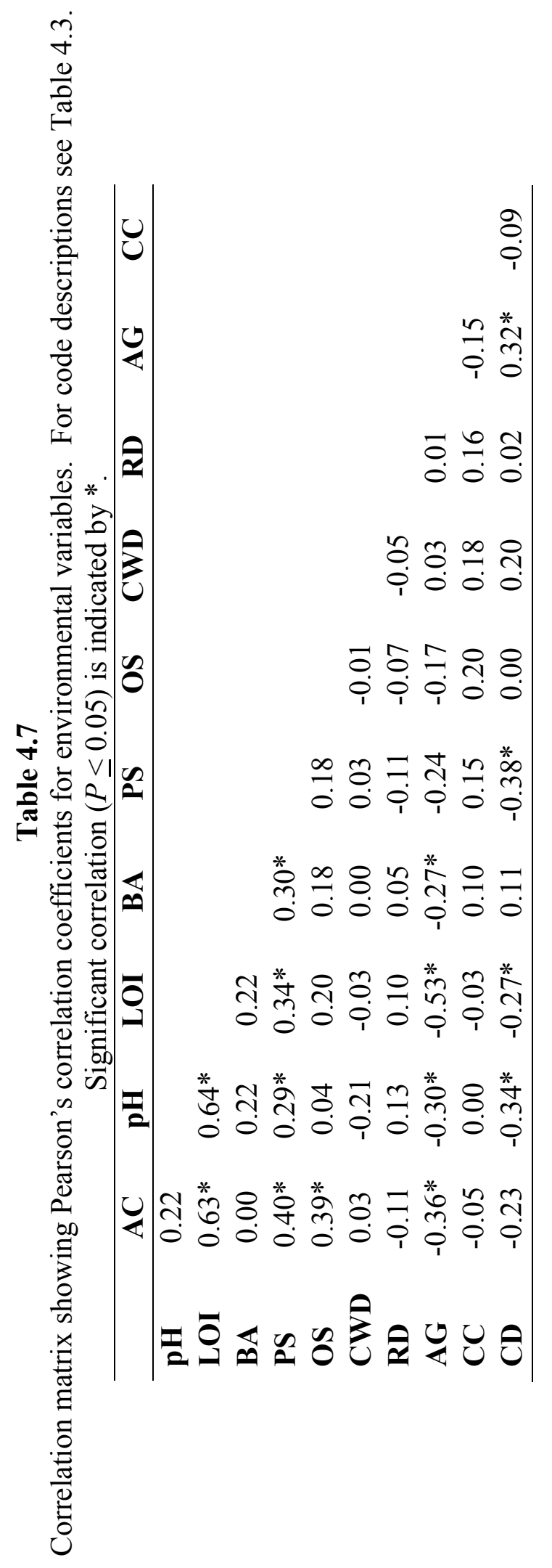




\section{Table 4.8}

Linear regression results comparing mean stand (transect) earthworm biomass to environmental variables. Significance $(P \leq 0.05)$ is indicated by $* \mathrm{R}^{2}$ values are reported for significant variables.

\begin{tabular}{lccc}
\hline Variable & Coefficient & $\boldsymbol{P}$-Value & $\mathbf{R}^{\mathbf{2}}$ \\
\hline Basal Area & 0.01 & 0.12 & - \\
Preferred Species & 0.03 & $0.02^{*}$ & 0.09 \\
Overstory Species & 0.04 & 0.47 & - \\
Canopy Cover & 0.01 & 0.49 & - \\
Conifer Dominance & -1.70 & $<0.01^{*}$ & 0.13 \\
Coarse Woody Debris & 0.004 & 0.99 & - \\
Soil pH & 0.43 & $<0.01^{*}$ & 0.12 \\
Loss on Ignition & 12.76 & $<0.01^{*}$ & 0.12 \\
Road Proximity & -0.03 & 0.27 & - \\
Agriculture Proximity & -0.14 & 0.12 & - \\
Anthropogenic Cover & 1.58 & $0.01^{*}$ & 0.10 \\
\hline
\end{tabular}




\section{Table 4.9}

Summary of multivariate regression results for the best model predicting earthworm biomass from environmental variables.

\begin{tabular}{lcc}
\hline Predictor & Coefficient & $\boldsymbol{P}$-Value \\
\hline Constant & 0.61 & 0.03 \\
Conifer Dominance & -1.56 & $<0.01$ \\
Anthropogenic Cover & 1.18 & 0.05 \\
Basal Area & 0.02 & 0.04 \\
\hline
\end{tabular}




\section{Table 4.10}

Summary statistics for the canonical correspondence analysis (CCA) of earthworm community composition as related to environmental variables.

\begin{tabular}{lccc}
\hline CCA Summary & Axis 1 & Axis 2 & Axis 3 \\
\hline Eigenvalue & 0.333 & 0.128 & 0.064 \\
Variance in community data & & & \\
$\quad$ \% of variance explained & 14.5 & 5.5 & 2.8 \\
$\quad$ Cumulative \% explained & 14.5 & 20.0 & 22.8 \\
Pearson Correlation & 0.830 & 0.619 & 0.648 \\
Inter-set Correlations & & & \\
$\quad$ Basal Area & -0.350 & 0.167 & -0.251 \\
Preferred Species & -0.224 & 0.223 & 0.020 \\
Overstory Species & 0.043 & 0.366 & -0.074 \\
Conifer Dominance & 0.398 & -0.172 & -0.184 \\
Coarse Woody Debris & -0.161 & 0.091 & 0.075 \\
Soil pH & -0.626 & 0.113 & 0.157 \\
Loss on Ignition & -0.533 & 0.154 & -0.056 \\
Road Proximity & -0.149 & -0.173 & 0.228 \\
Agriculture Proximity & -0.076 & -0.296 & 0.372 \\
Anthropogenic Cover & -0.361 & 0.111 & -0.294 \\
\hline
\end{tabular}




\section{Table 4.11}

Linear regression results comparing refuge mean earthworm biomass to landscape metrics calculated using all National Land Cover Dataset cover types. No variables were significant $(P \leq 0.05)$.

\begin{tabular}{lccc}
\hline Metric & Coefficient & $\boldsymbol{P}$-Value & $\mathbf{R}^{\mathbf{2}}$ \\
\hline Refuge & & & \\
Total Area & -0.00003 & 0.18 & - \\
Natural Patch Richness & -0.08 & 0.20 & - \\
Shannon's Diversity & 0.58 & 0.63 & - \\
Mean Patch Area & -0.02 & 0.90 & - \\
Largest Patch Index & -0.006 & 0.82 & - \\
Landscape Shape Index & -0.01 & 0.21 & - \\
Ecoregion & & & \\
Natural Patch Richness & -0.28 & 0.20 & - \\
Shannon's Diversity & 0.07 & 0.97 & - \\
Mean Patch Area & -0.003 & 0.99 & - \\
Largest Patch Index & -0.22 & 0.13 & - \\
Landscape Shape Index & -0.002 & 0.51 & - \\
\hline
\end{tabular}


Table 4.12

Linear regression results comparing refuge mean earthworm biomass to landscape metrics calculated for anthropogenic land cover types. Significance $(P \leq 0.05)$ is indicated by $* . \mathrm{R}^{2}$ values are reported for significant variables.

\begin{tabular}{lccc}
\hline Metric & Coefficient & $\boldsymbol{P}$-Value & $\mathbf{R}^{\mathbf{2}}$ \\
\hline Refuge & & & \\
Percent of Landscape & 0.03 & 0.37 & - \\
Mean Patch Area & 0.13 & $0.03^{*}$ & 0.74 \\
Largest Patch Index & 0.23 & 0.28 & - \\
Landscape Shape Index & -0.05 & 0.14 & - \\
Ecoregion & & & \\
Percent of Landscape & 0.009 & 0.29 & - \\
Mean Patch Area & 0.00009 & 0.79 & - \\
Largest Patch Index & 0.009 & 0.27 & - \\
Landscape Shape Index & -0.003 & 0.44 & - \\
\hline
\end{tabular}




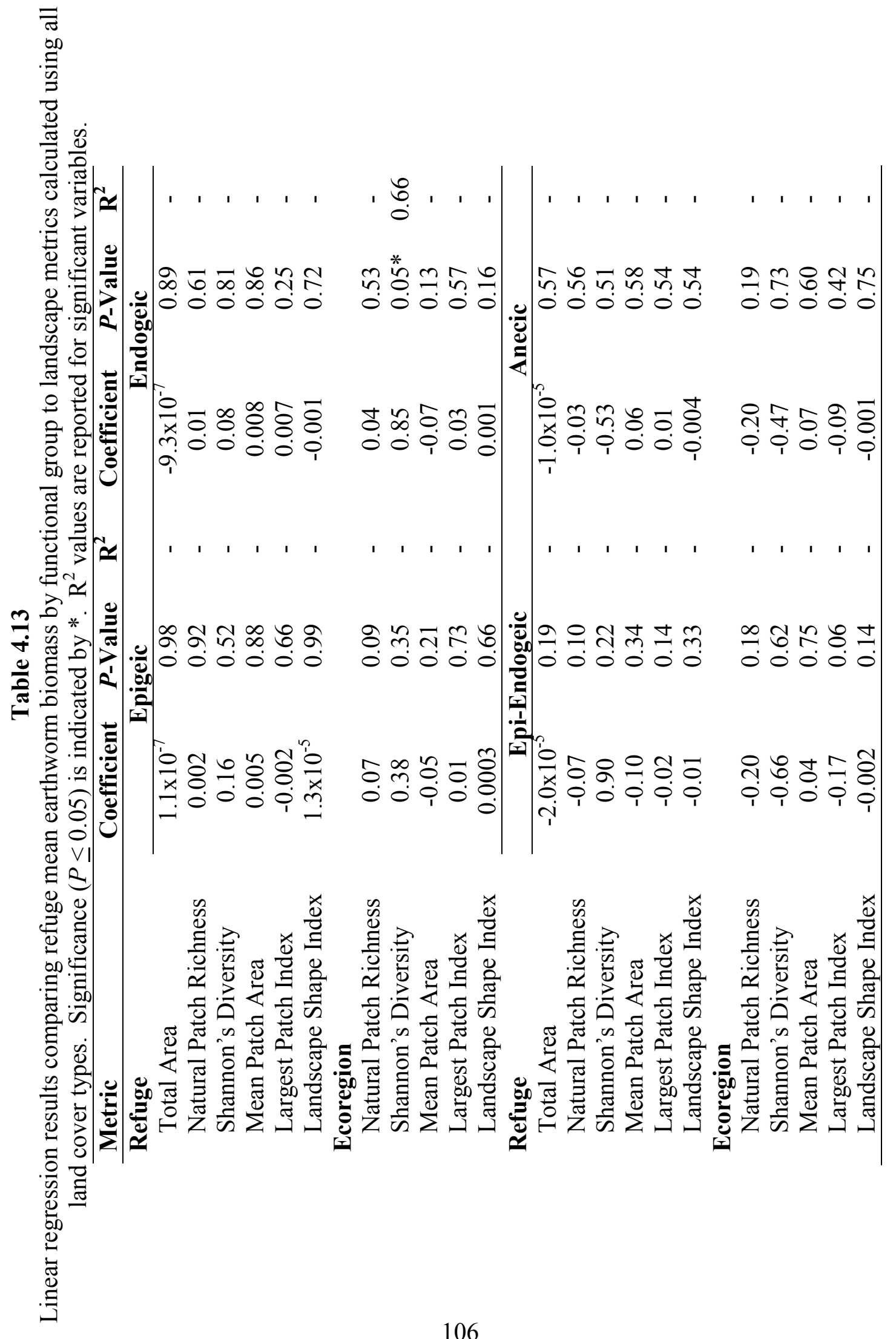




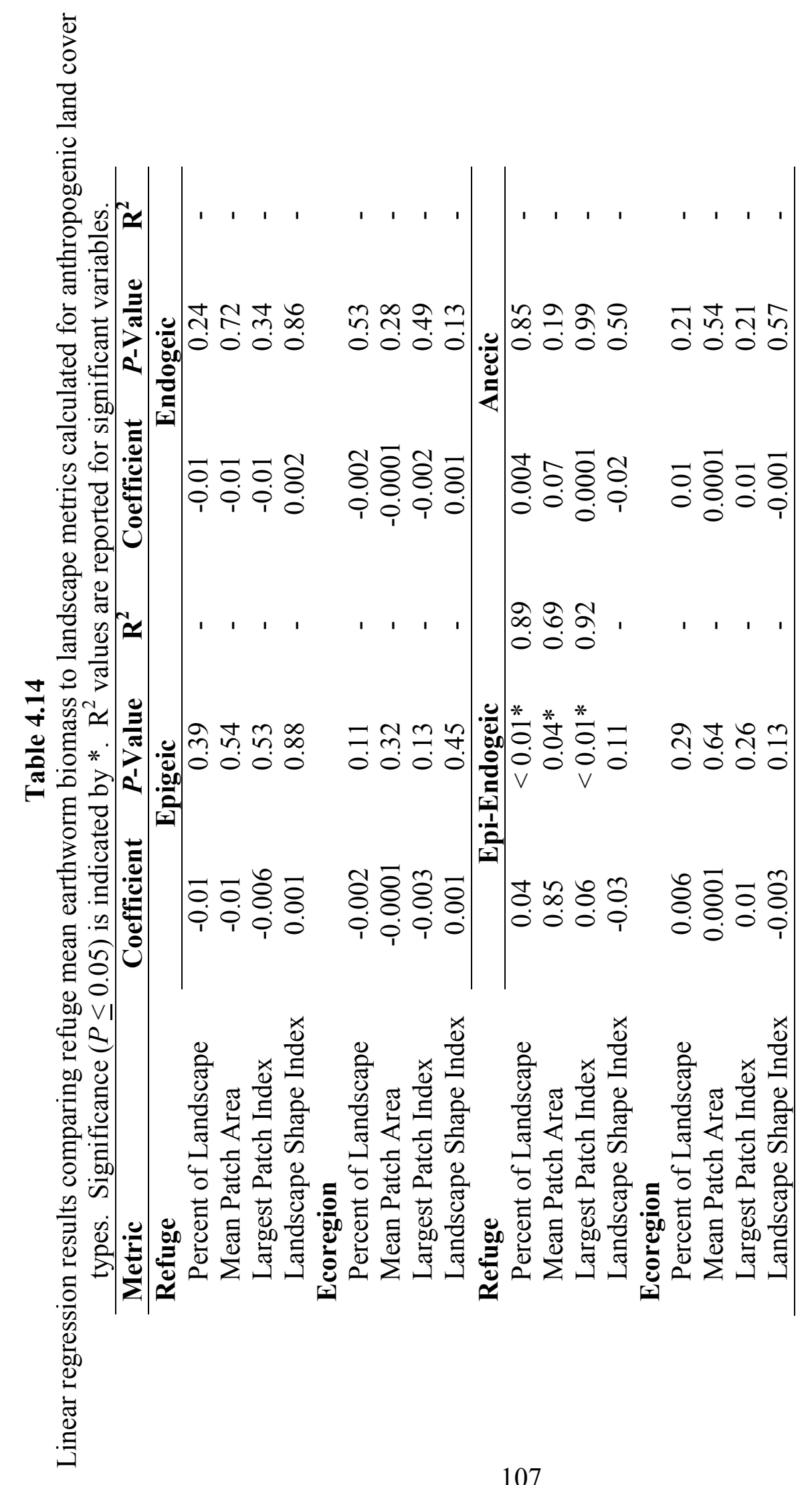


Table 4.15

Linear regression results comparing refuge earthworm community diversity to landscape metrics calculated for all land cover types. Significance $(P \leq 0.05)$ is indicated by $* \mathrm{R}^{2}$ values are reported for significant variables.

\begin{tabular}{lccc}
\hline Metric & Coefficient & $\boldsymbol{P}$-Value & $\mathbf{R}^{\mathbf{2}}$ \\
\hline Refuge & & & \\
Total Area & $1.0 \times 10^{-5}$ & 0.13 & - \\
Natural Patch Richness & 0.03 & 0.16 & - \\
Shannon's Diversity & 0.07 & 0.85 & - \\
Mean Patch Area & -0.007 & 0.89 & - \\
Largest Patch Index & -0.0007 & 0.93 & - \\
Landscape Shape Index & 0.004 & 0.14 & - \\
Ecoregion & & & \\
Natural Patch Richness & 0.14 & $<0.01^{*}$ & 0.94 \\
Shannon's Diversity & 0.40 & 0.52 & - \\
Mean Patch Area & -0.06 & 0.30 & - \\
Largest Patch Index & 0.08 & 0.09 & - \\
Landscape Shape Index & 0.0006 & 0.54 & - \\
\hline
\end{tabular}


Table 4.16

Linear regression results comparing refuge earthworm community diversity to landscape metrics calculated for anthropogenic land cover types. Significance $(P \leq 0.05)$ is indicated by $* . \mathrm{R}^{2}$ values are reported for significant variables.

\begin{tabular}{lccc}
\hline Metric & Coefficient & $\boldsymbol{P}$-Value & $\mathbf{R}^{\mathbf{2}}$ \\
\hline Refuge & & & \\
Percent of Landscape & -0.01 & 0.15 & - \\
Mean Patch Area & -0.04 & 0.07 & - \\
Largest Patch Index & -0.01 & 0.29 & - \\
Landscape Shape Index & 0.02 & 0.09 & - \\
Ecoregion & & & \\
Percent of Landscape & -0.005 & $<0.01 *$ & 0.89 \\
Mean Patch Area & -0.0001 & 0.19 & - \\
Largest Patch Index & -0.005 & $<0.01 *$ & 0.88 \\
Landscape Shape Index & 0.001 & 0.25 & - \\
\hline
\end{tabular}




\section{Dissertation Literature Cited}

Alban DH, Berry EC. 1994. Effects of earthworm invasion on morphology, carbon, and nitrogen of a forest soil. Applied Soil Ecology. 1:243-249.

Allendorf FW, Lundquist LL. 2003. Introduction: population biology, evolution, and control of invasive species. Conservation Biology. 17:24-30.

Asshoff R, Scheu S, Eisenhauer N. 2010. Different earthworm ecological groups interactively impact seedling establishment. European Journal of Soil Biology. 14:330-334.

Ayersman W, Strager MP, Strager JM. 2009. Modeling emerald ash borer establishment and spread using GIS. Proceedings of the 2009 ESRI Users Conference.

Bailey RG. 2009. Ecosystem Geography. 2nd ed. Springer, New York. 251 p.

Barley KP. 1961. Abundance of earthworms in agricultural land and their possible significance in agriculture. Advances in Agronomy. 13:249-268.

Bauer L, Gould J, Duan J, Ulyshen M. 2010. Emerald ash borer biological control. In: McManus KA, Gottschalk KW, editors. Proceedings of the 21st U.S. Department of Agriculture interagency research forum on invasive species 2010. USDA Forest Service, Northern Research Station, Gen. Tech. Rep. NRS-P-75. p. 70-73.

Bauer LS, Liu H, Miller DL. 2009. Emerald ash borer biological control: rearing, releasing, establishment, and efficiency of parasitoids. Proceedings of the 2009 USDA Research Forum on Invasive Species. January 13-16, Annapolis, MD.

Bechtold WA, Patterson PL. 2005. The enhanced forest inventory and analysis program: national sampling design and estimation procedures. USDA Forest Service Southern Research Station General Technical Report SRS-80. Asheville, NC.

Bohlen PJ, Groffman PM, Driscoll CT, Fahey TJ, Siccama TG. 2001. Plant-soilmicrobial interactions in a northern hardwood forest. Ecology. 82:965-978.

Bohlen, PJ, Groffman PM, Fahey TJ, Fisk MC, Suarez E, Pelletier DM, Fahey RT. 2004a. Ecosystem consequences of exotic earthworm invasion of north temperate forests. Ecosystems. 7:1-12.

Bohlen PJ, Pelletier DM, Groffman PM, Fahey TJ, Fisk MC. 2004b. Influence of earthworm invasion on redistribution and retention of soil carbon and nitrogen in northern temperate forests. Ecosystems. 7:13-27. 
Bohlen PJ, Scheu S, Hale CM, McLean MA, Migge S, Groffman PM, Parkinson D. 2004c. Non-native invasive earthworms as agents of change in northern temperate forests. Frontiers in Ecology and the Environment. 2:427-435.

Bouché MB 1977. Strategies lombricienes. Soil organisms as components of ecosystems. In: Lohm U, Persson T, editors. Ecological Bulletins, Stockholm. p. 122-132.

Burtelow AE, Bohlen PJ, Groffman PM. 1998. Influence of exotic earthworm invasion on soil organic matter, microbial biomass and denitrification potential in forest soils of the northeastern United States. Applied Soil Ecology. 9:197-202.

Callaham MA, Gonzalez G, Hale CM, Heneghan L, Lachnicht SL, Zou X. 2006. Policy and management responses to earthworm invasions in North America. Biological Invasions. 8:1317-1329.

Cameron EK, Bayne EM, Clapperton MJ. 2007. Human-facilitated invasion of exotic earthworms into northern boreal forests. Ecoscience. 14:482-490.

Cameron EK, Bayne EM, Coltman DW. 2008. Genetic structure of invasive earthworms Dendrobaena octaedra in the boreal forest of Alberta: insights into introduction mechanisms. Molecular Ecology. 17:1189-1197.

Cappaert D, McCullough DG, Poland TM, Siegert NW. 2005. Emerald ash borer in North America: a research and regulatory challenge. American Entomologist. 51:152165.

Chase JM, Leibold MA. 2003. Ecological niches: linking classical and contemporary approaches. Chicago, IL: The University of Chicago Press.

Chornesky EA, Bartuska AM, Aplet GH, Britton KO, Cummings-Carlson J, Davis FW, Eskow J, Gordon DR, Gottschalk KW, Haack RA, Hansen AJ, Mack RN, Rahel FJ, Shannon MA, Wainger LA, Bently Wigley T. 2005. Science priorities for reducing the threat of invasive species to sustainable forestry. BioScience. 55:335-348.

Clapperton MJ, Baker GH, Fox CA. 2008. Earthworms. In: Carter MR, Gregorich EG, editors. Soil Sampling and Methods of Analysis. $2^{\text {nd }}$ ed. Boca Raton, FL: CRC Press. p. 427-444.

Cleland DT, Ayers RE, McNab WH, Jensen ME, Bailey RG, King T, Russell WE. 1997. National hierarchical framework of ecological units. In: Boyce MS and A Haney eds. Ecosystem management: applications for sustainable forest and wildlife resources. New Haven: Yale University Press.

Clinton WJ. 1999. Executive Order No. 13112: Invasive Species. Federal Register 64. (http://www.invasivespeciesinfo.gov/laws/execorder.shtml) 
Coblentz BE. 1990. Exotic organisms: a dilemma for conservation biology. Conservation Biology. 4:261-265.

Corace RG III, Shartell LM, Schulte LA, Brininger WL Jr., McDowell MKD, Kashian DM. 2012. An ecoregional context for forest management on National Wildlife Refuges of the Upper Midwest, USA. Journal of Environmental Management. 49:359-371.

Dixon PM, Ellison AM, Gotelli NJ. 2005. Improving the precision of estimates of the frequency of rare events. Ecology. 86:1114-1123.

Dormann CF. 2007. Assessing the validity of autologistic regression. Ecological Modeling. 207:234-242.

Emerald Ash Borer (EAB) Info. 2011. http://emeraldashborer.info. Accessed 1 April 2011.

Edwards CA, Bohlen PJ. 1996. Biology and Ecology of Earthworms. London, UK: Chapman \& Hall. 426 p.

Elton CS. 1927. Animal ecology. London, UK: Sidgewick and Jackson. 204 p.

Elton CS. 1958. The ecology of invasions by animals and plants. London, UK: Methuen.

Environmental Systems Research Institute (ESRI). 2008. ArcGIS Desktop 9.3. Redlands, CA: Environmental Systems Research Institute.

Environmental Systems Research Institute (ESRI). 2011. ArcGIS Desktop: Release 10. Redlands, CA: Environmental Systems Research Institute.

Federal Register. 2003. Emerald ash borer, quarantine and regulations. 7 CFR Part 301. 68:59082-59091.

Forman RTT, Godron M. 1986. Landscape Ecology. New York: Wiley \& Sons. 619 p.

Forman RTT, Alexander LE. 1998. Roads and their major ecological effects. Annual Review of Ecological Systems. 29:207-231.

Francese JA, Oliver JB, Fraser I, Lance DR, Youssef N, Sawyer AJ, Mastro VC. 2008. Influence of trap placement and design on capture of the emerald ash borer (Coleoptera: Buprestidae). Journal of Economic Entomology. 101:1831-1837.

Frederick J. 2008. Ash resources threatened by the emerald ash borer (Agrilus planipennis Fairmaire) in recreational areas throughout Michigan. MS Thesis, Michigan Technological University, Houghton, MI. 
Frelich LE, Hale CM, Scheu S, Holdsworth AR, Heneghan L, Bohlen PJ, Reich PB. 2006. Earthworm invasion into previously earthworm-free temperate and boreal forests. Biological Invasions. 8:1235-1245.

Gates GE. 1982. Farwell to North American megadriles. Megadrilogica. 4:12-77.

Griffith B, Scott JM, Adamcik R, Ashe D, Czech B, Fischman R, Gonzalez P, Lawler J, McGuire AD, Pidgorna A. 2009. Climate change adaptation for the U.S. National Wildlife Refuge System. Environmental Management. 44:1043-1052.

Grinnell J. 1924. Geography and evolution. Ecology. 5:225-229.

Guisan A, Zimmermann NE. 2000. Predictive habitat distribution models in ecology. Ecological Modeling. 135:147-186.

Gundale MJ, Jolly WM, Deluca TH. 2005. Susceptibility of a northern hardwood forest to exotic earthworm invasion. Conservation Biology. 19:1075-1083.

Gunn A. 1992. The use of mustard to estimate earthworm populations. Pedobiologia. 36:65-67.

Haack RA, Herard F, Sun J, Turgeon JJ. 2010. Managing invasive populations of Asian longhorned beetle and citrus longhorned beetle: a worldwide perspective. Annual Review of Entomology. 55:521-546.

Hale CM. 2008. Evidence for human-mediated dispersal of exotic earthworms: support for exploring strategies to limit further spread. Molecular Ecology. 17:1165-1169.

Hale CM, Frelich LE, Reich PB. 2004. Allometric equations for estimation of ash-free dry mass from length measurements for selected European earthworm species (Lumbricidae) in the western Great Lakes region. American Midland Naturalist. 15:179-185.

Hale CM, Frelich LE, Reich PB. 2005. Exotic European earthworm invasion dynamics in northern hardwood forests of Minnesota, USA. Ecological Applications. 15:848-860.

Hale CM, Frelich LE, Reich PB. 2006. Changes in hardwood forest understory plant communities in response to European earthworm invasions. Ecology. 87:1637-1649.

Hale CM, Frelich LE, Reich PB, Pastor J. 2008. Exotic earthworm effects on hardwood forest floor, nutrient availability and native plants: a mesocosm study. Oecologia. 155:509-518. 
Hausman CE, Jaeger JF, Rocha OJ. 2010. Impacts of the emerald ash borer (EAB) eradication and tree mortality: potential for a secondary spread of invasive plant species. Biological Invasions. 12:2013-2023.

Heimpel GE, Frelich LE, Landis DA, Hopper KR, Hoelmer KA, Sezen Z, Asplen MK, Wu K. 2010. European buckthorn and Asian soybean aphid as components of an extensive invasional meltdown in North America. Biological Invasions. 12:29132931.

Hellmann JJ, Byers JE, Bierwagen BG, Dukes JS. 2008. Five potential consequences of climate change on invasive species. Conservation Biology. 22:534-543.

Helms JA, editor. 1998. The dictionary of forestry. Bethesda, MD: The Society of American Foresters. 210 p.

Hendriksen NB. 1990. Leaf litter selection by detritivore and geophagous earthworms. Biology and Fertility of Soils. 10:17-21.

Hendrix PF, Bohlen PJ. 2002. Exotic earthworm invasions in North America: ecological and policy implications. BioScience. 52:801-811.

Heneghan L, Steffen J, Fagen K. 2007. Interactions of an introduced shrub and introduced earthworms in an Illinois urban woodland: impact on leaf litter decomposition. Pedobiologia. 50:543-551.

Herms DA, Gandhi KJK, Smith A, Cardina J, Knight KS, Herms CP, Long RP, McCullough DG. 2009. Ecological impacts of emerald ash borer in forests of southeast Michigan. In: McManus KA, Gottschalk KW, editors. Proceedings of the 20th U.S. Department of Agriculture interagency research forum on invasive species 2009. USDA Forest Service, Northern Research Station, Gen. Tech. Rep. NRS-P-51. p. 36-37.

Hobbs RJ, Huenneke LF. 1992. Disturbance, diversity, and invasion: implications for conservation. Conservation Biology. 6:324-337.

Holdsworth AR, Frelich LE, Reich PB. 2007a. Effects of earthworm invasion on plant species richness in northern hardwood forests. Conservation Biology. 21:997-1008.

Holdsworth AR, Frelich LE, Reich PB. 2007b. Regional extent of an ecosystem engineer: earthworm invasion in northern hardwood forests. Ecological Applications. 17:16661677.

Holm S. 1979. A simple sequentially rejective multiple test procedure. Scandinavian Journal of Statistics. 6:65-70. 
Holmes TP, Aukema JE, Von Holle B, Liebhold A, Sills E. 2009. Economic impacts of invasive species in forests: Past, present, and future. Annals of the New York Academy of Sciences Year in Ecology and Conservation Biology 2009. 1162: 18-38.

Holmstrup M, Westh P. 1995. Effects of dehydration on water relations and survival of lumbricid earthworm egg capsules. Journal of Comparative Physiology. 165:377-383.

Hopfensperger KN, Leighton GM, Fahey TJ. 2011. Influence of invasive earthworms on above and belowground vegetation in a northern hardwood forest. American Midland Naturalist. 166:53-62.

Hulme PE. 2009. Trade, transport, and trouble: managing invasive species pathways in an era of globalization. Journal of Applied Ecology. 46:10-18.

Hutchinson RE. 1957. Concluding remarks. Cold Spring Harbor Symposia on Quantitative Biology. 22:415-427.

James SW, Hendrix PF. 2004. Invasion of exotic earthworms into North America and other regions. In: Edwards CA, editor. Earthworm Ecology. Boca Raton: CRC Press. p. 75-88.

Jones CG, Lawton JH, Shachak M. 1994. Organisms as ecosystem engineers. Oikos. 689:373-386.

Kalisz PJ, Wood HB. 1995. Native and exotic earthworms in wildland ecosystems. In: Hendrix, PF, editor. Earthworm ecology and biogeography in North America. Boca Raton, FL: Lewis Publishers. p. 117-126.

Kashian DM, Witter JA. 2011. Assessing the potential for ash canopy tree replacement via current regeneration following emerald ash borer-caused mortality on southeastern Michigan landscapes. Forest Ecology and Management. 261:480-488.

Knight TM, Dunn JL, Smith LA, Davis J, Kalisz S. 2009. Deer facilitate invasive plant success in a Pennsylvania forest understory. Natural Areas Journal. 29:110-116.

Kolar CS, Lodge DM. 2001. Progress in invasion biology: predicting invaders. Trends in Ecology and Evolution. 16:199-204.

Kovacs KF, Haight RG, McCullough DG, Mercader RJ, Siegert NW, Liebhold AM. 2010. Cost of potential emerald ash borer damage in U.S. communities, 2009-2019. Ecological Economics. 69:569-578.

Kraft LS, Crow TR, Buckley DS, Nauertz EA, Zasada JC. 2004. Effects of harvesting and deer browsing on attributes of understory plants in northern hardwood forests, Upper Michigan, USA. Forest Ecology and Management. 199:219-230. 
Lawrence AP, Bowers MA. 2002. A test of the 'hot' mustard extraction method of sampling earthworms. Soil Biology and Biochemistry. 34:549-552.

Lawrence B, Fisk MC, Fahey TJ, Suarez ER. 2003. Influence of nonnative earthworms in mycorrhizal colonization of sugar maple (Acer saccharum). New Phytologist. $157: 145-153$.

Lee KE. 1985. Earthworms, their ecology and relationships with soils and land use. New York: Academic Press.

Liebhold AM, Tobin PC. 2008. Population ecology of insect invasions and their management. Annual Review of Entomology. 53:387-408.

Lockwood JL, Hoopes MF, Marchetti MP. 2007. Invasion ecology. Malden, MA: Blackwell Sci. 304 p.

Lodge DM, Shrader-Frechette K. 2003. Nonindigenous species: ecological explanation, environmental ethics, and public policy. Conservation Biology. 17:31-37.

Loss SR, Blair RB. 2011. Reduced density and nest survival of ground-nesting songbirds relative to earthworm invasions in northern hardwood forests. Conservation Biology. 25:983-992.

Loss SR, Hueffmeier RM, Hale CM, Frelich LE, Host GE, Sjerven G. In Prep. A visual method for rapidly assessing earthworm invasions in northern hardwood forests.

MacFarlane DW, Meyer SP. 2005. Characteristics and distribution of potential ash tree hosts for emerald ash borer. Forest Ecology and Management. 213:15-24.

Madritch, MD and RL Lindroth. 2008. Removal of invasive shrubs reduces exotic earthworm populations. Biological Invasions. 11:663-671.

Maerz JC, Nuzzo VA, Blossey B. 2009. Declines in woodland salamander abundance associated with non-native earthworm and plant invasions. Conservation Biology. 23:975-981.

McCullough DG, Katovich SA. 2004. Emerald ash borer. USDA Forest Service, Northeastern Area, State and Private Forestry, Pest Alert NA-PR-02-04.

McCullough DG, Poland TM, Cappaert D. 2009. Attraction of the emerald ash borer to ash trees stressed by girdling, herbicide treatment, or wounding. Canadian Journal of Forest Research. 39:1331-1345.

McCune B, Mefford MJ. 1999. PC-ORD. Multivariate Analysis of Ecological Data. Version 5.0 Gleneden Beach, OR:MjM Software. 
McGarigal K, Cushman SA, Neel MC, Ene E. 2002. FRAGSTATS: Spatial Pattern Analysis Program for Categorical Maps. Amherst MA: University of Massachusetts.

McLean MA, Migge-Kleian S, Parkinson D. 2006. Earthworm invasions of ecosystems devoid of earthworms: effects on soil microbes. Biological Invasions. 8:1257-1273.

Mercader RJ, Siegert NW, Liebhold AM, McCullough DG. 2009. Dispersal of the emerald ash borer, Agrilus planipennis, in newly-colonized sites. Agricultural and Forest Entomology. 11:421-424.

Meretsky VJ, Fischman RL, Karr JR, Ashe DA, Scott JM, Noss RF, Schroeder RL. 2006. New directions in conservation for the National Wildlife Refuge System. BioScience. $56: 135-143$.

Michigan Department of Natural Resources (MI DNR). 2001. Michigan 2001 Integrated Forest Monitoring, Assessment, and Prescription (IFMAP) Gap Land Cover dataset. (http://www.mcgi.state.mi.us/mgdl).

Migge-Kleian S, McLean MA, Maerz JC, Heneghan L. 2006. The influence of invasive earthworms in indigenous fauna in ecosystems previously uninhabited by earthworms. Biological Invasions. 8:1275-1285.

Millers I, Lachance D, Burkman WG, Allen DC. 1991. North American sugar maple decline project: organization and field methods. US Department of Agriculture Forest Service, Northeastern Forest Experiment Station. Gen. Tech. Rep. NE-154.

Minnesota Department of Agriculture. 2006. Emerald ash borer introduction risk model for Minnesota. MDA Plant Protection Division, Invasive Species Exclusion Unit. 11 p.

Moser WK, Branard EL, Billings RF, Crocker SJ, Dix ME, Gray AN, Ice GG, Kim MS, Reid R, Rodman SU, McWilliams WH. 2009. Impacts of nonnative invasive species of US forests and recommendations for policy and management. Journal of Forestry. 107:320-327.

Muirhead JR, Leung B, van Overdijk C, Kelly DW, Nandakumar K, Marchant KR, MacIsaac HJ. 2006. Modeling local and long-distance dispersal of invasive emerald ash borer Agrilus planipennis (Coleoptera) in North America. Diversity and Distributions. 12:71-79.

National Invasive Species Council (NISC). 2008. 2008-2012 National Invasive Species Management Plan. 35 p.

Natural Resources Conservation Service (NRCS). 2006. Soil Survey Geographic (SSURGO) Database. (http://soildatamart.nrcs.usda.gov). 
Nuzzo VA, Maerz JC, Blossey B. 2009. Earthworm invasion as the driving force behind plant invasion and community change in northeastern American forests. Conservation Biology. 23:966-974.

O’Neill RV, Hunsaker CT, Timmins SP, Jackson BL, Jones KB, Riitters KH, Wickham JD. 1996. Scale problems in reporting landscape pattern at the regional scale. Landscape Ecology. 11:169-180.

Peterson AT. 2003. Predicting the geography of species' invasions via ecological niche modeling. The Quarterly Review of Biology. 78:419-433.

Peterson AT, Vieglais DA. 2001. Predicting species invasions using ecological niche modeling: new approaches from bioinformatics attack a pressing problem. BioScience. 51:363-371.

Petrillo HA, Corace RG III. 2011. Rapid ecological assessment of forests in the Laurentian Mixed Forest-Great Lakes Coastal Biological Network, Midwest Region, National Wildlife Refuge System, US Fish \& Wildlife Service.

Pimental D, Zuniga R, Morrison D. 2005. Update on the environmental and economic costs associated with alien-invasive species in the United States. Ecological Economics. 52:273-288.

Poland TM. 2007. Twenty million ash trees later: current status of emerald ash borer in Michigan. Newsletter of the Michigan Entomological Society. 52:10-14.

Poland TM, McCullough DG. 2006. Emerald ash borer: invasion of the urban forest and the threat to North America's ash resource. Journal of Forestry. 104:118-124.

Poland TM, McCullough DG. 2010. SLAM: A multi-agency pilot project to SL.ow A.sh M.ortality caused by emerald ash borer in outlier sites. Newsletter of the Michigan Entomological Society. 55:4-8.

Prasad AM, Iverson LR, Peters MP, Bossenbroek JM, Matthews SN, Sydnor TD, Schwartz MW. 2010. Modeling the invasive emerald ash borer risk of spread using a spatially explicit cellular model. Landscape Ecology. 25:353-369.

R Development Core Team. 2011. R: A language and environment for statistical computing. Vienna, Austria: R Foundation for Statistical Computing.

Rabaglia R, Duerr D, Acciavatti R, Ragenovich I. 2008. Early detection and rapid response for non-native bark and ambrosia beetles. USDA Forest Service, Forest Health Protection. (http://fs.fed.us/foresthealth/publications/EDRRProjectReport.pdf). 
Rebek EJ, Herms DA, Smitley DR. 2008. Interspecific variation in resistance to emerald ash borer (Coleoptera: Buprestidae) among North American and Asian ash (Fraxinus spp.). Environmental Entomology. 37:242-246.

Reich PB, Oleksyn J, Modrzynski J, Mrozinski P, Hobbie SE, Eissenstat DM, Chorover J, Chadwick OA, Hale CM, Tjoelker MG. 2005. Linking litter calcium, earthworms and soil properties: a common garden test with 14 tree species. Ecology Letters. 8:811-818.

Richardson DM, Pyšek P. 2008. Fifty years of invasion ecology - the legacy of Charles Elton. Diversity and Distributions. 14:161-168.

Ruiz GM, Carlton JT (Editors). 2003. Invasive species: vectors and management strategies. Island Press, Washington, D.C.

Sakai AK, Allendorf FW, Holt JS, Lodge DM, Molofsky J, With KA, Baughman S, Cabin RJ, Cohen JE, Ellstrand NC, McCauley DE, O'Neil P, Parker IM, Thompson JN, Weller SG. 2001. The population biology of invasive species. Annual Review of Ecology, Evolution, and Systematics. 32:305-332.

Schaetzl RJ, Krist FJ, Stanley K, Hupy CM. 2009. The natural soil drainage index: an ordinal estimate of long-term soil wetness. Physical Geography. 30:383-409.

Scheu S. 2003. Effects of earthworms on plant growth: patterns and perspectives. Pedobiologia. 47:846-856.

Scheu S, Parkinson D. 1994. Effects of earthworms on nutrient dynamics, carbon turnover and microorganisms in soils from cold temperate forests of the Canadian Rocky Mountains - laboratory studies. Applied Soil Ecology. 1:113-125.

Schroeder RL, Holler JI, Taylor JP. 2004. Managing National Wildlife Refuges for historic and nonhistoric conditions: determining the role of the refuge in the ecosystem. Natural Resources Journal. 44:1185-1210.

Schwert DP, Dance KW. 1979. Earthworm cocoons as a drift component in a southern Ontario stream. Canadian Field Naturalist. 93:180-183.

Scott JM, Loveland T, Gergely K, Strittholt J, Staus N. 2004. National Wildlife Refuge System:ecological context and integrity. Natural Resources Journal. 44:1041-1066.

Shartell LM, Nagel LM, Storer AJ. 2011. Multi-criteria risk model for garlic mustard (Alliaria petiolata) in Michigan's Upper Peninsula. American Midland Naturalist. 165:116-127. 
Shea K, Chesson P. 2002. Community ecology theory as a framework for biological invasions. Trends in Ecology and Evolution. 17:170-176.

Simberloff D. 2006. Invasional meltdown 6 years later: important phenomenon, unfortunate metaphor, or both? Ecology Letters. 9:912-919.

Simberloff D, Von Holle B. 1999. Positive interactions of nonindigenous species: invasional meltdown? Biological Invasions. 1:21-32.

State of Michigan. 2007. Michigan Geographic Data Library /). Center for Geographic Information, Department of Information Technology. (http://mcgi.state.mi.us/mgdl

State of Michigan. 2009. Michigan Geographic Data Library. Center for Geographic Information, Department of Information Technology. (http://mcgi.state.mi.us/mgdl).

Stinson KA, Campbell SA, Powell JR, Wolfe BE, Callaway RM, Thelen GC, Hallett SG, Prati D, Klironomos JN. 2006. Invasive plant suppresses the growth of native tree seedlings by disrupting belowground mutalisms. PLoS Biology. 4:727-731.

Store R, Kangas J. 2001. Integrating spatial multi-criteria evaluation and expert knowledge for GIS-based habitat suitability modeling. Landscape and Urban Planning. 55:79-93.

Suarez ER, Fahey TJ, Yavitt JB, Groffman PM, Bohlen PJ. 2006. Patterns of litter disappearance in a northern hardwood forest invaded by exotic earthworms. Ecological Applications. 16:154-165.

Subler S, Baranski CM, Edwards CA. 1997. Earthworm additions increased short-term nitrogen availability and leaching in two grain-crop agroecosystems. Soil Biology and Biochemistry. 29:413-421.

Sutherland S. 2004. What makes a weed a weed: life history traits of native and exotic plants in the USA. Population Ecology. 141:24-39.

Systat Software. 2008. SigmaPlot 11. User's Guide. San Jose, CA: Systat Software Inc.

Taylor RAJ, Poland TM, Bauer LS, Windell KN, Kautz JL. 2007. Emerald ash borer flight estimates revised. In: Mastro V, Reardon R, Parra G, compilers. Proceedings of the emerald ash borer and Asian longhorned beetle research and technology development meeting. USDA Forest Service FHTET-2007-04.

Thomas GW. 1996. Soil pH and Soil Acidity. In: Sparks DL, editor. Methods of Soil Analysis, Part 3 - Chemical Methods. Madison, Wisconsin: Soil Science Society of America. p. 475-490. 
Tiunov AV, Hale CM, Holdsworth AR, Vsevolodova-Peral TS. 2006. Invasion patterns of Lumbricidae into previously earthworm-free areas of northeastern Europe and the western Great Lakes region of North America. Biological Invasions. 8:1223-1234.

Turner MG, Gardner RH, O’Neill RV. 2001 Landscape ecology in theory and practice. New York: Springer. 401 p.

United States Geological Survey (USGS). 2011. National Land Cover Database 2006. Multi-Resolution Land Characteristics (MRLC) Consortium. (http://www.mrlc.gov/nlcd2006_update).

Webster CR, Jenkins MA, Jose S. 2006. Woody invaders and the challenges they pose to forest ecosystems in the eastern United States. Journal of Forestry. 104:366-374.

Webster CR, Jenkins MA, Rock JH. 2005. Long-term response of spring flora to chronic herbivory and deer exclusion in great Smoky Mountains National Park, USA.

Biological Conservation. 125:297-307.

Whitney KD, Gabler CA. 2008. Rapid evolution in introduced species, 'invasive traits' and recipient communities: challenges for predicting invasive potential. Diversity and Distributions. 14:569-580.

Williamson M. 1996. Biological invasions. London, UK: Chapman \& Hall.

Yatso K, Lilleskov E. In Prep. Effects of tree litter type and soil type on growth of an introduced earthworm (Lumbricus terrestris): implications for invasion dynamics. 


\section{Appendix}

\section{A. Calculated Landscape Metrics}

Table A.1

Landscape metrics based on the 2006 National Land Cover Dataset at the refuge and ecoregion levels (Chapter 4). Variables codes: TA $=$ total area (ha), NPR $=$ natural patch richness, SHDI = Shannon's diversity index, MPA = mean patch area (ha), LPI = largest patch index, LSI = landscape shape index. Metrics were calculated using the spatial analysis program FRAGSTATS (McGarigal et al. 2002).

\begin{tabular}{lcccccc}
\hline & TA & NPR & SHDI & MPA & LPI & LSI \\
\hline Refuge & & & & & & \\
Horicon & 8849 & 4.50 & 1.22 & 10.19 & 35.05 & 24.91 \\
Ottawa & 3480 & 2.33 & 1.04 & 11.60 & 26.93 & 13.13 \\
Rice Lake & 7316 & 5.00 & 1.61 & 9.38 & 19.79 & 22.31 \\
Shiawassee & 3882 & 2.75 & 1.82 & 5.57 & 10.17 & 22.08 \\
Seney & 38,626 & 12.0 & 1.34 & 8.12 & 22.33 & 99.94 \\
Tamarac & 17,770 & 12.0 & 1.42 & 7.94 & 49.48 & 37.89 \\
Ecoregion & & & & & & \\
Horicon & $1,126,427$ & 0.80 & 1.73 & 8.47 & 1.34 & 305.43 \\
Ottawa & $1,603,168$ & 0.83 & 1.54 & 11.16 & 1.03 & 315.64 \\
Rice Lake & $1,280,707$ & 3.50 & 1.91 & 6.16 & 2.46 & 383.64 \\
Shiawassee & 530,918 & 0.60 & 1.73 & 7.96 & 0.62 & 214.50 \\
Seney & 746,220 & 3.50 & 1.69 & 7.70 & 4.87 & 294.70 \\
Tamarac & $2,640,053$ & 2.33 & 2.01 & 6.54 & 5.06 & 553.16 \\
\hline
\end{tabular}




\section{Table A.2}

Landscape metrics for anthropogenic cover types at the refuge and ecoregion levels (Chapter 4). National Land Cover Data types considered anthropogenic were: 1) developed open space, 2) developed low intensity, 3) developed medium intensity, 4) developed high intensity, 5) hay-pasture, and 6) cultivated crops. Variable codes: PLAND = percent of the landscape, MPA = mean patch area (ha), LPI = largest patch index, LSI = landscape shape index. Metrics were calculated using the spatial analysis program FRAGSTATS (McGarigal et al. 2002).

\begin{tabular}{lcccc}
\hline & PLAND & MPA & LPI & LSI \\
\hline Refuge & & & & \\
Horicon & 7.69 & 11.73 & 2.16 & 17.66 \\
Ottawa & 13.50 & 6.71 & 3.52 & 14.34 \\
Rice Lake & 3.16 & 5.77 & 1.17 & 19.03 \\
Shiawassee & 28.32 & 12.22 & 18.31 & 13.91 \\
Seney & 1.57 & 3.92 & 0.23 & 37.18 \\
Tamarac & 1.98 & 1.96 & 0.12 & 28.86 \\
Ecoregion & & & & \\
Horicon & 75.20 & 1065.56 & 74.96 & 124.92 \\
Ottawa & 87.45 & 2572.56 & 87.32 & 87.66 \\
Rice Lake & 8.74 & 41.71 & 7.71 & 212.28 \\
Shiawassee & 72.52 & 782.53 & 72.30 & 73.75 \\
Seney & 4.39 & 9.69 & 2.92 & 172.43 \\
Tamarac & 39.10 & 78.90 & 31.51 & 310.25 \\
\hline
\end{tabular}




\section{B. Descriptive Statistics for Environmental Variables}

Table B.1

Descriptive statistics (number of plots, mean, standard deviation, minimum, and maximum) by transect for environmental variables used in the assessment of earthworm patterns in National Wildlife Refuges (Chapter 4). Anthropogenic cover was calculated by transect and this value is presented under mean. Canopy cover was not measured at Horicon. Variables are described in Table 4.1.

\begin{tabular}{|c|c|c|c|c|c|c|c|}
\hline Refuge & Transect & $\mathbf{N}$ & Variable & Mean & SD & Min & Max \\
\hline \multirow[t]{10}{*}{ Horicon } & BRDG & 5 & $\mathrm{BA}$ & 22.94 & 26.37 & 0.00 & 62.16 \\
\hline & & & PS & 0.00 & 0.00 & 0.00 & 0.00 \\
\hline & & & OS & 0.80 & 0.45 & 0.00 & 1.00 \\
\hline & & & $\mathrm{CD}$ & 0.00 & 0.00 & 0.00 & 0.00 \\
\hline & & & CWD & 0.60 & 0.55 & 0.00 & 1.00 \\
\hline & & & $\mathrm{pH}$ & 6.37 & 0.24 & 6.06 & 6.72 \\
\hline & & & LOI & 0.06 & 0.01 & 0.05 & 0.07 \\
\hline & & & $\mathrm{RD}$ & 108.94 & 28.15 & 76.06 & 146.04 \\
\hline & & & $\mathrm{AG}$ & $1,052.27$ & 8.45 & $1,041.57$ & $1,062.81$ \\
\hline & & & $\mathrm{AC}$ & 0.03 & & & \\
\hline \multirow[t]{10}{*}{ Horicon } & EGRT & 5 & BA & 31.41 & 12.10 & 18.42 & 45.01 \\
\hline & & & PS & 2.41 & 2.55 & 0.00 & 5.31 \\
\hline & & & OS & 2.80 & 0.84 & 2.00 & 4.00 \\
\hline & & & $\mathrm{CD}$ & 0.00 & 0.00 & 0.00 & 0.00 \\
\hline & & & CWD & 0.40 & 0.55 & 0.00 & 1.00 \\
\hline & & & $\mathrm{pH}$ & 6.51 & 0.52 & 5.65 & 7.00 \\
\hline & & & LOI & 0.09 & 0.02 & 0.07 & 0.13 \\
\hline & & & $\mathrm{RD}$ & 12.22 & 10.08 & 1.33 & 22.56 \\
\hline & & & $\mathrm{AG}$ & $1,249.54$ & 8.14 & $1,237.98$ & $1,258.86$ \\
\hline & & & $\mathrm{AC}$ & 0.16 & & & \\
\hline \multirow[t]{10}{*}{ Horicon } & HDQT & 5 & $\mathrm{BA}$ & 17.95 & 14.87 & 0.00 & 39.15 \\
\hline & & & PS & 16.61 & 13.83 & 0.00 & 34.91 \\
\hline & & & OS & 1.80 & 1.10 & 0.00 & 3.00 \\
\hline & & & $\mathrm{CD}$ & 0.00 & 0.00 & 0.00 & 0.00 \\
\hline & & & CWD & 0.60 & 0.55 & 0.00 & 1.00 \\
\hline & & & $\mathrm{pH}$ & 6.60 & 0.22 & 6.36 & 6.92 \\
\hline & & & LOI & 0.11 & 0.01 & 0.09 & 0.12 \\
\hline & & & $\mathrm{RD}$ & 39.22 & 28.00 & 9.11 & 74.91 \\
\hline & & & $A G$ & 74.54 & 27.67 & 44.61 & 109.59 \\
\hline & & & $\mathrm{AC}$ & 0.87 & & & \\
\hline
\end{tabular}


Table B.1 Continued

\begin{tabular}{|c|c|c|c|c|c|c|c|}
\hline Refuge & Transect & $\mathbf{N}$ & Variable & Mean & SD & Min & Max \\
\hline \multirow[t]{10}{*}{ Horicon } & HUNT & 5 & $\mathrm{BA}$ & 37.09 & 29.08 & 7.86 & 79.43 \\
\hline & & & PS & 0.00 & 0.00 & 0.00 & 0.00 \\
\hline & & & OS & 1.80 & 0.45 & 1.00 & 2.00 \\
\hline & & & $\mathrm{CD}$ & 0.00 & 0.00 & 0.00 & 0.00 \\
\hline & & & CWD & 0.60 & 0.55 & 0.00 & 1.00 \\
\hline & & & $\mathrm{pH}$ & 5.76 & 0.36 & 5.35 & 6.17 \\
\hline & & & LOI & 0.06 & 0.00 & 0.05 & 0.06 \\
\hline & & & $\mathrm{RD}$ & $1,161.07$ & 27.27 & $1,129.22$ & $1,195.29$ \\
\hline & & & $\mathrm{AG}$ & $1,105.79$ & 12.59 & $1,089.94$ & $1,121.41$ \\
\hline & & & $\mathrm{AC}$ & 0 & & & \\
\hline \multirow[t]{10}{*}{ Horicon } & OSRN & 5 & $\mathrm{BA}$ & 39.17 & 39.55 & 0.00 & 81.93 \\
\hline & & & PS & 0.00 & 0.00 & 0.00 & 0.00 \\
\hline & & & OS & 1.00 & 1.00 & 0.00 & 2.00 \\
\hline & & & $\mathrm{CD}$ & 0.00 & 0.00 & 0.00 & 0.00 \\
\hline & & & CWD & 0.00 & 0.00 & 0.00 & 0.00 \\
\hline & & & $\mathrm{pH}$ & 6.64 & 0.24 & 6.40 & 6.94 \\
\hline & & & LOI & 0.08 & 0.02 & 0.05 & 0.10 \\
\hline & & & $\mathrm{RD}$ & 337.72 & 6.23 & 332.06 & 346.80 \\
\hline & & & $\mathrm{AG}$ & 772.40 & 19.56 & 746.43 & 795.65 \\
\hline & & & $\mathrm{AC}$ & 0.01 & & & \\
\hline \multirow[t]{10}{*}{ Horicon } & OSRS & 5 & $\mathrm{BA}$ & 18.83 & 17.84 & 0.00 & 48.44 \\
\hline & & & PS & 0.00 & 0.00 & 0.00 & 0.00 \\
\hline & & & OS & 0.80 & 0.45 & 0.00 & 1.00 \\
\hline & & & $\mathrm{CD}$ & 0.00 & 0.00 & 0.00 & 0.00 \\
\hline & & & CWD & 0.00 & 0.00 & 0.00 & 0.00 \\
\hline & & & $\mathrm{pH}$ & 6.26 & 0.52 & 5.60 & 6.92 \\
\hline & & & LOI & 0.06 & 0.01 & 0.05 & 0.07 \\
\hline & & & $\mathrm{RD}$ & 629.93 & 4.16 & 625.07 & 635.28 \\
\hline & & & $\mathrm{AG}$ & 551.17 & 14.85 & 531.39 & 565.12 \\
\hline & & & $\mathrm{AC}$ & $<0.01$ & & & \\
\hline \multirow[t]{10}{*}{ Horicon } & PNT & 5 & BA & 33.16 & 22.60 & 15.13 & 68.82 \\
\hline & & & PS & 31.97 & 22.62 & 15.13 & 68.82 \\
\hline & & & OS & 2.20 & 1.10 & 1.00 & 3.00 \\
\hline & & & $\mathrm{CD}$ & 0.00 & 0.00 & 0.00 & 0.00 \\
\hline & & & CWD & 0.00 & 0.00 & 0.00 & 0.00 \\
\hline & & & $\mathrm{pH}$ & 6.67 & 0.10 & 6.55 & 6.78 \\
\hline & & & LOI & 0.15 & 0.01 & 0.13 & 0.16 \\
\hline & & & $\mathrm{RD}$ & 213.59 & 29.89 & 168.77 & 247.85 \\
\hline & & & $\mathrm{AG}$ & 54.93 & 25.95 & 18.32 & 86.80 \\
\hline & & & $\mathrm{AC}$ & 0.84 & & & \\
\hline
\end{tabular}


Table B.1 Continued

\begin{tabular}{|c|c|c|c|c|c|c|c|}
\hline Refuge & Transect & $\mathbf{N}$ & Variable & Mean & SD & Min & Max \\
\hline \multirow[t]{10}{*}{ Horicon } & RDFX & 5 & BA & 26.64 & 34.85 & 5.02 & 87.96 \\
\hline & & & PS & 5.86 & 8.77 & 0.00 & 20.83 \\
\hline & & & OS & 1.40 & 0.55 & 1.00 & 2.00 \\
\hline & & & $\mathrm{CD}$ & 0.00 & 0.00 & 0.00 & 0.00 \\
\hline & & & CWD & 0.40 & 0.55 & 0.00 & 1.00 \\
\hline & & & $\mathrm{pH}$ & 6.77 & 0.28 & 6.32 & 7.02 \\
\hline & & & LOI & 0.11 & 0.04 & 0.07 & 0.16 \\
\hline & & & $\mathrm{RD}$ & 251.87 & 8.46 & 240.27 & 260.38 \\
\hline & & & $\mathrm{AG}$ & 721.66 & 10.01 & 714.62 & 738.33 \\
\hline & & & $\mathrm{AC}$ & 0.24 & & & \\
\hline \multirow[t]{10}{*}{ Horicon } & ROCK & 5 & $\mathrm{BA}$ & 44.76 & 18.77 & 26.75 & 66.77 \\
\hline & & & PS & 42.06 & 18.87 & 26.75 & 63.80 \\
\hline & & & OS & 2.00 & 0.00 & 2.00 & 2.00 \\
\hline & & & $\mathrm{CD}$ & 0.00 & 0.00 & 0.00 & 0.00 \\
\hline & & & CWD & 0.40 & 0.55 & 0.00 & 1.00 \\
\hline & & & $\mathrm{pH}$ & 6.88 & 0.15 & 6.63 & 7.01 \\
\hline & & & LOI & 0.11 & 0.04 & 0.07 & 0.18 \\
\hline & & & $\mathrm{RD}$ & 71.08 & 32.26 & 24.87 & 108.39 \\
\hline & & & $\mathrm{AG}$ & 79.76 & 31.32 & 34.69 & 115.55 \\
\hline & & & $\mathrm{AC}$ & 0.87 & & & \\
\hline \multirow[t]{10}{*}{ Horicon } & STER & 5 & $\mathrm{BA}$ & 47.90 & 26.79 & 12.34 & 84.89 \\
\hline & & & PS & 0.60 & 0.82 & 0.00 & 1.63 \\
\hline & & & OS & 1.80 & 0.84 & 1.00 & 3.00 \\
\hline & & & $\mathrm{CD}$ & 0.00 & 0.00 & 0.00 & 0.00 \\
\hline & & & CWD & 0.40 & 0.55 & 0.00 & 1.00 \\
\hline & & & $\mathrm{pH}$ & 5.87 & 0.13 & 5.74 & 6.03 \\
\hline & & & LOI & 0.08 & 0.01 & 0.07 & 0.09 \\
\hline & & & $\mathrm{RD}$ & 45.25 & 4.46 & 38.07 & 48.38 \\
\hline & & & $\mathrm{AG}$ & $1,445.34$ & 21.35 & $1,412.72$ & $1,466.47$ \\
\hline & & & $\mathrm{AC}$ & 0.06 & & & \\
\hline \multirow[t]{9}{*}{ Ottawa } & BNUT & 4 & BA & 20.08 & 3.73 & 17.26 & 25.50 \\
\hline & & & PS & 19.11 & 3.25 & 16.17 & 23.51 \\
\hline & & & OS & 2.25 & 0.50 & 2.00 & 3.00 \\
\hline & & & $\mathrm{CC}$ & 86.00 & 0.54 & 85.25 & 86.50 \\
\hline & & & $\mathrm{CD}$ & 0.00 & 0.00 & 0.00 & 0.00 \\
\hline & & & CWD & 1.00 & 0.00 & 1.00 & 1.00 \\
\hline & & & $\mathrm{pH}$ & 5.99 & 0.18 & 5.83 & 6.19 \\
\hline & & & LOI & 0.09 & 0.01 & 0.08 & 0.10 \\
\hline & & & $\mathrm{RD}$ & 51.70 & 20.56 & 27.83 & 74.73 \\
\hline
\end{tabular}


Table B.1 Continued

\begin{tabular}{|c|c|c|c|c|c|c|c|}
\hline Refuge & Transect & $\mathbf{N}$ & Variable & Mean & SD & Min & Max \\
\hline \multirow[t]{2}{*}{ Ottawa } & BNUT & & $\mathrm{AG}$ & 144.17 & 53.93 & 80.37 & 202.43 \\
\hline & & & $\mathrm{AC}$ & 0.11 & & & \\
\hline \multirow[t]{11}{*}{ Ottawa } & BOSS & 9 & $\mathrm{BA}$ & 30.83 & 13.22 & 17.54 & 52.71 \\
\hline & & & PS & 22.62 & 14.23 & 0.00 & 48.98 \\
\hline & & & OS & 2.44 & 0.88 & 1.00 & 4.00 \\
\hline & & & $\mathrm{CC}$ & 86.44 & 2.15 & 82.50 & 89.75 \\
\hline & & & $\mathrm{CD}$ & 0.00 & 0.00 & 0.00 & 0.00 \\
\hline & & & CWD & 0.56 & 0.53 & 0.00 & 1.00 \\
\hline & & & $\mathrm{pH}$ & 6.12 & 0.17 & 5.84 & 6.30 \\
\hline & & & LOI & 0.11 & 0.01 & 0.10 & 0.13 \\
\hline & & & $\mathrm{RD}$ & 315.98 & 55.08 & 225.33 & 385.92 \\
\hline & & & $\mathrm{AG}$ & 31.94 & 26.31 & 0.00 & 89.13 \\
\hline & & & $\mathrm{AC}$ & 0.90 & & & \\
\hline \multirow[t]{11}{*}{ Ottawa } & $\mathrm{CC}$ & 3 & $\mathrm{BA}$ & 3.62 & 5.01 & 0.00 & 9.34 \\
\hline & & & PS & 3.62 & 5.01 & 0.00 & 9.34 \\
\hline & & & OS & 0.67 & 0.58 & 0.00 & 1.00 \\
\hline & & & $\mathrm{CC}$ & 77.83 & 6.66 & 70.50 & 83.50 \\
\hline & & & $\mathrm{CD}$ & 0.00 & 0.00 & 0.00 & 0.00 \\
\hline & & & CWD & 0.00 & 0.00 & 0.00 & 0.00 \\
\hline & & & $\mathrm{pH}$ & 5.88 & 0.07 & 5.81 & 5.95 \\
\hline & & & LOI & 0.08 & 0.00 & 0.07 & 0.08 \\
\hline & & & $\mathrm{RD}$ & 148.93 & 35.06 & 113.96 & 184.08 \\
\hline & & & $\mathrm{AG}$ & 89.86 & 15.18 & 74.45 & 104.80 \\
\hline & & & $\mathrm{AC}$ & 0.26 & & & \\
\hline \multirow[t]{11}{*}{ Ottawa } & DAR-B & 3 & $\mathrm{BA}$ & 22.95 & 9.92 & 11.50 & 29.05 \\
\hline & & & PS & 6.08 & 1.56 & 5.01 & 7.87 \\
\hline & & & OS & 2.33 & 0.58 & 2.00 & 3.00 \\
\hline & & & $\mathrm{CC}$ & 87.58 & 1.66 & 86.50 & 89.50 \\
\hline & & & $\mathrm{CD}$ & 0.00 & 0.00 & 0.00 & 0.00 \\
\hline & & & CWD & 0.00 & 0.00 & 0.00 & 0.00 \\
\hline & & & $\mathrm{pH}$ & 7.01 & 0.42 & 6.53 & 7.26 \\
\hline & & & LOI & 0.05 & 0.01 & 0.04 & 0.07 \\
\hline & & & $\mathrm{RD}$ & 22.11 & 11.93 & 9.06 & 32.47 \\
\hline & & & $\mathrm{AG}$ & 34.72 & 22.57 & 8.88 & 50.55 \\
\hline & & & $\mathrm{AC}$ & 0.02 & & & \\
\hline
\end{tabular}


Table B.1 Continued

\begin{tabular}{|c|c|c|c|c|c|c|c|}
\hline Refuge & Transect & $\mathbf{N}$ & Variable & Mean & SD & Min & Max \\
\hline \multirow[t]{11}{*}{ Ottawa } & DAR-W & 3 & $\mathrm{BA}$ & 17.39 & 5.92 & 11.58 & 23.42 \\
\hline & & & PS & 16.55 & 6.15 & 11.58 & 23.42 \\
\hline & & & OS & 1.67 & 0.58 & 1.00 & 2.00 \\
\hline & & & $\mathrm{CC}$ & 77.92 & 10.63 & 67.50 & 88.75 \\
\hline & & & $\mathrm{CD}$ & 0.00 & 0.00 & 0.00 & 0.00 \\
\hline & & & CWD & 0.67 & 0.58 & 0.00 & 1.00 \\
\hline & & & $\mathrm{pH}$ & 6.44 & 0.73 & 5.88 & 7.27 \\
\hline & & & LOI & 0.11 & 0.01 & 0.10 & 0.11 \\
\hline & & & $\mathrm{RD}$ & 43.31 & 16.50 & 26.19 & 59.11 \\
\hline & & & $\mathrm{AG}$ & 70.98 & 26.00 & 44.15 & 96.07 \\
\hline & & & $\mathrm{AC}$ & 0.23 & & & \\
\hline \multirow[t]{11}{*}{ Ottawa } & LAMB & 6 & $\mathrm{BA}$ & 99.17 & 96.72 & 18.40 & 242.23 \\
\hline & & & PS & 5.58 & 7.63 & 0.00 & 17.16 \\
\hline & & & OS & 2.17 & 0.75 & 1.00 & 3.00 \\
\hline & & & $\mathrm{CC}$ & 83.46 & 8.43 & 70.50 & 90.25 \\
\hline & & & $\mathrm{CD}$ & 0.00 & 0.00 & 0.00 & 0.00 \\
\hline & & & CWD & 0.17 & 0.41 & 0.00 & 1.00 \\
\hline & & & $\mathrm{pH}$ & 7.33 & 0.15 & 7.11 & 7.51 \\
\hline & & & LOI & 0.07 & 0.03 & 0.05 & 0.11 \\
\hline & & & $\mathrm{RD}$ & 80.33 & 23.04 & 46.82 & 108.79 \\
\hline & & & $\mathrm{AG}$ & 200.55 & 21.61 & 177.07 & 226.34 \\
\hline & & & $\mathrm{AC}$ & $<0.01$ & & & \\
\hline \multirow[t]{11}{*}{ Ottawa } & NORTH & 6 & $\mathrm{BA}$ & 24.30 & 17.59 & 4.31 & 49.14 \\
\hline & & & PS & 9.58 & 9.13 & 0.00 & 23.09 \\
\hline & & & OS & 2.83 & 1.17 & 1.00 & 4.00 \\
\hline & & & $\mathrm{CC}$ & 88.88 & 1.46 & 86.75 & 90.50 \\
\hline & & & $\mathrm{CD}$ & 0.00 & 0.00 & 0.00 & 0.00 \\
\hline & & & CWD & 0.67 & 0.52 & 0.00 & 1.00 \\
\hline & & & $\mathrm{pH}$ & 5.92 & 0.17 & 5.68 & 6.18 \\
\hline & & & LOI & 0.10 & 0.01 & 0.09 & 0.11 \\
\hline & & & $\mathrm{RD}$ & 71.66 & 31.86 & 41.31 & 116.65 \\
\hline & & & $\mathrm{AG}$ & 216.37 & 62.69 & 130.95 & 310.71 \\
\hline & & & $\mathrm{AC}$ & 0.27 & & & \\
\hline \multirow[t]{5}{*}{ Ottawa } & POINT & 6 & $\mathrm{BA}$ & 66.11 & 37.68 & 21.73 & 109.00 \\
\hline & & & PS & 39.61 & 37.49 & 0.00 & 109.00 \\
\hline & & & OS & 2.50 & 0.55 & 2.00 & 3.00 \\
\hline & & & $\mathrm{CC}$ & 83.00 & 7.57 & 68.00 & 87.75 \\
\hline & & & $\mathrm{CD}$ & 0.00 & 0.00 & 0.00 & 0.00 \\
\hline
\end{tabular}


Table B.1 Continued

\begin{tabular}{|c|c|c|c|c|c|c|c|}
\hline Refuge & Transect & $\mathbf{N}$ & Variable & Mean & SD & Min & Max \\
\hline \multirow[t]{6}{*}{ Ottawa } & POINT & & CWD & 0.00 & 0.00 & 0.00 & 0.00 \\
\hline & & & $\mathrm{pH}$ & 7.32 & 0.20 & 7.11 & 7.59 \\
\hline & & & LOI & 0.06 & 0.02 & 0.04 & 0.08 \\
\hline & & & $\mathrm{RD}$ & 39.11 & 16.76 & 13.68 & 57.79 \\
\hline & & & $\mathrm{AG}$ & 15.73 & 24.57 & 0.00 & 60.51 \\
\hline & & & $\mathrm{AC}$ & 0.02 & & & \\
\hline \multirow[t]{11}{*}{ Ottawa } & PRICE & 8 & $\mathrm{BA}$ & 22.11 & 15.08 & 7.53 & 51.62 \\
\hline & & & PS & 19.14 & 16.15 & 1.68 & 50.21 \\
\hline & & & OS & 1.88 & 0.83 & 1.00 & 3.00 \\
\hline & & & $\mathrm{CC}$ & 86.31 & 2.31 & 83.00 & 89.00 \\
\hline & & & $\mathrm{CD}$ & 0.00 & 0.00 & 0.00 & 0.00 \\
\hline & & & CWD & 0.38 & 0.52 & 0.00 & 1.00 \\
\hline & & & $\mathrm{pH}$ & 5.59 & 0.33 & 4.81 & 5.88 \\
\hline & & & LOI & 0.11 & 0.01 & 0.09 & 0.12 \\
\hline & & & $\mathrm{RD}$ & 128.69 & 63.62 & 31.43 & 203.68 \\
\hline & & & $\mathrm{AG}$ & 111.69 & 42.54 & 56.05 & 175.55 \\
\hline & & & $\mathrm{AC}$ & 0.57 & & & \\
\hline \multirow[t]{11}{*}{ Ottawa } & VCW & 6 & BA & 34.60 & 17.92 & 15.34 & 64.43 \\
\hline & & & PS & 15.22 & 10.63 & 0.00 & 25.32 \\
\hline & & & OS & 2.83 & 0.75 & 2.00 & 4.00 \\
\hline & & & $\mathrm{CC}$ & 87.63 & 1.28 & 86.25 & 89.25 \\
\hline & & & $\mathrm{CD}$ & 0.00 & 0.00 & 0.00 & 0.00 \\
\hline & & & CWD & 0.33 & 0.52 & 0.00 & 1.00 \\
\hline & & & $\mathrm{pH}$ & 5.90 & 0.28 & 5.56 & 6.18 \\
\hline & & & LOI & 0.09 & 0.02 & 0.07 & 0.11 \\
\hline & & & $\mathrm{RD}$ & 72.10 & 38.85 & 10.77 & 113.03 \\
\hline & & & $\mathrm{AG}$ & 262.34 & 77.65 & 157.47 & 350.51 \\
\hline & & & $\mathrm{AC}$ & 0.30 & & & \\
\hline \multirow[t]{11}{*}{ Rice Lake } & EIG & 5 & BA & 29.46 & 25.20 & 2.98 & 62.02 \\
\hline & & & PS & 22.78 & 23.88 & 2.98 & 62.02 \\
\hline & & & OS & 2.00 & 0.71 & 1.00 & 3.00 \\
\hline & & & $\mathrm{CC}$ & 91.25 & 2.73 & 88.00 & 94.75 \\
\hline & & & $\mathrm{CD}$ & 0.00 & 0.00 & 0.00 & 0.00 \\
\hline & & & CWD & 0.00 & 0.00 & 0.00 & 0.00 \\
\hline & & & $\mathrm{pH}$ & 5.47 & 0.24 & 5.09 & 5.68 \\
\hline & & & LOI & 0.05 & 0.01 & 0.04 & 0.06 \\
\hline & & & $\mathrm{RD}$ & 78.01 & 29.43 & 38.37 & 111.40 \\
\hline & & & $\mathrm{AG}$ & 572.67 & 2.96 & 569.68 & 577.29 \\
\hline & & & $\mathrm{AC}$ & 0.04 & & & \\
\hline
\end{tabular}


Table B.1 Continued

\begin{tabular}{|c|c|c|c|c|c|c|c|}
\hline Refuge & Transect & $\mathbf{N}$ & Variable & Mean & SD & Min & Max \\
\hline \multirow[t]{11}{*}{ Rice Lake } & FIVE & 5 & $\mathrm{BA}$ & 18.39 & 11.52 & 6.83 & 34.12 \\
\hline & & & PS & 13.28 & 10.42 & 0.00 & 22.47 \\
\hline & & & OS & 2.20 & 0.84 & 1.00 & 3.00 \\
\hline & & & $\mathrm{CC}$ & 88.35 & 2.61 & 85.50 & 92.00 \\
\hline & & & $\mathrm{CD}$ & 0.00 & 0.00 & 0.00 & 0.00 \\
\hline & & & CWD & 0.20 & 0.45 & 0.00 & 1.00 \\
\hline & & & $\mathrm{pH}$ & 5.49 & 0.27 & 5.24 & 5.89 \\
\hline & & & LOI & 0.05 & 0.02 & 0.03 & 0.07 \\
\hline & & & $\mathrm{RD}$ & 63.68 & 26.94 & 30.66 & 94.48 \\
\hline & & & $\mathrm{AG}$ & 775.08 & 27.77 & 744.37 & 807.57 \\
\hline & & & $\mathrm{AC}$ & 0.04 & & & \\
\hline \multirow[t]{11}{*}{ Rice Lake } & FOUR & 5 & $\mathrm{BA}$ & 16.18 & 12.35 & 5.94 & 35.09 \\
\hline & & & PS & 1.00 & 2.24 & 0.00 & 5.01 \\
\hline & & & OS & 1.40 & 0.55 & 1.00 & 2.00 \\
\hline & & & $\mathrm{CC}$ & 80.20 & 8.25 & 66.75 & 87.00 \\
\hline & & & $\mathrm{CD}$ & 0.00 & 0.00 & 0.00 & 0.00 \\
\hline & & & CWD & 0.40 & 0.55 & 0.00 & 1.00 \\
\hline & & & $\mathrm{pH}$ & 4.67 & 0.06 & 4.60 & 4.76 \\
\hline & & & LOI & 0.06 & 0.03 & 0.04 & 0.12 \\
\hline & & & $\mathrm{RD}$ & 209.69 & 26.45 & 175.45 & 243.22 \\
\hline & & & $\mathrm{AG}$ & 56.11 & 26.46 & 21.84 & 89.56 \\
\hline & & & $\mathrm{AC}$ & 0.21 & & & \\
\hline \multirow[t]{11}{*}{ Rice Lake } & H65 & 5 & $\mathrm{BA}$ & 16.79 & 11.08 & 5.41 & 32.74 \\
\hline & & & PS & 2.30 & 4.16 & 0.00 & 9.59 \\
\hline & & & OS & 1.80 & 0.84 & 1.00 & 3.00 \\
\hline & & & $\mathrm{CC}$ & 82.70 & 5.00 & 75.75 & 87.50 \\
\hline & & & $\mathrm{CD}$ & 0.00 & 0.00 & 0.00 & 0.00 \\
\hline & & & CWD & 0.20 & 0.45 & 0.00 & 1.00 \\
\hline & & & $\mathrm{pH}$ & 4.93 & 0.15 & 4.75 & 5.11 \\
\hline & & & LOI & 0.04 & 0.01 & 0.04 & 0.05 \\
\hline & & & $\mathrm{RD}$ & 73.23 & 13.85 & 54.87 & 87.78 \\
\hline & & & $\mathrm{AG}$ & 24.99 & 13.71 & 12.92 & 45.98 \\
\hline & & & $\mathrm{AC}$ & 0.29 & & & \\
\hline \multirow[t]{7}{*}{ Rice Lake } & NIN & 5 & $\mathrm{BA}$ & 25.87 & 10.11 & 13.06 & 39.34 \\
\hline & & & PS & 16.05 & 7.61 & 9.40 & 29.14 \\
\hline & & & OS & 2.20 & 0.84 & 1.00 & 3.00 \\
\hline & & & $\mathrm{CC}$ & 92.90 & 0.74 & 92.00 & 93.75 \\
\hline & & & $\mathrm{CD}$ & 0.00 & 0.00 & 0.00 & 0.00 \\
\hline & & & CWD & 0.00 & 0.00 & 0.00 & 0.00 \\
\hline & & & $\mathrm{pH}$ & 5.23 & 0.21 & 4.91 & 5.46 \\
\hline
\end{tabular}


Table B.1 Continued

\begin{tabular}{|c|c|c|c|c|c|c|c|}
\hline Refuge & Transect & $\mathbf{N}$ & Variable & Mean & SD & Min & Max \\
\hline \multirow[t]{4}{*}{ Rice Lake } & NIN & & LOI & 0.05 & 0.01 & 0.04 & 0.07 \\
\hline & & & $\mathrm{RD}$ & 71.20 & 25.25 & 42.68 & 104.64 \\
\hline & & & $\mathrm{AG}$ & 68.47 & 25.45 & 39.81 & 102.22 \\
\hline & & & $\mathrm{AC}$ & 0.13 & & & \\
\hline \multirow{11}{*}{ Rice Lake } & PINK & 5 & BA & 20.14 & 6.43 & 14.34 & 30.00 \\
\hline & & & PS & 10.52 & 5.98 & 0.00 & 14.34 \\
\hline & & & OS & 2.80 & 0.45 & 2.00 & 3.00 \\
\hline & & & $\mathrm{CC}$ & 85.10 & 3.20 & 81.00 & 89.75 \\
\hline & & & $\mathrm{CD}$ & 0.11 & 0.16 & 0.00 & 0.34 \\
\hline & & & CWD & 0.80 & 0.45 & 0.00 & 1.00 \\
\hline & & & $\mathrm{pH}$ & 5.06 & 0.20 & 4.81 & 5.35 \\
\hline & & & LOI & 0.05 & 0.01 & 0.04 & 0.06 \\
\hline & & & $\mathrm{RD}$ & 47.40 & 7.86 & 38.04 & 54.52 \\
\hline & & & $\mathrm{AG}$ & 960.12 & 23.66 & 929.51 & 987.26 \\
\hline & & & $\mathrm{AC}$ & 0.05 & & & \\
\hline \multirow{11}{*}{ Rice Lake } & RNA & 5 & BA & 30.03 & 6.73 & 22.25 & 36.54 \\
\hline & & & PS & 0.00 & 0.00 & 0.00 & 0.00 \\
\hline & & & OS & 2.20 & 0.45 & 2.00 & 3.00 \\
\hline & & & $\mathrm{CC}$ & 81.40 & 5.16 & 76.00 & 90.00 \\
\hline & & & $\mathrm{CD}$ & 0.61 & 0.38 & 0.00 & 0.90 \\
\hline & & & CWD & 0.00 & 0.00 & 0.00 & 0.00 \\
\hline & & & $\mathrm{pH}$ & 6.44 & - & - & - \\
\hline & & & LOI & 0.10 & - & - & - \\
\hline & & & $\mathrm{RD}$ & 485.90 & 5.31 & 478.86 & 492.60 \\
\hline & & & $\mathrm{AG}$ & 744.70 & 23.81 & 718.13 & 775.65 \\
\hline & & & $\mathrm{AC}$ & 0 & & & \\
\hline \multirow[t]{11}{*}{ Rice Lake } & SRR & 10 & $\mathrm{BA}$ & 38.18 & 17.38 & 13.41 & 64.29 \\
\hline & & & PS & 32.60 & 16.74 & 13.41 & 64.29 \\
\hline & & & OS & 1.90 & 0.74 & 1.00 & 3.00 \\
\hline & & & $\mathrm{CC}$ & 91.65 & 2.04 & 89.00 & 94.75 \\
\hline & & & $\mathrm{CD}$ & 0.03 & 0.10 & 0.00 & 0.30 \\
\hline & & & CWD & 0.00 & 0.00 & 0.00 & 0.00 \\
\hline & & & $\mathrm{pH}$ & 5.69 & 0.41 & 4.81 & 6.33 \\
\hline & & & LOI & 0.06 & 0.02 & 0.04 & 0.08 \\
\hline & & & $\mathrm{RD}$ & 193.05 & 10.90 & 179.90 & 210.36 \\
\hline & & & $\mathrm{AG}$ & $1,368.82$ & 4.52 & $1,361.63$ & $1,376.79$ \\
\hline & & & $\mathrm{AC}$ & 0.05 & & & \\
\hline \multirow[t]{3}{*}{ Rice Lake } & THR & 5 & BA & 31.70 & 11.30 & 19.13 & 49.59 \\
\hline & & & PS & 5.56 & 6.77 & 0.00 & 15.78 \\
\hline & & & OS & 2.40 & 1.14 & 1.00 & 4.00 \\
\hline
\end{tabular}


Table B.1 Continued

\begin{tabular}{|c|c|c|c|c|c|c|c|}
\hline Refuge & Transect & $\mathbf{N}$ & Variable & Mean & SD & Min & Max \\
\hline \multirow[t]{8}{*}{ Rice Lake } & THR & & $\mathrm{CC}$ & 88.40 & 1.83 & 85.75 & 90.75 \\
\hline & & & $\mathrm{CD}$ & 0.00 & 0.00 & 0.00 & 0.00 \\
\hline & & & CWD & 0.20 & 0.45 & 0.00 & 1.00 \\
\hline & & & $\mathrm{pH}$ & 5.55 & 0.18 & 5.27 & 5.73 \\
\hline & & & LOI & 0.05 & 0.02 & 0.03 & 0.08 \\
\hline & & & $\mathrm{RD}$ & 31.45 & 16.15 & 11.92 & 54.55 \\
\hline & & & $\mathrm{AG}$ & 756.97 & 2.03 & 755.54 & 760.33 \\
\hline & & & $\mathrm{AC}$ & 0.04 & & & \\
\hline \multirow[t]{11}{*}{ Rice Lake } & TWOA & 5 & $\mathrm{BA}$ & 20.68 & 5.06 & 12.84 & 26.99 \\
\hline & & & PS & 13.00 & 9.02 & 0.00 & 24.17 \\
\hline & & & OS & 2.20 & 0.84 & 1.00 & 3.00 \\
\hline & & & $\mathrm{CC}$ & 88.30 & 1.35 & 86.50 & 90.00 \\
\hline & & & $\mathrm{CD}$ & 0.00 & 0.00 & 0.00 & 0.00 \\
\hline & & & CWD & 0.20 & 0.45 & 0.00 & 1.00 \\
\hline & & & $\mathrm{pH}$ & 4.95 & 0.25 & 4.63 & 5.27 \\
\hline & & & LOI & 0.04 & 0.01 & 0.04 & 0.05 \\
\hline & & & $\mathrm{RD}$ & 30.16 & 9.60 & 14.19 & 37.68 \\
\hline & & & $\mathrm{AG}$ & 70.63 & 19.80 & 46.22 & 94.57 \\
\hline & & & $\mathrm{AC}$ & 0.04 & & & \\
\hline \multirow[t]{11}{*}{ Rice Lake } & TWOB & 4 & BA & 27.89 & 12.92 & 18.79 & 46.47 \\
\hline & & & PS & 1.66 & 2.29 & 0.00 & 4.85 \\
\hline & & & OS & 3.00 & 0.82 & 2.00 & 4.00 \\
\hline & & & $\mathrm{CC}$ & 85.06 & 5.44 & 77.50 & 90.00 \\
\hline & & & $\mathrm{CD}$ & 0.00 & 0.00 & 0.00 & 0.00 \\
\hline & & & CWD & 0.00 & 0.00 & 0.00 & 0.00 \\
\hline & & & $\mathrm{pH}$ & 4.90 & 0.05 & 4.84 & 4.96 \\
\hline & & & LOI & 0.04 & 0.00 & 0.04 & 0.04 \\
\hline & & & $\mathrm{RD}$ & 46.54 & 16.45 & 24.65 & 60.38 \\
\hline & & & $\mathrm{AG}$ & 80.43 & 5.65 & 72.39 & 84.98 \\
\hline & & & $\mathrm{AC}$ & 0.04 & & & \\
\hline \multirow[t]{9}{*}{ Rice Lake } & WD & 6 & $\mathrm{BA}$ & 18.78 & 14.36 & 0.00 & 36.28 \\
\hline & & & PS & 2.92 & 7.15 & 0.00 & 17.51 \\
\hline & & & OS & 1.50 & 1.05 & 0.00 & 3.00 \\
\hline & & & $\mathrm{CC}$ & 88.96 & 3.82 & 84.00 & 94.50 \\
\hline & & & $\mathrm{CD}$ & 0.00 & 0.00 & 0.00 & 0.00 \\
\hline & & & CWD & 0.17 & 0.41 & 0.00 & 1.00 \\
\hline & & & $\mathrm{pH}$ & 5.14 & 0.10 & 5.01 & 5.30 \\
\hline & & & LOI & 0.04 & 0.01 & 0.04 & 0.05 \\
\hline & & & $\mathrm{RD}$ & 98.87 & 30.66 & 58.18 & 137.85 \\
\hline
\end{tabular}


Table B.1 Continued

\begin{tabular}{|c|c|c|c|c|c|c|c|}
\hline Refuge & Transect & $\mathbf{N}$ & Variable & Mean & SD & Min & Max \\
\hline \multirow[t]{2}{*}{ Rice Lake } & WD & & AG & 88.38 & 28.91 & 50.74 & 125.76 \\
\hline & & & $\mathrm{AC}$ & 0.11 & & & \\
\hline \multirow[t]{11}{*}{ Shiawassee } & BOAT & 6 & BA & 21.72 & 13.12 & 4.67 & 34.19 \\
\hline & & & PS & 16.20 & 12.65 & 1.93 & 33.12 \\
\hline & & & OS & 2.17 & 0.41 & 2.00 & 3.00 \\
\hline & & & $\mathrm{CC}$ & 85.58 & 3.20 & 81.00 & 89.00 \\
\hline & & & $\mathrm{CD}$ & 0.00 & 0.00 & 0.00 & 0.00 \\
\hline & & & CWD & 0.17 & 0.41 & 0.00 & 1.00 \\
\hline & & & $\mathrm{pH}$ & 7.36 & 0.19 & 7.12 & 7.55 \\
\hline & & & LOI & 0.10 & 0.02 & 0.06 & 0.12 \\
\hline & & & $\mathrm{RD}$ & 148.21 & 61.24 & 65.80 & 236.15 \\
\hline & & & AG & 122.62 & 78.40 & 2.38 & 226.88 \\
\hline & & & $\mathrm{AC}$ & 0.38 & & & \\
\hline \multirow[t]{11}{*}{ Shiawassee } & CASS & 7 & BA & 41.02 & 26.32 & 7.01 & 90.90 \\
\hline & & & PS & 26.72 & 16.30 & 7.01 & 53.07 \\
\hline & & & OS & 2.29 & 0.76 & 1.00 & 3.00 \\
\hline & & & $\mathrm{CC}$ & 89.57 & 1.81 & 87.50 & 92.50 \\
\hline & & & $\mathrm{CD}$ & 0.00 & 0.00 & 0.00 & 0.00 \\
\hline & & & CWD & 0.14 & 0.38 & 0.00 & 1.00 \\
\hline & & & $\mathrm{pH}$ & 5.13 & 0.52 & 4.25 & 5.92 \\
\hline & & & LOI & 0.06 & 0.04 & 0.04 & 0.14 \\
\hline & & & $\mathrm{RD}$ & 159.63 & 35.11 & 114.08 & 202.86 \\
\hline & & & $\mathrm{AG}$ & 183.24 & 49.43 & 130.08 & 250.69 \\
\hline & & & $\mathrm{AC}$ & 0.50 & & & \\
\hline \multirow[t]{11}{*}{ Shiawassee } & CASS-S & 8 & BA & 32.65 & 31.34 & 8.25 & 104.93 \\
\hline & & & PS & 28.28 & 26.63 & 0.00 & 84.82 \\
\hline & & & OS & 2.13 & 1.25 & 1.00 & 4.00 \\
\hline & & & $\mathrm{CC}$ & 81.22 & 7.64 & 66.25 & 91.50 \\
\hline & & & $\mathrm{CD}$ & 0.00 & 0.00 & 0.00 & 0.00 \\
\hline & & & CWD & 0.25 & 0.46 & 0.00 & 1.00 \\
\hline & & & $\mathrm{pH}$ & 7.51 & 0.16 & 7.25 & 7.74 \\
\hline & & & LOI & 0.11 & 0.01 & 0.09 & 0.13 \\
\hline & & & $\mathrm{RD}$ & 339.39 & 24.35 & 287.89 & 362.12 \\
\hline & & & $\mathrm{AG}$ & 357.14 & 28.28 & 317.91 & 397.77 \\
\hline & & & $\mathrm{AC}$ & 0.32 & & & \\
\hline \multirow[t]{5}{*}{ Shiawassee } & EVON-N & 9 & BA & 47.56 & 36.66 & 0.00 & 109.00 \\
\hline & & & PS & 37.12 & 29.93 & 0.00 & 87.82 \\
\hline & & & OS & 1.33 & 0.71 & 0.00 & 2.00 \\
\hline & & & $\mathrm{CC}$ & 81.47 & 5.80 & 74.00 & 90.50 \\
\hline & & & $\mathrm{CD}$ & 0.00 & 0.00 & 0.00 & 0.00 \\
\hline
\end{tabular}


Table B.1 Continued

\begin{tabular}{|c|c|c|c|c|c|c|c|}
\hline Refuge & Transect & $\mathbf{N}$ & Variable & Mean & SD & Min & Max \\
\hline \multirow[t]{6}{*}{ Shiawassee } & EVON-N & & CWD & 0.22 & 0.44 & 0.00 & 1.00 \\
\hline & & & $\mathrm{pH}$ & 7.63 & 0.10 & 7.41 & 7.77 \\
\hline & & & LOI & 0.10 & 0.00 & 0.09 & 0.10 \\
\hline & & & $\mathrm{RD}$ & 56.67 & 21.60 & 13.12 & 93.16 \\
\hline & & & $\mathrm{AG}$ & 174.57 & 25.72 & 137.20 & 216.15 \\
\hline & & & $\mathrm{AC}$ & 0.18 & & & \\
\hline \multirow[t]{11}{*}{ Shiawassee } & EVON-S & 6 & $\mathrm{BA}$ & 36.43 & 16.40 & 11.12 & 51.11 \\
\hline & & & PS & 24.44 & 13.99 & 11.12 & 48.47 \\
\hline & & & OS & 1.83 & 0.75 & 1.00 & 3.00 \\
\hline & & & $\mathrm{CC}$ & 81.42 & 2.44 & 77.00 & 84.25 \\
\hline & & & $\mathrm{CD}$ & 0.00 & 0.00 & 0.00 & 0.00 \\
\hline & & & CWD & 0.50 & 0.55 & 0.00 & 1.00 \\
\hline & & & $\mathrm{pH}$ & 7.50 & 0.23 & 7.26 & 7.83 \\
\hline & & & LOI & 0.11 & 0.00 & 0.10 & 0.11 \\
\hline & & & $\mathrm{RD}$ & 153.48 & 94.76 & 36.91 & 285.68 \\
\hline & & & $\mathrm{AG}$ & 253.10 & 50.51 & 200.50 & 315.82 \\
\hline & & & $\mathrm{AC}$ & 0.17 & & & \\
\hline \multirow[t]{11}{*}{ Shiawassee } & GP & 7 & BA & 20.13 & 11.54 & 8.06 & 37.90 \\
\hline & & & PS & 7.70 & 11.02 & 0.00 & 31.37 \\
\hline & & & OS & 2.86 & 1.07 & 1.00 & 4.00 \\
\hline & & & $\mathrm{CC}$ & 84.75 & 2.78 & 80.50 & 89.25 \\
\hline & & & $\mathrm{CD}$ & 0.00 & 0.00 & 0.00 & 0.00 \\
\hline & & & CWD & 0.14 & 0.38 & 0.00 & 1.00 \\
\hline & & & $\mathrm{pH}$ & 7.62 & 0.14 & 7.41 & 7.88 \\
\hline & & & LOI & 0.09 & 0.01 & 0.08 & 0.12 \\
\hline & & & $\mathrm{RD}$ & 157.17 & 25.17 & 121.28 & 192.68 \\
\hline & & & $\mathrm{AG}$ & 355.89 & 22.97 & 313.46 & 376.98 \\
\hline & & & $\mathrm{AC}$ & 0.55 & & & \\
\hline \multirow[t]{11}{*}{ Shiawassee } & POOL & 9 & BA & 46.78 & 30.74 & 20.43 & 118.32 \\
\hline & & & PS & 43.83 & 32.12 & 18.95 & 118.32 \\
\hline & & & OS & 1.11 & 0.33 & 1.00 & 2.00 \\
\hline & & & $\mathrm{CC}$ & 82.61 & 3.31 & 75.25 & 86.25 \\
\hline & & & $\mathrm{CD}$ & 0.00 & 0.00 & 0.00 & 0.00 \\
\hline & & & CWD & 0.56 & 0.53 & 0.00 & 1.00 \\
\hline & & & $\mathrm{pH}$ & 7.35 & 0.15 & 7.11 & 7.58 \\
\hline & & & LOI & 0.09 & 0.02 & 0.04 & 0.12 \\
\hline & & & $\mathrm{RD}$ & 161.04 & 92.34 & 30.06 & 287.49 \\
\hline & & & $\mathrm{AG}$ & 179.02 & 69.02 & 98.82 & 273.98 \\
\hline & & & $\mathrm{AC}$ & 0.14 & & & \\
\hline
\end{tabular}


Table B.1 Continued

\begin{tabular}{|c|c|c|c|c|c|c|c|}
\hline Refuge & Transect & $\mathbf{N}$ & Variable & Mean & SD & Min & Max \\
\hline \multirow[t]{11}{*}{ Seney } & CHF-TA & 9 & BA & 26.90 & 11.07 & 12.38 & 46.09 \\
\hline & & & PS & 24.36 & 13.73 & 3.13 & 46.09 \\
\hline & & & OS & 1.78 & 0.67 & 1.00 & 3.00 \\
\hline & & & $\mathrm{CC}$ & 95.50 & 0.87 & 94.00 & 96.00 \\
\hline & & & CD & 0.00 & 0.00 & 0.00 & 0.00 \\
\hline & & & CWD & 0.56 & 0.53 & 0.00 & 1.00 \\
\hline & & & $\mathrm{pH}$ & 4.74 & 0.26 & 4.27 & 5.10 \\
\hline & & & LOI & 0.05 & 0.01 & 0.04 & 0.07 \\
\hline & & & $\mathrm{RD}$ & 203.32 & 26.63 & 169.25 & 241.06 \\
\hline & & & $\mathrm{AG}$ & 280.47 & 92.69 & 177.00 & 429.26 \\
\hline & & & $\mathrm{AC}$ & 0.13 & & & \\
\hline \multirow[t]{11}{*}{ Seney } & CHF-TB & 9 & $\mathrm{BA}$ & 37.61 & 20.37 & 12.48 & 71.00 \\
\hline & & & PS & 35.23 & 22.09 & 5.39 & 71.00 \\
\hline & & & OS & 2.11 & 0.60 & 1.00 & 3.00 \\
\hline & & & $\mathrm{CC}$ & 94.39 & 1.36 & 92.50 & 96.00 \\
\hline & & & $\mathrm{CD}$ & 0.00 & 0.00 & 0.00 & 0.00 \\
\hline & & & CWD & 0.67 & 0.50 & 0.00 & 1.00 \\
\hline & & & $\mathrm{pH}$ & 5.21 & 0.37 & 4.76 & 5.70 \\
\hline & & & LOI & 0.05 & 0.01 & 0.04 & 0.07 \\
\hline & & & $\mathrm{RD}$ & 29.67 & 22.93 & 2.76 & 71.00 \\
\hline & & & $\mathrm{AG}$ & 173.23 & 98.75 & 23.99 & 314.27 \\
\hline & & & $\mathrm{AC}$ & 0.13 & & & \\
\hline \multirow[t]{11}{*}{ Seney } & $\mathrm{COF}$ & 6 & $\mathrm{BA}$ & 17.30 & 12.96 & 0.00 & 32.56 \\
\hline & & & PS & 11.87 & 12.08 & 0.00 & 28.29 \\
\hline & & & OS & 1.00 & 0.63 & 0.00 & 2.00 \\
\hline & & & $\mathrm{CC}$ & 93.67 & 1.63 & 91.50 & 95.50 \\
\hline & & & $\mathrm{CD}$ & 0.00 & 0.00 & 0.00 & 0.00 \\
\hline & & & CWD & 0.67 & 0.52 & 0.00 & 1.00 \\
\hline & & & $\mathrm{pH}$ & 4.90 & 0.19 & 4.71 & 5.22 \\
\hline & & & LOI & 0.06 & 0.01 & 0.05 & 0.07 \\
\hline & & & $\mathrm{RD}$ & 125.11 & 79.80 & 40.58 & 251.45 \\
\hline & & & $\mathrm{AG}$ & 317.04 & 26.12 & 285.56 & 358.65 \\
\hline & & & $\mathrm{AC}$ & 0.32 & & & \\
\hline \multirow[t]{7}{*}{ Seney } & $\mathrm{D}-\mathrm{C} 2 \mathrm{O}$ & 3 & BA & 4.30 & 7.45 & 0.00 & 12.91 \\
\hline & & & PS & 4.30 & 7.45 & 0.00 & 12.91 \\
\hline & & & OS & 0.33 & 0.58 & 0.00 & 1.00 \\
\hline & & & $\mathrm{CC}$ & 35.25 & 37.41 & 0.00 & 74.50 \\
\hline & & & $\mathrm{CD}$ & 0.00 & 0.00 & 0.00 & 0.00 \\
\hline & & & CWD & 0.00 & 0.00 & 0.00 & 0.00 \\
\hline & & & $\mathrm{pH}$ & 4.74 & 0.13 & 4.61 & 4.86 \\
\hline
\end{tabular}


Table B.1 Continued

\begin{tabular}{|c|c|c|c|c|c|c|c|}
\hline Refuge & Transect & $\mathbf{N}$ & Variable & Mean & SD & Min & Max \\
\hline \multirow[t]{4}{*}{ Seney } & $\mathrm{D}-\mathrm{C} 2 \mathrm{O}$ & & LOI & 0.02 & 0.01 & 0.01 & 0.02 \\
\hline & & & RD & 19.32 & 3.40 & 15.86 & 22.66 \\
\hline & & & $\mathrm{AG}$ & $5,333.52$ & 49.47 & $5,282.83$ & $5,381.68$ \\
\hline & & & $\mathrm{AC}$ & 0.06 & & & \\
\hline \multirow[t]{11}{*}{ Seney } & D-CUT & 21 & BA & 19.62 & 20.68 & 0.00 & 65.96 \\
\hline & & & PS & 0.00 & 0.00 & 0.00 & 0.00 \\
\hline & & & OS & 1.19 & 0.81 & 0.00 & 3.00 \\
\hline & & & $\mathrm{CC}$ & 67.29 & 14.91 & 32.75 & 86.75 \\
\hline & & & $\mathrm{CD}$ & 0.60 & 0.45 & 0.00 & 1.00 \\
\hline & & & CWD & 0.48 & 0.51 & 0.00 & 1.00 \\
\hline & & & $\mathrm{pH}$ & 4.27 & 0.24 & 3.84 & 4.65 \\
\hline & & & LOI & 0.02 & 0.01 & 0.01 & 0.06 \\
\hline & & & $\mathrm{RD}$ & 89.71 & 19.89 & 50.41 & 125.57 \\
\hline & & & $\mathrm{AG}$ & $5,634.92$ & 221.80 & $5,283.20$ & $5,995.28$ \\
\hline & & & $\mathrm{AC}$ & 0.05 & & & \\
\hline \multirow[t]{11}{*}{ Seney } & D-PINE & 21 & $\mathrm{BA}$ & 27.85 & 19.75 & 1.51 & 102.99 \\
\hline & & & PS & 1.29 & 4.38 & 0.00 & 18.54 \\
\hline & & & OS & 1.86 & 0.79 & 1.00 & 3.00 \\
\hline & & & $\mathrm{CC}$ & 83.51 & 5.79 & 68.25 & 91.00 \\
\hline & & & $\mathrm{CD}$ & 0.85 & 0.25 & 0.09 & 1.00 \\
\hline & & & CWD & 0.19 & 0.40 & 0.00 & 1.00 \\
\hline & & & $\mathrm{pH}$ & 4.43 & 0.24 & 4.01 & 4.87 \\
\hline & & & LOI & 0.02 & 0.01 & 0.01 & 0.04 \\
\hline & & & $\mathrm{RD}$ & 46.43 & 25.86 & 8.85 & 140.12 \\
\hline & & & $\mathrm{AG}$ & $4,757.84$ & $2,51.70$ & $4,408.54$ & $5,178.63$ \\
\hline & & & $\mathrm{AC}$ & 0.04 & & & \\
\hline \multirow[t]{11}{*}{ Seney } & HARD & 8 & BA & 31.65 & 14.67 & 6.28 & 47.91 \\
\hline & & & PS & 10.25 & 13.60 & 0.00 & 37.05 \\
\hline & & & OS & 2.13 & 0.99 & 1.00 & 4.00 \\
\hline & & & $\mathrm{CC}$ & 88.91 & 4.19 & 81.75 & 94.50 \\
\hline & & & $\mathrm{CD}$ & 0.06 & 0.15 & 0.00 & 0.43 \\
\hline & & & CWD & 0.88 & 0.35 & 0.00 & 1.00 \\
\hline & & & $\mathrm{pH}$ & 4.69 & 0.21 & 4.31 & 5.00 \\
\hline & & & LOI & 0.04 & 0.02 & 0.02 & 0.07 \\
\hline & & & $\mathrm{RD}$ & 125.14 & 86.88 & 28.29 & 249.22 \\
\hline & & & $\mathrm{AG}$ & 162.80 & 85.35 & 48.94 & 303.22 \\
\hline & & & $\mathrm{AC}$ & 0.12 & & & \\
\hline
\end{tabular}


Table B.1 Continued

\begin{tabular}{|c|c|c|c|c|c|c|c|}
\hline Refuge & Transect & $\mathbf{N}$ & Variable & Mean & SD & Min & Max \\
\hline \multirow[t]{11}{*}{ Seney } & HEM & 4 & BA & 82.28 & 14.85 & 61.50 & 96.26 \\
\hline & & & PS & 0.51 & 1.03 & 0.00 & 2.05 \\
\hline & & & OS & 2.75 & 1.50 & 2.00 & 5.00 \\
\hline & & & $\mathrm{CC}$ & 86.88 & 3.60 & 81.75 & 89.50 \\
\hline & & & $\mathrm{CD}$ & 0.99 & 0.03 & 0.94 & 1.00 \\
\hline & & & CWD & 0.75 & 0.50 & 0.00 & 1.00 \\
\hline & & & $\mathrm{pH}$ & 4.04 & 0.20 & 3.86 & 4.32 \\
\hline & & & LOI & 0.07 & 0.01 & 0.06 & 0.09 \\
\hline & & & $\mathrm{RD}$ & 324.74 & 120.87 & 143.44 & 386.13 \\
\hline & & & $A G$ & 273.20 & 98.87 & 126.66 & 340.14 \\
\hline & & & $\mathrm{AC}$ & 0.07 & & & \\
\hline \multirow[t]{11}{*}{ Seney } & SH-N & 9 & BA & 27.64 & 17.38 & 9.46 & 67.56 \\
\hline & & & PS & 26.84 & 17.12 & 9.46 & 67.56 \\
\hline & & & OS & 1.67 & 0.71 & 1.00 & 3.00 \\
\hline & & & $\mathrm{CC}$ & 91.47 & 2.59 & 88.00 & 95.50 \\
\hline & & & $\mathrm{CD}$ & 0.00 & 0.00 & 0.00 & 0.00 \\
\hline & & & CWD & 0.56 & 0.53 & 0.00 & 1.00 \\
\hline & & & $\mathrm{pH}$ & 4.50 & 0.17 & 4.25 & 4.78 \\
\hline & & & LOI & 0.04 & 0.01 & 0.03 & 0.05 \\
\hline & & & $\mathrm{RD}$ & 118.64 & 9.23 & 105.27 & 132.48 \\
\hline & & & $\mathrm{AG}$ & 137.51 & 10.09 & 123.40 & 151.24 \\
\hline & & & $\mathrm{AC}$ & 0.19 & & & \\
\hline \multirow[t]{11}{*}{ Seney } & SH-R & 9 & BA & 29.16 & 18.17 & 2.81 & 60.05 \\
\hline & & & PS & 23.71 & 22.04 & 0.00 & 60.05 \\
\hline & & & OS & 2.00 & 0.87 & 1.00 & 4.00 \\
\hline & & & $\mathrm{CC}$ & 91.42 & 2.66 & 87.75 & 94.75 \\
\hline & & & $\mathrm{CD}$ & 0.03 & 0.08 & 0.00 & 0.24 \\
\hline & & & CWD & 0.78 & 0.44 & 0.00 & 1.00 \\
\hline & & & $\mathrm{pH}$ & 4.59 & 0.16 & 4.42 & 4.92 \\
\hline & & & LOI & 0.04 & 0.01 & 0.03 & 0.04 \\
\hline & & & $\mathrm{RD}$ & 87.47 & 23.46 & 61.55 & 126.99 \\
\hline & & & $\mathrm{AG}$ & 215.64 & 85.58 & 75.74 & 311.83 \\
\hline & & & $\mathrm{AC}$ & 0.20 & & & \\
\hline \multirow[t]{7}{*}{ Seney } & WILD & 13 & BA & 24.08 & 11.52 & 5.28 & 47.29 \\
\hline & & & PS & 22.60 & 9.69 & 3.53 & 37.57 \\
\hline & & & OS & 1.92 & 0.86 & 1.00 & 4.00 \\
\hline & & & $\mathrm{CC}$ & 93.29 & 2.89 & 86.50 & 96.00 \\
\hline & & & $\mathrm{CD}$ & 0.03 & 0.09 & 0.00 & 0.33 \\
\hline & & & CWD & 0.54 & 0.52 & 0.00 & 1.00 \\
\hline & & & $\mathrm{pH}$ & 4.28 & 0.23 & 3.97 & 4.77 \\
\hline
\end{tabular}


Table B.1 Continued

\begin{tabular}{|c|c|c|c|c|c|c|c|}
\hline Refuge & Transect & $\mathbf{N}$ & Variable & Mean & SD & Min & Max \\
\hline \multirow[t]{4}{*}{ Seney } & WILD & & LOI & 0.02 & 0.01 & 0.01 & 0.04 \\
\hline & & & $\mathrm{RD}$ & 103.44 & 43.79 & 22.75 & 152.15 \\
\hline & & & $\mathrm{AG}$ & $10,663.66$ & 131.42 & $10,453.96$ & $10,854.23$ \\
\hline & & & $\mathrm{AC}$ & 0.04 & & & \\
\hline \multirow[t]{11}{*}{ Tamarac } & AUTO & 5 & $\mathrm{BA}$ & 25.36 & 13.12 & 3.93 & 36.00 \\
\hline & & & PS & 0.00 & 0.00 & 0.00 & 0.00 \\
\hline & & & OS & 2.80 & 0.84 & 2.00 & 4.00 \\
\hline & & & $\mathrm{CC}$ & 94.10 & 0.68 & 93.50 & 95.25 \\
\hline & & & $\mathrm{CD}$ & 0.18 & 0.41 & 0.00 & 0.91 \\
\hline & & & CWD & 0.00 & 0.00 & 0.00 & 0.00 \\
\hline & & & $\mathrm{pH}$ & 5.61 & 0.10 & 5.46 & 5.73 \\
\hline & & & LOI & 0.03 & 0.01 & 0.02 & 0.05 \\
\hline & & & $\mathrm{RD}$ & 90.17 & 33.61 & 50.76 & 134.12 \\
\hline & & & $\mathrm{AG}$ & $4,327.48$ & 33.71 & $4,288.15$ & $4,371.55$ \\
\hline & & & $\mathrm{AC}$ & 0.01 & & & \\
\hline \multirow[t]{11}{*}{ Tamarac } & BEAV & 6 & $\mathrm{BA}$ & 30.43 & 14.88 & 15.67 & 50.70 \\
\hline & & & PS & 28.82 & 15.15 & 11.10 & 50.70 \\
\hline & & & OS & 2.50 & 1.05 & 1.00 & 4.00 \\
\hline & & & $\mathrm{CC}$ & 93.04 & 2.12 & 89.50 & 95.25 \\
\hline & & & $\mathrm{CD}$ & 0.00 & 0.00 & 0.00 & 0.00 \\
\hline & & & CWD & 0.33 & 0.52 & 0.00 & 1.00 \\
\hline & & & $\mathrm{pH}$ & 6.32 & 0.22 & 5.95 & 6.55 \\
\hline & & & LOI & 0.04 & 0.01 & 0.03 & 0.06 \\
\hline & & & $\mathrm{RD}$ & 674.44 & 15.10 & 653.80 & 694.56 \\
\hline & & & $\mathrm{AG}$ & $2,590.94$ & 14.14 & $2,572.91$ & $2,606.60$ \\
\hline & & & $\mathrm{AC}$ & 0 & & & \\
\hline \multirow[t]{11}{*}{ Tamarac } & BRUCE & 6 & $\mathrm{BA}$ & 13.70 & 5.51 & 7.19 & 20.19 \\
\hline & & & PS & 0.27 & 0.66 & 0.00 & 1.63 \\
\hline & & & OS & 2.17 & 0.98 & 1.00 & 3.00 \\
\hline & & & $\mathrm{CC}$ & 89.46 & 2.29 & 87.25 & 93.50 \\
\hline & & & $\mathrm{CD}$ & 0.00 & 0.00 & 0.00 & 0.00 \\
\hline & & & CWD & 0.00 & 0.00 & 0.00 & 0.00 \\
\hline & & & $\mathrm{pH}$ & 5.60 & 0.13 & 5.46 & 5.80 \\
\hline & & & LOI & 0.03 & 0.00 & 0.02 & 0.03 \\
\hline & & & $\mathrm{RD}$ & 138.46 & 33.50 & 97.87 & 185.71 \\
\hline & & & $\mathrm{AG}$ & $2,108.82$ & 31.81 & $2,066.00$ & $2,152.01$ \\
\hline & & & $\mathrm{AC}$ & 0.01 & & & \\
\hline \multirow[t]{3}{*}{ Tamarac } & CHIP & 6 & $\mathrm{BA}$ & 15.36 & 5.66 & 7.80 & 22.40 \\
\hline & & & PS & 13.25 & 6.44 & 6.42 & 22.40 \\
\hline & & & OS & 2.50 & 0.84 & 2.00 & 4.00 \\
\hline
\end{tabular}


Table B.1 Continued

\begin{tabular}{|c|c|c|c|c|c|c|c|}
\hline Refuge & Transect & $\mathbf{N}$ & Variable & Mean & SD & Min & Max \\
\hline \multirow[t]{8}{*}{ Tamarac } & CHIP & & $\mathrm{CC}$ & 92.63 & 1.77 & 89.75 & 95.00 \\
\hline & & & $\mathrm{CD}$ & 0.00 & 0.00 & 0.00 & 0.00 \\
\hline & & & CWD & 0.33 & 0.52 & 0.00 & 1.00 \\
\hline & & & $\mathrm{pH}$ & 7.02 & 0.49 & 6.08 & 7.37 \\
\hline & & & LOI & 0.11 & 0.07 & 0.02 & 0.20 \\
\hline & & & $\mathrm{RD}$ & 442.16 & 31.51 & 398.80 & 480.37 \\
\hline & & & $\mathrm{AG}$ & $2,607.24$ & 26.24 & $2,570.19$ & $2,637.19$ \\
\hline & & & $\mathrm{AC}$ & 0 & & & \\
\hline \multirow[t]{11}{*}{ Tamarac } & H143 & 6 & $\mathrm{BA}$ & 20.39 & 8.95 & 3.88 & 30.65 \\
\hline & & & PS & 0.00 & 0.00 & 0.00 & 0.00 \\
\hline & & & OS & 1.33 & 0.52 & 1.00 & 2.00 \\
\hline & & & $\mathrm{CC}$ & 87.33 & 9.11 & 69.75 & 95.25 \\
\hline & & & $\mathrm{CD}$ & 0.15 & 0.38 & 0.00 & 0.93 \\
\hline & & & CWD & 0.83 & 0.41 & 0.00 & 1.00 \\
\hline & & & $\mathrm{pH}$ & 5.76 & 0.16 & 5.59 & 6.02 \\
\hline & & & LOI & 0.05 & 0.01 & 0.03 & 0.07 \\
\hline & & & $\mathrm{RD}$ & 115.45 & 30.98 & 78.35 & 154.17 \\
\hline & & & $\mathrm{AG}$ & $2,113.84$ & 25.89 & $2,081.23$ & $2,144.07$ \\
\hline & & & $\mathrm{AC}$ & 0.06 & & & \\
\hline \multirow[t]{11}{*}{ Tamarac } & H35 & 6 & $\mathrm{BA}$ & 17.89 & 13.94 & 5.03 & 33.25 \\
\hline & & & PS & 0.39 & 0.95 & 0.00 & 2.32 \\
\hline & & & OS & 2.00 & 1.26 & 1.00 & 4.00 \\
\hline & & & $\mathrm{CC}$ & 93.46 & 2.54 & 89.50 & 96.75 \\
\hline & & & $\mathrm{CD}$ & 0.28 & 0.31 & 0.00 & 0.63 \\
\hline & & & CWD & 0.50 & 0.55 & 0.00 & 1.00 \\
\hline & & & $\mathrm{pH}$ & 5.55 & 0.29 & 5.20 & 6.00 \\
\hline & & & LOI & 0.03 & 0.01 & 0.02 & 0.04 \\
\hline & & & $\mathrm{RD}$ & 148.30 & 15.65 & 129.13 & 168.12 \\
\hline & & & $\mathrm{AG}$ & $2,538.76$ & 28.19 & $2,500.95$ & $2,575.43$ \\
\hline & & & $\mathrm{AC}$ & 0.04 & & & \\
\hline \multirow[t]{9}{*}{ Tamarac } & LITT & 4 & $\mathrm{BA}$ & 13.02 & 10.02 & 5.08 & 27.55 \\
\hline & & & PS & 6.83 & 7.22 & 0.00 & 17.02 \\
\hline & & & OS & 2.00 & 0.82 & 1.00 & 3.00 \\
\hline & & & $\mathrm{CC}$ & 90.56 & 3.27 & 86.75 & 94.50 \\
\hline & & & $\mathrm{CD}$ & 0.00 & 0.00 & 0.00 & 0.00 \\
\hline & & & CWD & 0.00 & 0.00 & 0.00 & 0.00 \\
\hline & & & $\mathrm{pH}$ & 6.07 & 0.24 & 5.91 & 6.42 \\
\hline & & & LOI & 0.03 & 0.01 & 0.02 & 0.05 \\
\hline & & & $\mathrm{RD}$ & 459.38 & 3.73 & 455.04 & 463.49 \\
\hline
\end{tabular}


Table B.1 Continued

\begin{tabular}{|c|c|c|c|c|c|c|c|}
\hline Refuge & Transect & $\mathbf{N}$ & Variable & Mean & SD & Min & Max \\
\hline \multirow[t]{2}{*}{ Tamarac } & LITT & & $\mathrm{AG}$ & $3,761.83$ & 22.79 & $3,736.97$ & $3,789.22$ \\
\hline & & & $\mathrm{AC}$ & 0 & & & \\
\hline \multirow[t]{11}{*}{ Tamarac } & OGEM & 6 & $\mathrm{BA}$ & 18.24 & 7.96 & 3.88 & 25.73 \\
\hline & & & PS & 1.96 & 3.18 & 0.00 & 7.39 \\
\hline & & & OS & 2.50 & 1.38 & 1.00 & 4.00 \\
\hline & & & $\mathrm{CC}$ & 90.83 & 2.67 & 87.25 & 94.75 \\
\hline & & & $\mathrm{CD}$ & 0.27 & 0.39 & 0.00 & 1.00 \\
\hline & & & CWD & 0.50 & 0.55 & 0.00 & 1.00 \\
\hline & & & $\mathrm{pH}$ & 6.07 & 0.41 & 5.56 & 6.68 \\
\hline & & & LOI & 0.07 & 0.02 & 0.05 & 0.10 \\
\hline & & & $\mathrm{RD}$ & 99.70 & 21.49 & 66.47 & 122.48 \\
\hline & & & $\mathrm{AG}$ & $1,168.39$ & 31.38 & $1,128.69$ & $1,212.55$ \\
\hline & & & $\mathrm{AC}$ & 0 & & & \\
\hline \multirow[t]{11}{*}{ Tamarac } & SETT & 6 & $\mathrm{BA}$ & 25.39 & 10.98 & 10.92 & 34.31 \\
\hline & & & PS & 14.74 & 9.05 & 3.30 & 27.29 \\
\hline & & & OS & 1.83 & 0.75 & 1.00 & 3.00 \\
\hline & & & $\mathrm{CC}$ & 89.88 & 2.16 & 87.00 & 93.00 \\
\hline & & & $\mathrm{CD}$ & 0.00 & 0.00 & 0.00 & 0.00 \\
\hline & & & CWD & 0.83 & 0.41 & 0.00 & 1.00 \\
\hline & & & $\mathrm{pH}$ & 6.45 & 0.08 & 6.29 & 6.53 \\
\hline & & & LOI & 0.04 & 0.01 & 0.03 & 0.04 \\
\hline & & & $\mathrm{RD}$ & 133.39 & 39.03 & 80.42 & 185.98 \\
\hline & & & $\mathrm{AG}$ & $3,379.83$ & 38.93 & $3,326.88$ & $3,432.30$ \\
\hline & & & $\mathrm{AC}$ & 0.03 & & & \\
\hline \multirow[t]{11}{*}{ Tamarac } & SRIV & 6 & $\mathrm{BA}$ & 17.97 & 8.62 & 8.48 & 30.67 \\
\hline & & & PS & 0.00 & 0.00 & 0.00 & 0.00 \\
\hline & & & OS & 1.50 & 0.55 & 1.00 & 2.00 \\
\hline & & & $\mathrm{CC}$ & 85.17 & 12.36 & 61.25 & 96.75 \\
\hline & & & $\mathrm{CD}$ & 0.69 & 0.43 & 0.00 & 1.00 \\
\hline & & & CWD & 1.00 & 0.00 & 1.00 & 1.00 \\
\hline & & & $\mathrm{pH}$ & 5.33 & 0.12 & 5.12 & 5.44 \\
\hline & & & LOI & 0.02 & 0.01 & 0.02 & 0.03 \\
\hline & & & $\mathrm{RD}$ & 153.92 & 21.17 & 123.99 & 182.44 \\
\hline & & & $\mathrm{AG}$ & $3,891.81$ & 5.85 & $3,881.81$ & $3,899.76$ \\
\hline & & & $\mathrm{AC}$ & 0 & & & \\
\hline \multirow[t]{5}{*}{ Tamarac } & STAM & 6 & $\mathrm{BA}$ & 25.55 & 10.79 & 9.38 & 40.34 \\
\hline & & & PS & 25.55 & 10.79 & 9.38 & 40.34 \\
\hline & & & OS & 1.50 & 0.84 & 1.00 & 3.00 \\
\hline & & & $\mathrm{CC}$ & 90.63 & 2.00 & 88.00 & 93.25 \\
\hline & & & $\mathrm{CD}$ & 0.00 & 0.00 & 0.00 & 0.00 \\
\hline
\end{tabular}


Table B.1 Continued

\begin{tabular}{|c|c|c|c|c|c|c|c|}
\hline Refuge & Transect & $\mathbf{N}$ & Variable & Mean & SD & Min & Max \\
\hline \multirow[t]{6}{*}{ Tamarac } & STAM & & CWD & 0.50 & 0.55 & 0.00 & 1.00 \\
\hline & & & $\mathrm{pH}$ & 6.31 & 0.14 & 6.18 & 6.57 \\
\hline & & & LOI & 0.03 & 0.01 & 0.03 & 0.04 \\
\hline & & & $\mathrm{RD}$ & 91.19 & 36.47 & 41.55 & 139.01 \\
\hline & & & $\mathrm{AG}$ & $1,942.03$ & 31.45 & $1,900.42$ & $1,983.34$ \\
\hline & & & $\mathrm{AC}$ & 0.05 & & & \\
\hline \multirow[t]{11}{*}{ Tamarac } & TEA & 6 & $\mathrm{BA}$ & 3.98 & 1.65 & 1.57 & 5.87 \\
\hline & & & PS & 0.00 & 0.00 & 0.00 & 0.00 \\
\hline & & & OS & 1.00 & 0.00 & 1.00 & 1.00 \\
\hline & & & $\mathrm{CC}$ & 90.88 & 2.01 & 87.75 & 93.25 \\
\hline & & & $\mathrm{CD}$ & 0.00 & 0.00 & 0.00 & 0.00 \\
\hline & & & CWD & 0.17 & 0.41 & 0.00 & 1.00 \\
\hline & & & $\mathrm{pH}$ & 5.91 & 0.16 & 5.75 & 6.14 \\
\hline & & & LOI & 0.04 & 0.01 & 0.03 & 0.05 \\
\hline & & & $\mathrm{RD}$ & 82.71 & 25.59 & 52.04 & 120.47 \\
\hline & & & $\mathrm{AG}$ & $4,887.73$ & 8.34 & $4,877.89$ & $4,900.86$ \\
\hline & & & $\mathrm{AC}$ & 0 & & & \\
\hline \multirow[t]{11}{*}{ Tamarac } & WAUB & 5 & $\mathrm{BA}$ & 21.84 & 8.94 & 6.28 & 28.47 \\
\hline & & & PS & 2.51 & 3.88 & 0.00 & 8.83 \\
\hline & & & OS & 2.60 & 1.14 & 1.00 & 4.00 \\
\hline & & & $\mathrm{CC}$ & 91.70 & 2.83 & 88.00 & 94.75 \\
\hline & & & $\mathrm{CD}$ & 0.00 & 0.00 & 0.00 & 0.00 \\
\hline & & & CWD & 0.80 & 0.45 & 0.00 & 1.00 \\
\hline & & & $\mathrm{pH}$ & 5.78 & 0.22 & 5.48 & 6.10 \\
\hline & & & LOI & 0.04 & 0.01 & 0.02 & 0.05 \\
\hline & & & $\mathrm{RD}$ & 184.09 & 21.98 & 156.71 & 207.11 \\
\hline & & & $\mathrm{AG}$ & $1,888.94$ & 11.02 & $1,876.82$ & $1,904.54$ \\
\hline & & & $\mathrm{AC}$ & 0.03 & & & \\
\hline \multirow[t]{11}{*}{ Tamarac } & WILDE & 5 & $\mathrm{BA}$ & 25.59 & 21.52 & 0.00 & 44.25 \\
\hline & & & PS & 0.00 & 0.00 & 0.00 & 0.00 \\
\hline & & & OS & 1.20 & 0.84 & 0.00 & 2.00 \\
\hline & & & $\mathrm{CC}$ & 92.00 & 2.53 & 88.50 & 94.50 \\
\hline & & & $\mathrm{CD}$ & 0.68 & 0.42 & 0.00 & 1.00 \\
\hline & & & CWD & 0.60 & 0.55 & 0.00 & 1.00 \\
\hline & & & $\mathrm{pH}$ & 5.75 & 0.24 & 5.43 & 6.04 \\
\hline & & & LOI & 0.04 & 0.01 & 0.03 & 0.05 \\
\hline & & & $\mathrm{RD}$ & 131.14 & 19.73 & 112.37 & 162.98 \\
\hline & & & $\mathrm{AG}$ & $2,149.25$ & 20.11 & $2,130.21$ & $2,181.75$ \\
\hline & & & $\mathrm{AC}$ & 0.04 & & & \\
\hline
\end{tabular}

